Finite-Difference Interblock Transmissivity for Unconfined Aquifers and for Aquifers having Smoothly Varying Transmissivity

by Daniel J. Goode and Charles A. Appel

U.S. GEOLOGICAL SURVEY

Water-Resources Investigations Report 92-4124

Menlo Park, California 


\section{U.S. DEPARTMENT OF THE INTERIOR}

MANUEL LUJAN, JR., Secretary

\section{U.S. GEOLOGICAL SURVEY}

Dallas L. Peck, Director

For additional information write to:

Daniel J. Goode U.S. Geological Survey 345 Middlefield Road, MS 496 Menlo Park, CA 94025
Copies of this report can be purchased from:

U.S. Geological Survey

Books and Open File Reports Section

P.O. Box 25425

Denver, CO 80225

(303) 236-7476 


\section{PREFACE}

Interblock transmissivity functions to be used in block-centered finite-difference models of ground-water flow are derived in this report. Computer program subroutines to evaluate these functions and to be used with the flow model of McDonald and Harbaugh (1988) are documented. The methodology contained in these computer programs is based on specific assumptions and has limitations that must be thoroughly understood to obtain meaningful results. The user is requested to notify the originating office of any errors found in this report or in the computer programs.

Copies of the computer program for the model of McDonald and Harbaugh are available at cost of processing from:

U.S. Geological Survey

WATSTORE Program Office

437 National Center

Reston, VA 22092 


\section{CONTENTS}

Page

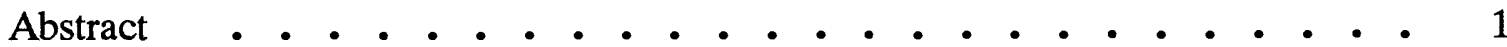

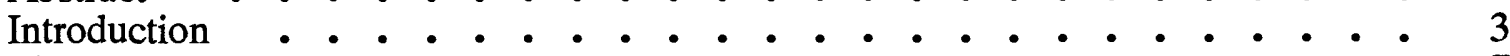

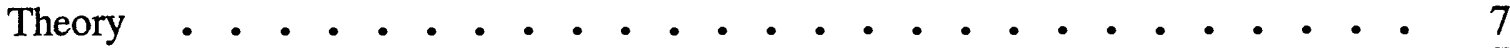

Governing equation . • • . . . . . . . • • . . . . . . 7

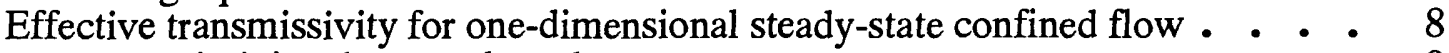

Transmissivity changes abruptly . . . . . . . . . . . . . . 9

Transmissivity linear function of distance in flow direction . . . . . 10

Effective transmissivity for one-dimensional steady-state unconfined flow - . $\quad 11$

Homogeneous unconfined aquifer with no recharge $\quad$ - . . . . . 11

Homogeneous unconfined aquifer with recharge $\quad$ • . . . . 12

Unconfined aquifer with hydraulic conductivity a linear function of

distance in flow direction . . . . . . . . . . . . . 13

Comparison of effective transmissivity functions . . . . . . . . . . 14

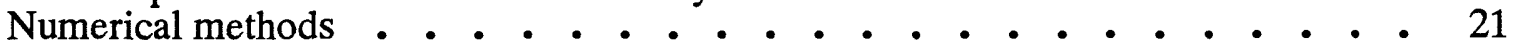

Finite-difference representation of flow equation . . . . . . . . . 21

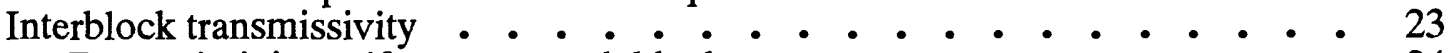

Transmissivity uniform over each block . . . . . . . . . . . 24

Transmissivity varies linearly between nodes . . • . . . . . . 25

Unconfined aquifer with uniform hydraulic conductivity . . . . . . 27

Unconfined aquifer with hydraulic conductivity varying linearly

between nodes . • • • . . . . . . . . . . . 28

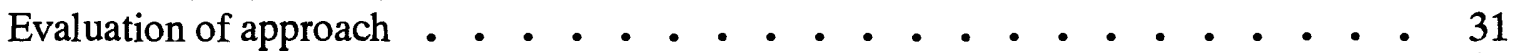

Two-dimensional examples with analytical solutions . • • • . . . . . 31

Transmissivity a linear function of distance in flow direction, no recharge . . . . . . . . . . . . . . . . . 34

Transmissivity a linear function of distance in flow direction, with recharge . . . . . . . . . . . . . . . . 36

Homogeneous unconfined aquifer, no recharge . . . . . . . . . 38

Homogeneous unconfined aquifer, with recharge $\quad$ • . . . . . . 39

Unconfined aquifer with hydraulic conductivity a linear function of

distance in flow direction, no recharge . . . . . . . . . . . . 41

Heterogeneous three-dimensional confined aquifer . . • . . . • . . 43

Simulation from study of Avra Valley Aquifer, Arizona • . . • . . . 46

Summary and conclusions . . . . . . . . . . . . . . . . . . 55

References . • • • • . . . . . . . . . . . . . . . . . . . 59

Appendix A: Proof that the logarithmic mean transmissivity is larger than the

geometric mean transmissivity . . . . . . . . . . . . . 61

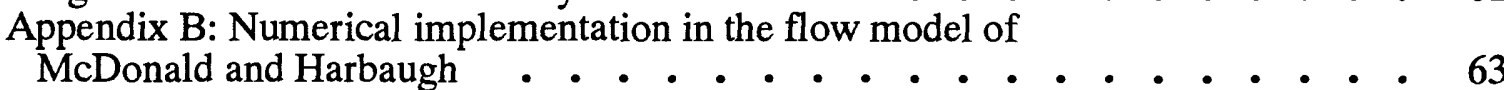

Overview ............................ . . . 63

Changes to the MAIN program . . . . . . . . . . . . . 65

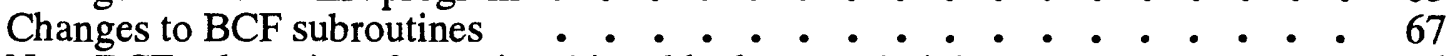

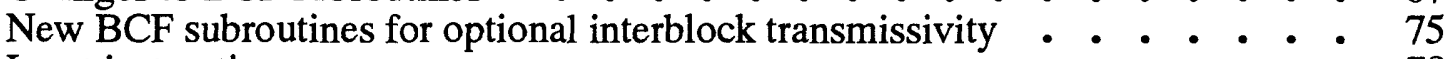

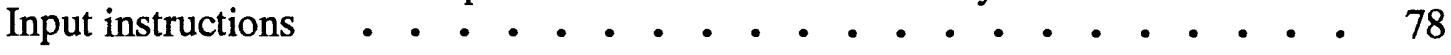




\section{ILLUSTRATIONS}

Figure 1. Graph showing ratio of arithmetic, logarithmic, and harmonic effective transmissivities to transmissivity at point 1 . . . . . . 16

2. Graph showing enlarged portion of Figure 1 . . . . . . 17

3. Graph showing ratio of effective transmissivity as arithmetic mean saturated thickness times logarithmic mean hydraulic conductivity to the transmissivity at point 1 as a function of transmissivity . . . . 18

4. Graph showing enlarged portion of Figure 3 . . . . . . 19

5. Graph showing ratio of effective transmissivity as arithmetic mean saturated thickness times logarithmic mean hydraulic conductivity to the transmissivity at point 1 as a function of hydraulic conductivity . . 20

6. Schematic of two-dimensional finite-difference discretization scheme. . 22

7. Schematic of grid for two-dimensional simulations showing boundary conditions and orientation of the parallel flow vector . . . . . 33

8. Schematic of grid for three-dimensional simulation showing boundary conditions and shaded cells where node value of hydraulic conductivity is 10 times value in rest of grid . . . . . . . . . 44 44

9. Contour and gray-scale map of hydraulic conductivity of layer 1 of Avra Valley aquifer model . . . . . . . . . 4 48

10. Contour and gray-scale map of transmissivity of layer 2 of Avra Valley aquifer model

11. Contour map of new simulated heads using alternative interblock transmissivities for Avra Valley aquifer model . . . . . . . 51

12. Contour and gray-scale map of new simulated head minus results of Hanson and others (1990) for Avra Valley aquifer model . . . . 52 


\section{TABLES}

Page

Table 1. Exact effective transmissivity functions for one-dimensional steady-state flow with no recharge . . . . . . . . . 15

2. Summary of example simulations . . . . . . . . 32

3. Specified volumetric flux into boundary cells for cases 2D-C1, 2D-U1 and $2 \mathrm{D}-\mathrm{U} 3$, flow direction $30^{\circ}$ to grid, no recharge . . . . 34

4. Transmissivity at nodes for cases $2 \mathrm{D}-\mathrm{C} 1$ and $2 \mathrm{D}-\mathrm{C} 2$, transmissivity a linear function of distance in flow direction $30^{\circ}$ to grid . . . . . . 35

5. Head for case $2 \mathrm{D}-\mathrm{C} 1$, transmissivity a linear function of distance in flow

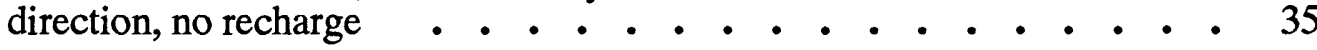

6. Error for case 2D-C1, transmissivity a linear function of distance in flow

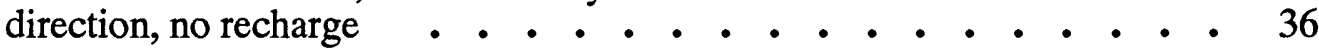

7. Specified volumetric flux into boundary cells for cases $2 \mathrm{D}-\mathrm{C} 2$ and 2D-U2, flow direction $30^{\circ}$ to grid, with recharge . . . . . .

8. Head for case 2D-C2, transmissivity a linear function of flow direction coordinate, with recharge ..............

9. Error for case 2D-C2, transmissivity a linear function of flow direction coordinate, with recharge . . . . . . . . . 38

10. Head for case 2D-U1, homogeneous unconfined aquifer, no recharge . . 38

11. Error for case 2D-U1, homogeneous unconfined aquifer, no recharge • 39

12. Head for case 2D-U2, homogeneous unconfined aquifer, with recharge . 40

13. Error for case 2D-U2, homogeneous unconfined aquifer, with recharge . 40

14. Hydraulic conductivity at nodes for case 2D-U3, unconfined aquifer with hydraulic conductivity a linear function of distance in flow direction .

15. Head for case 2D-U3, unconfined aquifer with hydraulic conductivity a linear function of flow direction coordinate, no recharge . . . .

16. Error for case 2D-U3, unconfined aquifer with hydraulic conductivity a linear function of flow direction coordinate, no recharge . . . .

17. Head in row 3 , layer 2 for case $3 D$, heterogeneous confined aquifer, no recharge

18. Head in column 3 , layer 3 for case $3 \mathrm{D}$, heterogeneous confined aquifer, no recharge 


\section{TABLES--continued}

Page

Table 19. Error for case 3D, heterogeneous confined aquifer, no recharge . 46

20. Computed fluxes at constant head boundary nodes for Avra Valley aquifer example simulation

\section{CONVERSION FACTORS AND ABBREVIATIONS}

$\begin{array}{lcc}\text { Multiply } & \text { by } & \text { To Obtain } \\ \text { meter }(\mathrm{m}) & 3.281 & \text { foot }(\mathrm{ft}) \\ \begin{array}{l}\text { meter squared per day } \\ \left(\mathrm{m}^{2} / \mathrm{day}\right)\end{array} & 10.76 & \begin{array}{c}\text { foot squared per day } \\ (\mathrm{ft} 2 / \mathrm{day})\end{array} \\ \begin{array}{c}\text { meter cubed per day } \\ \left(\mathrm{m}^{3} / \text { day }\right)\end{array} & 35.32 & \begin{array}{c}\text { foot cubed per day } \\ (\mathrm{ft} 3 / \text { day })\end{array} \\ \begin{array}{c}\text { meter cubed per hour } \\ \left(\mathrm{m}^{3} / \text { hour }\right)\end{array} & 35.32 & \begin{array}{c}\text { foot cubed per hour } \\ (\mathrm{ft} 3 / \text { hour })\end{array}\end{array}$




\title{
Finite-Difference Interblock Transmissivity for Unconfined Aquifers and for Aquifers having Smoothly Varying Transmissivity
}

\author{
by Daniel J. Goode and Charles A. Appel
}

\begin{abstract}
More accurate alternatives to the widely used harmonic mean interblock transmissivity are proposed for block-centered finite-difference models of ground-water flow in unconfined aquifers and in aquifers having smoothly varying transmissivity. The harmonic mean is the exact interblock transmissivity for steady-state one-dimensional flow with no recharge if the transmissivity is assumed to be spatially uniform over each finitedifference block, changing abruptly at the block interface. However, the harmonic mean may be inferior to other means if transmissivity varies in a continuous or smooth manner between nodes. Alternative interblock transmissivity functions are analytically derived for the case of steady-state one-dimensional flow with no recharge. The second author has previously derived the exact interblock transmissivity, the logarithmic mean, for onedimensional flow when transmissivity is a linear function of distance in the direction of flow. We show that the logarithmic mean transmissivity is also exact for uniform flow parallel to the direction of changing transmissivity in a two- or three-dimensional model, regardless of grid orientation relative to the flow vector. For the case of horizontal flow in a homogeneous unconfined or water-table aquifer with a horizontal bottom and with areally distributed recharge, the exact interblock transmissivity is the unweighted arithmetic mean of transmissivity at the nodes. This mean also exhibits no grid-orientation effect for unidirectional flow in a two-dimensional model. For horizontal flow in an unconfined aquifer with no recharge where hydraulic conductivity is a linear function of distance in the direction of flow the exact interblock transmissivity is the product of the arithmetic mean saturated thickness and the logarithmic mean hydraulic conductivity. For several hypothetical two- and three-dimensional cases with smoothly varying transmissivity or hydraulic conductivity, the harmonic mean is shown to yield the least accurate solution to the flow equation of the alternatives considered. Application of the alternative interblock transmissivities to a regional aquifer system model indicates that the changes in computed heads and fluxes are typically small, relative to model calibration error. For this example, the use of alternative interblock transmissivities resulted in an increase in computational
\end{abstract}


effort of less than 3 percent. Numerical algorithms to compute alternative interblock transmissivity functions in a modular three-dimensional flow model are presented and documented. 


\section{INTRODUCTION}

Appel (1976) examined the computation of interblock transmissivity for blockcentered finite-difference models of ground-water flow and derived the exact onedimensional interblock transmissivity for the case of transmissivity varying linearly between nodes with no recharge, and steady-state flow. He pointed out that significant errors in the solution of the ground-water flow equation can result from the use of the harmonic or arithmetic mean for some variations of block size and transmissivity. Although the harmonic mean is based on the somewhat unnatural assumption that transmissivity is spatially uniform over each finite-difference block, and changes discontinuously at the block boundaries, it remains the default function for interblock transmissivity in general ground-water flow models (for example, Konikow and Bredehoeft, 1978; McDonald and Harbaugh, 1988).

In addition to Appel (1976), a few other authors have noted the sensitivity of model results to the choice of interblock transmissivity. Anderson and others (1984) found that the computed flux into a drain in an unconfined aquifer significantly descreased when the harmonic mean was used. Goode (1990) showed that the interblock transmissivity of Appel (1976) yielded more accurate potentiometric heads than the harmonic mean in a simulation of two-dimensional flow in a confined aquifer with a linear change in transmissivity in both directions. Haverkamp and others (1977) and Schnabel and Richie (1984) evaluated several methods for computing interblock hydraulic conductivity in onedimensional unsaturated flow models, in which the hydraulic conductivity is a nonlinear function of head. Schnabel and Richie (1984) noted that the harmonic mean gave unrealistic results for infiltration of a sharp wetting front and recommended integration of the unsaturated conductivity function to determine interblock conductance.

Visual inspection of practically any sediment outcrop reveals lithologic heterogeneity even at a small scale. As found in a variety of studies, such lithologic heterogeneity results in heterogeneity of the hydraulic conductivity. Following are some references that describe hydraulic conductivity data for closely spaced samples and thus reflect small scale variability. Gelhar (1986) shows a plot (his figure 2) of the logarithm of permeability (from laboratory analyses of cores) as compared with location of cores taken at about 0.3 meter intervals along a 60 meter section in a vertical borehole in the Mt. Simon Sandstone aquifer in central Illinois. Smith (1981) reported on the variation of hydraulic conductivity measurements made on two 100 point line samples collected at 0.3 meter 
intervals. One line of samples was parallel to the bedding, and the other line was perpendicular to the bedding, of the Quadra Sand--a stratified unconsolidated sand deposit exposed in a series of cliffs near Vancouver, Canada. Measured hydraulic conductivity ranged from roughly 0.01 to $0.1 \mathrm{~m} / \mathrm{s}$ and was not strongly correlated over spatial separations greater than $1 \mathrm{~m}$. Goggin and others (1992) reported on thousands of permeability measurements made on outcrops and cores of eolian (wind blown) sandstones to estimate small-scale variations using a mechanical field permeameter. More than 2,800 measurements were made at an average vertical spacing of about 0.013 meter over a continuous core made up mostly of the Page Sandstone. Measurements also were made 25 meters away on the surface of the Page Sandstone outcrop. About 450 measurements were taken at an average vertical spacing of 0.025 meters and about 100 measurements were taken at an average horizontal spacing of 0.25 meters at the outcrop. Vertical transects were sampled from segments of the Nugget Sandstone and the Tensleep Sandstone at an average spacing of about 0.3 meters. These data show large ranges of permeability but relatively small coefficients of variation within a single stratification type. Weber (1986) describes two orders of magnitude range in permeability measurements made on several cores where the sample points are a few centimeters apart.

There is a growing body of literature (see review by Gomez-Hernandez and Gorelick, 1989) on approaches to determine "effective" or "best" ground-water model parameter values taking into consideration the apparent spatial variability of the parameters at different scales. That effort is still in the developmental stage. Although it is not our intent to summarize, or add to, that body of work, we do need to refer to it briefly to make clear the distinction between certain terms which could be confused. On the basis of numerical experiments, Warren and Price (1961) concluded that (p. 165) "The most probable behavior of a heterogeneous system with single-phase flow approaches that of a homogeneous system having a permeability equal to the geometric mean of the individual permeabilities." Those experiments did not recognize any spatial trends or structure to the hydraulic conductivity. It is as if the hydraulic conductivity of a block is independent of the conductivity of its neighbors. From his review of his own work and that of others, Gelhar (1986) observed (p. 138S) " . . the stochastic results for the two-dimensional isotropic case suggest a simple rule of thumb for evaluating effective large-scale properties; that is, the [logarithm of the] large-scale transmissivity of an aquifer is obtained by averaging the logarithms of the local transmissivities that are measured." Note that this is equivalent to stating that the effective large-scale transmissivity is the geometric mean of the measured transmissivities. From their numerical experimentation, Gomez-Hernandez and Gorelick 
(1989) concluded that the use of the geometric mean as an effective hydraulic conductivity seemed to be appropriate away from a pumping well but "the geometric mean failed to reproduce the expected value of simulated heads near the well locations."

Considering the degree of spatial variation observed at points centimeters or meters apart one might ask if it is overkill to represent the spatial variation between numerical block centers, separated commonly by distances of 100 's or 1,000's of meters, by a function any more complex than the stairstep variation associated with the weighted harmonic mean interblock transmissivity. All of the above-mentioned references indicate that hydraulic conductivity can vary at the smallest scales for which it is even practical to measure this property. Does the conceptual model of a linear variation in hydraulic conductivity run the risk of seeming to represent the aquifer more accurately than the field data justify? In this context, is the use of the harmonic mean justified over even simpler means, such as the arithmetic mean? For the present work, we leave the overall conceptualization of spatial heterogeneity to the modeler, but suggest improved numerical approximations for a few specific deterministic cases. At worst, these methods may offer no significant improvement in real-world accuracy. However, the theoretical considerations may be sufficient to encourage consideration of alternative interblock transmissivities that have essentially the same computational cost as the harmonic mean.

In this report, one-dimensional solutions of the steady-state horizontal groundwater flow equation are interpreted to yield exact effective transmissivity between two points for different cases of deterministic spatial heterogeneity: The block-centered finitedifference solution of the steady-state two-dimensional flow equation is reviewed, highlighting computation of interblock transmissivity. Numerical solutions of the groundwater flow equation using alternative interblock transmissivities are compared for several simple hypothetical cases. Finally, model simulations of a large scale aquifer system are repeated with alternative interblock transmissivity functions to illustrate the practical effects of their use. The appendix includes subroutines for the modular three-dimensional groundwater flow model (MODFLOW) of McDonald and Harbaugh (1988) to compute alternative horizontal interblock transmissivity functions. 


\section{THEORY}

\section{Governing Equation}

The governing equation for steady-state horizontal ground-water flow may be written (Bear, 1979):

$$
\nabla \mathbf{T} \nabla \mathrm{h}+\mathrm{W}=0
$$

where $\mathrm{h}[\mathrm{L}]$ is potentiometric head, $\mathbf{T}\left[\mathrm{L}^{2} \mathrm{~T}^{-1}\right]$ is the transmissivity tensor, and $\mathrm{W}\left[\mathrm{LT}^{-1}\right]$ is the volumetric source rate per unit area (recharge). Boundary conditions for (1) included specified head, specified flux, and mixed or leaky conditions. If the $\mathrm{x}$ and $\mathrm{y}$ coordinates are aligned with the principal axes of the transmissivity tensor then

$$
\mathbf{T}=\left[\begin{array}{cc}
\mathrm{T}_{\mathrm{xx}} & 0 \\
0 & \mathrm{~T}_{\mathrm{yy}}
\end{array}\right] .
$$

In a layered three-dimensional model (for example, McDonald and Harbaugh, 1988) an equation analogous to (1) is applicable for each model layer and W is the net vertical inflow from below and above. In this case $\mathrm{W}$ depends on $\mathrm{h}$, hence the equations for each layer are coupled through $\mathrm{W}$.

Under unconfined conditions, transmissivity is often assumed to be a linear function of head:

$$
\mathbf{T}=\mathbf{K}(\mathrm{h}-\mathrm{b})
$$

where $\mathbf{K}\left[\mathrm{LT}^{-1}\right]$ is the hydraulic conductivity tensor, and $\mathrm{b}[\mathrm{L}]$ is the elevation of the bottom of the aquifer or layer. In this case, the potentiometric head coincides with the water table or the top of the saturated zone, and it is free to move in time in response to hydraulic stresses. Because the head must vary spatially in order for flow to occur, transmissivity is almost everywhere spatially nonuniform for unconfined conditions.

Under confined conditions, where the top of the saturated zone is defined by the interface between the aquifer and an overlying confining unit, transmissivity is mostly assumed to be constant in time. However, transmissivity may be spatially nonuniform due 
to the hydrogeologic characteristics of the aquifer. In fact, the ubiquitous heterogeneity of aquifers is the focus of much current research. For both confined and unconfined conditions, the governing equation (1) allows for nonuniform as well as anisotropic $\left(\mathrm{T}_{\mathrm{xx}} \neq \mathrm{T}_{\mathrm{yy}}\right)$ transmissivity.

\section{Effective Transmissivity for One-Dimensional Steady-State Confined Flow}

For one-dimensional steady confined flow, with no leakage or recharge, the governing equation can be written:

$$
\frac{\mathrm{d}}{\mathrm{ds}} \mathrm{T}(\mathrm{s}) \frac{\mathrm{dh}}{\mathrm{ds}}=0
$$

where $\mathrm{s}$ is the coordinate aligned with the flow direction, and transmissivity $\mathrm{T}$ is a function of $\mathrm{s}$. This equation is a statement of uniform flux, and is integrated once to yield the flux:

$$
q=-T(s) \frac{d h}{d s}
$$

where $\mathrm{q}\left[\mathrm{L}^{2} \mathrm{~T}^{-1}\right]$ is the volumetric flux per unit width of aquifer, and is spatially uniform. This equation can be integrated, giving:

$$
\int_{h_{1}}^{h_{2}} d h=h_{2}-h_{1}=-q \int_{s_{1}}^{s_{2}} \frac{d s}{T(s)}
$$

where $h_{1}$ and $h_{2}[L]$ are potentiometric heads at $s_{1}$ and $s_{2}$, respectively. Equation (6) shows that the head difference between two points and the discharge are related by (Collins, 1961, p. 78):

$$
\mathrm{q}=\overline{\mathrm{T}} \frac{\mathrm{h}_{1}-\mathrm{h}_{2}}{\Delta \mathrm{s}},
$$

when $\overline{\mathrm{T}}$ is defined from (Collins, 1961; compare to Bear, 1979, p. 177): 


$$
\frac{1}{\bar{T}}=\frac{1}{\Delta s} \int_{s_{1}}^{s_{2}} \frac{d s}{T(s)} .
$$

where $\Delta s=s_{2}-s_{1}$. The inverse of equation (8), $\overline{\mathrm{T}}$, can be considered the effective transmissivity and it is evaluated for abrupt and smooth variability of $\mathrm{T}(\mathrm{s})$ in the sequel.

\section{Transmissivity changes abruptly}

If the transmissivity changes abruptly between points 1 and 2 , then (8) can be written:

$$
\frac{1}{\mathrm{~T}_{\mathrm{h}}}=\frac{1}{\Delta \mathrm{s}}\left[\frac{\mathrm{s}_{\mathrm{b}}-\mathrm{s}_{1}}{\mathrm{~T}_{1}}+\frac{\mathrm{s}_{2}-\mathrm{s}_{\mathrm{b}}}{\mathrm{T}_{2}}\right],
$$

where $T_{1}$ and $T_{2}$ are the values of transmissivity at points 1 and 2 , respectively, and $s_{b}$ is the location of the discontinuous change in $T$. In this case, $T_{h}$ is the spatially weighted harmonic mean of $T_{1}$ and $T_{2}$. If $s_{b}$ is halfway between points 1 and 2 , then (9) can be written:

$$
\mathrm{T}_{\mathrm{h}}=\frac{2 \mathrm{~T}_{1} \mathrm{~T}_{2}}{\mathrm{~T}_{1}+\mathrm{T}_{2}}
$$

The harmonic mean in this form is valid as long as at least one of the transmissivities is nonzero and automatically yields zero effective transmissivity if one transmissivity is zero. When one of the transmissivities is large, relative to the other, the effective transmissivity is essentially twice the smaller value, and is insensitive to changes in the larger value. 


\section{Transmissivity linear function of distance in flow direction}

If transmissivity is a linear function of $\mathrm{s}$, then (8) can be integrated to yield (Butler, 1957, p. 78; Appel, 1976):

$$
\mathrm{T}_{\lambda}=\frac{\mathrm{T}_{2}-\mathrm{T}_{1}}{\ln \left(\mathrm{T}_{2} / \mathrm{T}_{1}\right)},
$$

where $T_{\lambda}$ is the logarithmic mean transmissivity. [Our use of the name "logarithmic mean" is due to Bird and others (1960, p. 467) who present the same expression except that the transmissivity in our case is replaced by a temperature difference between two parallel fluid streams in their case.] If the transmissivity is uniform, equation (11) cannot be used, but then from (8), $T_{\lambda}=T_{1}=T_{2}$. In addition, equation (11) cannot be used if either transmissivity is zero, but in this case, the effective transmissivity is also zero.

If transmissivity is piece-wise linear across a one-dimensional flow domain, the effective transmissivity for the entire domain can be computed from equation (8) as:

$$
\frac{1}{\bar{T}}=\frac{1}{\Delta s} \sum_{i=1}^{N-1}\left[\left(s_{i+1}-s_{i}\right) \frac{\ln \left(T_{i+1} / T_{i}\right)}{T_{i+1}-T_{i}}\right]
$$

where $\mathrm{N}$ is the number of points where $\mathrm{T}$ is known (and assumed to vary linearly between) and $\Delta s$ is the length of the domain. This is analogous to the effective hydraulic conductivity for flow across $\mathrm{N}$ layers of differing $\mathrm{K}$.

The direction of the head gradient is parallel to the direction of flow, $\mathrm{s}$, and for $\mathrm{s}_{1}=0$ head is given by (after Appel, 1976):

$$
h(s)=h_{1}-\frac{q}{\alpha} \ln \left(1+\frac{\alpha s}{T_{1}}\right) .
$$

where $\alpha \equiv \partial \mathrm{T} / \partial \mathrm{s}\left[\mathrm{LT}^{-1}\right]$ is the uniform rate of change of transmissivity in the direction of flow. As with (11), equation (13) is only valid for nonzero $\alpha$ and $T_{1}$ as well as positive $T_{1}$ $+\alpha_{s_{2}}=T_{2}$. 


\section{Effective Transmissivity for One-Dimensional Steady-State Unconfined Flow}

For the case of one-dimensional unconfined flow with recharge and a horizontal aquifer bottom at elevation zero, the governing equation (1) can be written:

$$
\frac{d}{d s} K(s) h \frac{d h}{d s}=-W \text {, }
$$

where the hydraulic conductivity is a function of $s$ and the recharge rate $\mathrm{W}$ is spatially uniform. Integration once yields an expression for flux:

$$
\mathrm{q}_{1}+\mathrm{W}\left(\mathrm{s}-\mathrm{s}_{1}\right)=-\mathrm{K}(\mathrm{s}) \mathrm{h} \frac{\mathrm{dh}}{\mathrm{ds}},
$$

where $\mathrm{q}_{1}$ is here the volumetric flux per unit width at $\mathrm{s}_{1}$. This expression will be evaluated in the sequel for the case of uniform $\mathrm{K}(\mathrm{s})=\mathrm{K}$ with no recharge $(\mathrm{W}=0)$, the case of uniform $\mathrm{K}$ with uniform recharge $\mathrm{W}$, and for the case of linearly varying $\mathrm{K}(\mathrm{s})$ with no recharge.

\section{Homogeneous unconfined aquifer with no recharge}

For the case of spatially uniform hydraulic conductivity $\mathrm{K}$ and no recharge $(\mathrm{W}=0)$, equation (15) can be integrated:

$$
\int_{s_{1}}^{s_{2}} d s=-\frac{K}{q} \int_{h_{1}}^{h_{2}} h d h
$$

where the subscript 1 on $\mathrm{q}$ has been dropped because $\mathrm{q}$ is uniform. Thus, the relation between the flux and the head at two points is (compare to Bear, 1979, p. 180):

$$
\mathrm{q}=\frac{\mathrm{K}}{2 \Delta \mathrm{s}}\left(\mathrm{h}_{1}^{2}-\mathrm{h}_{2}^{2}\right) \text {. }
$$

Using the substitutions (from (3)) $\mathrm{T}_{1}=\mathrm{Kh} \mathrm{h}_{1}, \mathrm{~T}_{2}=\mathrm{Kh}_{2}$, equation (17) becomes 


$$
q=\frac{\left(T_{1}+T_{2}\right)}{2} \frac{\left(h_{1}-h_{2}\right)}{\Delta s}
$$

which shows that the effective transmissivity between points 1 and 2 (see equation (7)) is the arithmetic mean of the transmissivity at points 1 and 2 :

$$
\mathrm{T}_{\mathrm{a}}=\frac{\mathrm{T}_{1}+\mathrm{T}_{2}}{2}
$$

No spatial weighting occurs because the hydraulic conductivity and aquifer bottom elevation are spatially uniform between points 1 and 2 . If either $T_{1}$ or $T_{2}$ is zero, then (19) cannot be used and the effective transmissivity is zero.

The head also changes only in the direction of flow, $s$, and for $\mathrm{s}_{1}=0$ is given by:

$$
(h(s))^{2}=h_{1}^{2}-\frac{2 q s}{K}
$$

\section{Homogeneous unconfined aquifer with recharge}

For the case of spatially uniform hydraulic conductivity $\mathrm{K}$ and uniform recharge $\mathrm{W}$, equation (15) can be integrated to give the relation between the flux, as a function now of s, and the head at two points (compare to Bear, 1979, p. 180):

$$
\mathrm{q}(\mathrm{s})=\mathrm{q}_{1}+\mathrm{W}\left(\mathrm{s}-\mathrm{s}_{1}\right)=\frac{\mathrm{K}}{2 \Delta \mathrm{s}}\left(\mathrm{h}_{1}^{2}-\mathrm{h}_{2}^{2}\right)+\mathrm{W}\left(\mathrm{s}-\frac{\Delta \mathrm{s}}{2}\right)
$$

At a point half-way between $s_{1}$ and $s_{2}$, that is $s=\Delta s / 2$, the last term in (21) drops out:

$$
\mathrm{q}(\mathrm{s}=\Delta \mathrm{s} / 2)=\frac{\mathrm{K}}{2 \Delta \mathrm{s}}\left(\mathrm{h}_{1}^{2}-\mathrm{h}_{2}^{2}\right)
$$

which is identical to equation (17) above, except that the flux is the value midway between $s_{1}$ and $s_{2}$, instead of the uniform flux for the previous case of no recharge. Following the reasoning in the previous section, the negative of the finite-difference head gradient multiplied by the arithmetic mean transmissivity yields the flux midway between the two points for the case of uniform recharge. 
The head also changes only in the direction of flow, $s$, and for $s_{1}=0$ is given by:

$$
(h(s))^{2}=h_{1}^{2}-\frac{2 q_{1} s}{K}-\frac{W s^{2}}{K} .
$$

\section{Unconfined aquifer with hydraulic conductivity a linear function of distance in flow direction}

For the case of no recharge $(\mathrm{W}=0)$, but spatially variable hydraulic conductivity, equation (15) can be integrated:

$$
\int_{h_{1}}^{h_{2}} h d h=-\int_{s_{1}}^{s_{2}} \frac{q d s}{K(s)},
$$

where the subscript 1 on $q$ has been dropped because $q$ is uniform. For the case of $\mathrm{K}(\mathrm{s}) \mathrm{a}$ linear function of s, equation (24) yields:

$$
\frac{\mathrm{h}_{2}^{2}-\mathrm{h}_{1}^{2}}{2}=-\mathrm{q} \Delta \mathrm{s} \frac{\ln \left(\mathrm{K}_{2} / \mathrm{K}_{1}\right)}{\mathrm{K}_{2}-\mathrm{K}_{1}}
$$

where $\mathrm{K}_{1} \equiv \mathrm{K}\left(\mathrm{s}_{1}\right)$ and $\mathrm{K}_{2} \equiv \mathrm{K}\left(\mathrm{s}_{2}\right)$. Thus, the exact effective transmissivity is given by the product of the arithmetic mean head (that is, saturated thickness) and the logarithmic mean hydraulic conductivity:

$$
\mathrm{T}_{\mathrm{a} \lambda}=\frac{\mathrm{h}_{1}+\mathrm{h}_{2}}{2} \frac{\mathrm{K}_{2}-\mathrm{K}_{1}}{\ln \left(\mathrm{K}_{2} / \mathrm{K}_{1}\right)}
$$

If $K_{1}=K_{2}$, then equation (19) is used instead of (26). If either $K_{1}$ or $K_{2}$ is zero, $T_{a \lambda}$ is also zero.

The head also changes only in the direction of flow, $s$, and, for $\mathrm{s}_{1}=0$ is given by:

$$
(h(s))^{2}=h_{1}^{2}-\frac{2 q}{\alpha_{k}} \ln \left(1+\frac{\alpha_{k} s}{K_{1}}\right) .
$$


where $\alpha_{k} \equiv \partial \mathrm{K} / \partial \mathrm{s}\left[\mathrm{T}^{-1}\right]$ is the uniform rate of change of hydraulic conductivity in the direction of flow.

\section{Comparison of Effective Transmissivity Functions}

The effective transmissivity functions are summarized in table 1 . The logarithmic mean (Appel, 1976) is compared to the harmonic, geometric $\left[\left(\mathrm{T}_{1} \mathrm{~T}_{2}\right)^{1 / 2}\right]$, and arithmetric means in figures 1 and 2 in a nondimensional form (effective $\mathrm{T}$ over $\mathrm{T}_{1}$ as a function of $\mathrm{T}_{2}$ $/ \mathrm{T}_{1}$ ). The harmonic mean underestimates the effective $\mathrm{T}$ for the unconfined case with uniform hydraulic conductivity (arithmetic mean) and for confined systems with linear variability in $\mathrm{T}$ (logarithmic mean) because it more heavily weights the low $\mathrm{T}$ value. The geometric mean exhibits less error for both cases and is similar to the logarithmic mean, but still weights the lower $T$ value excessively. For positive $T_{1} \neq T_{2}$, the logarithmic mean is always larger than the geometric mean (Appendix A). As noted previously, the harmonic mean asymptotically approaches $2 \mathrm{~T}_{1}\left(\mathrm{~T} / \mathrm{T}_{1}=2\right)$ as $\mathrm{T}_{2}$ approaches infinity, while the three other means continue to increase indefinitely with increasing $\mathrm{T}_{2}$.

For the case of a water-table system with hydraulic conductivity varying linearly in space, the exact effective $T$ depends on the relative variability in head. The effective $T_{a \lambda}$ for an unconfined aquifer with linearly varying hydraulic conductivity is shown for several ratios of $h_{2} / h_{1}$ and compared to the arithmetic mean and the logarithmic mean transmissivity in figures 3 and 4. Here, the aquifer bottom elevation is assumed to be zero, so the head ratios correspond to the ratios in saturated thickness. When the ratio $h_{2} / h_{1}$ is greater than 1 , flow is in the negative $s$ direction (that is, from point 2 to point 1 ). If $h_{2} / h_{1}$ $=T_{2} / T_{1}$, then $K(s)=K$ is uniform and the logarithmic mean transmissivity reduces to the arithmetic mean, $T_{a \lambda}=T_{a}$. If the transmissivities at points 1 and 2 are equal, $T_{2} / T_{1}=1$, then $\mathrm{K}$ must be variable because the heads are not equal if flow is occuring. The effective $T_{a \lambda}$ for the case of $T_{2} / T_{1}=1$ is greater than either $T_{1}$ or $T_{2}$ because the nonlinear variability in saturated thickness and the linear variability in $\mathrm{K}$ yield transmissivities between point 1 and 2 that are larger than the values at 1 and 2 . This relation is clarified by figure 5 , which shows the ratio of $T_{a \lambda} / T_{1}$ as a function of $K_{1} / K_{2}$, for several values of $\mathrm{h}_{2} / \mathrm{h}_{1}$. 


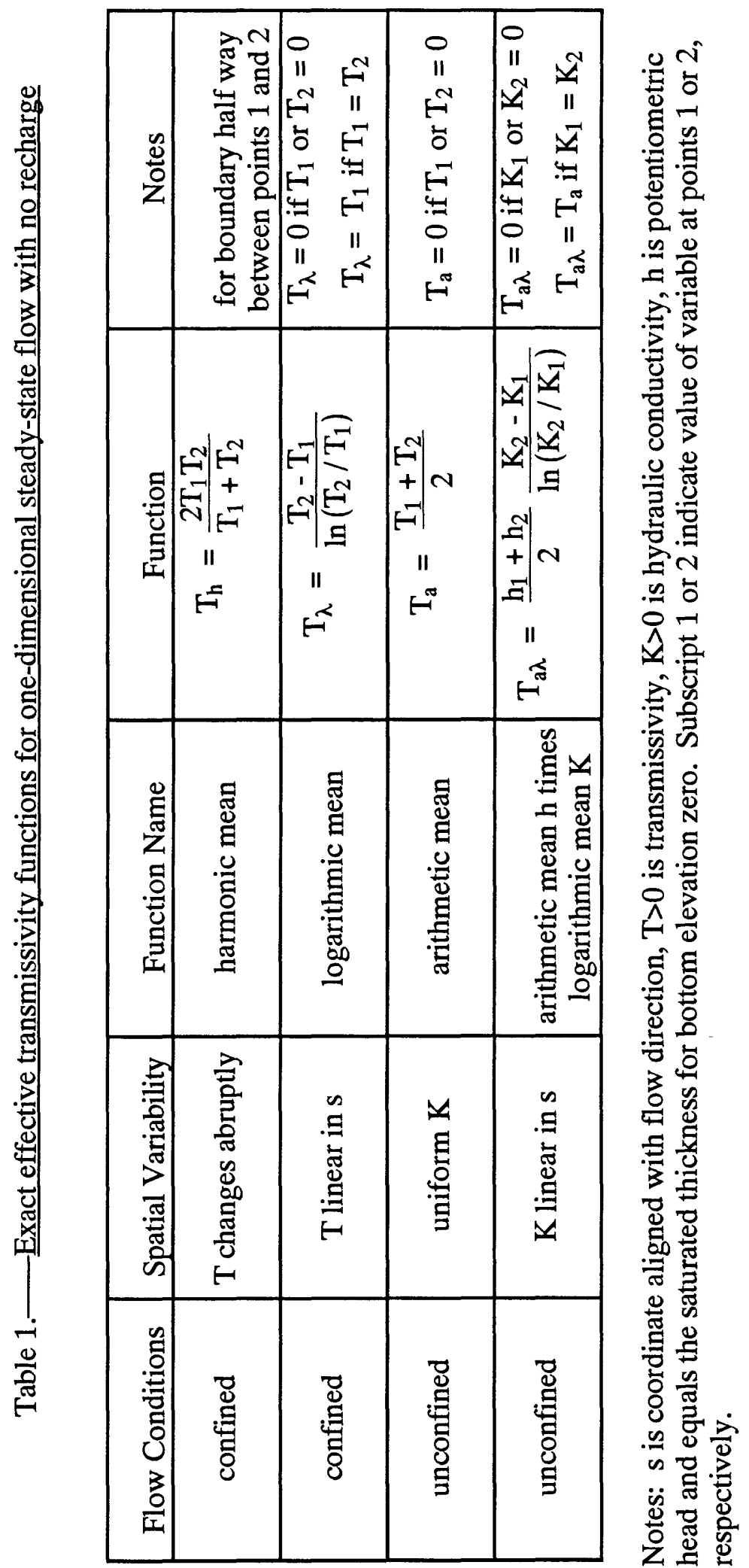




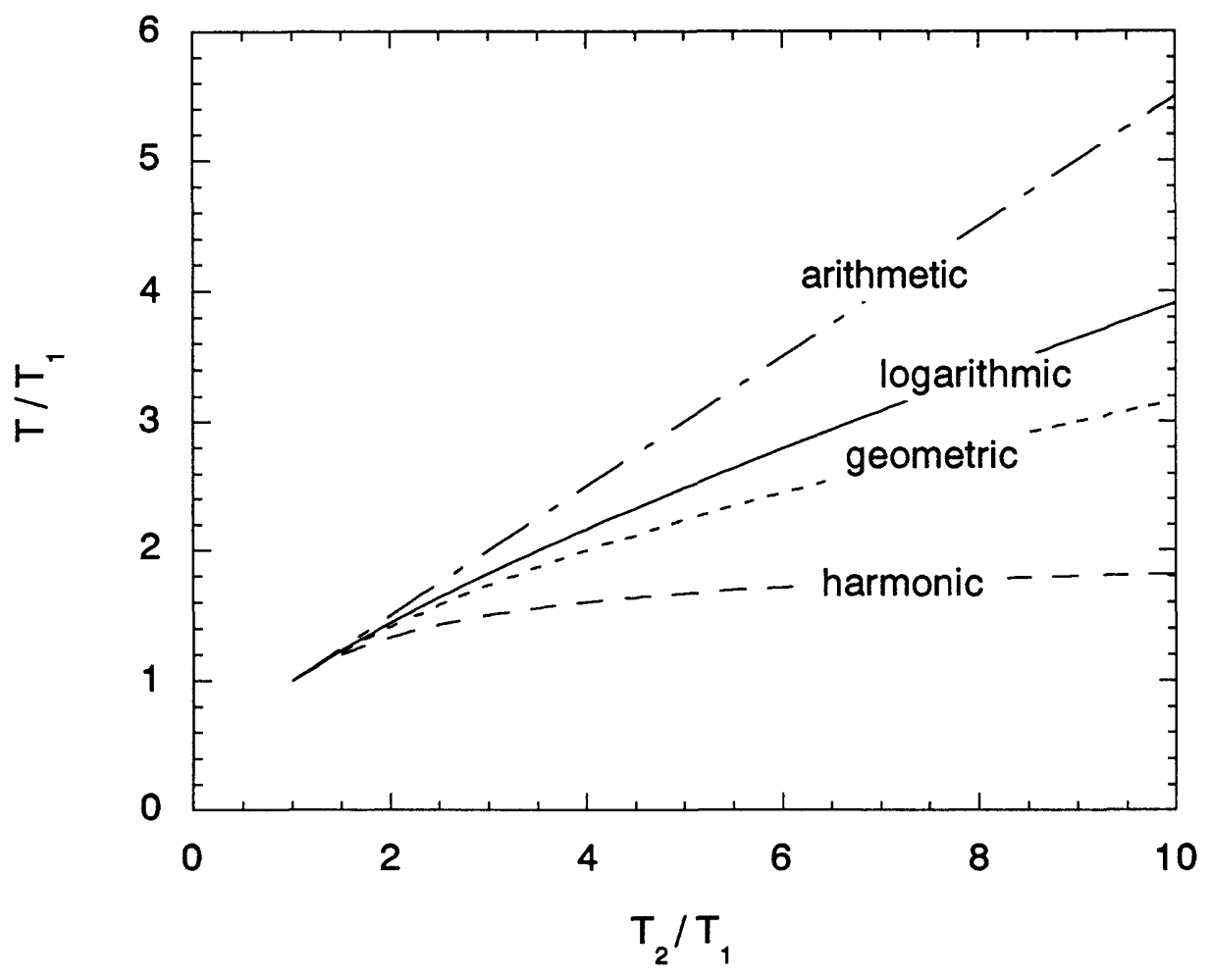

Figure 1.--Graph showing ratio of arithmetic, logarithmic, and harmonic effective transmissivities to transmissivity at point $1\left(\mathrm{~T} / \mathrm{T}_{1}\right)$ as a function of the ratio of transmissivity at point 2 to that at point $1\left(\mathrm{~T}_{2} / \mathrm{T}_{1}\right)$. Geometric mean transmissivity shown for comparison.

The importance of selecting the appropriate effective transmissivity depends on the magnitude of changes in transmissivity between points 1 and 2 where the head is evaluated, and on the magnitude of head changes for the unconfined case. When these changes are small then any of the functions will yield essentially the same results. Errors due to using an incorrect effective transmissivity increase with the magnitude of the changes in transmissivity, or with the magnitude of the changes in saturated thickness and hydraulic conductivity for the unconfined case. 


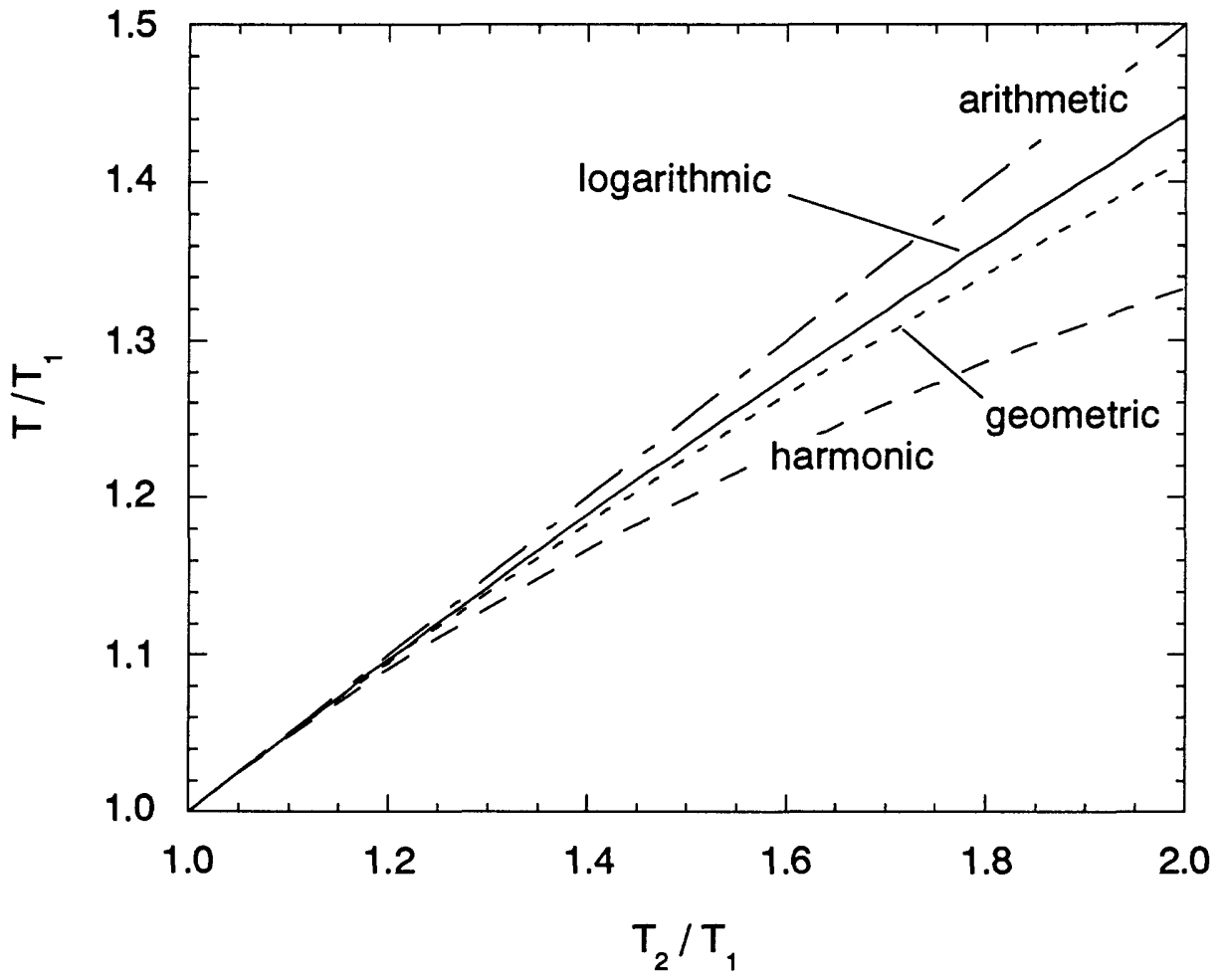

Figure 2.--Graph showing enlarged portion of Figure 1 for small values of the ratio of transmissivity at point 2 to that at point 1 . 


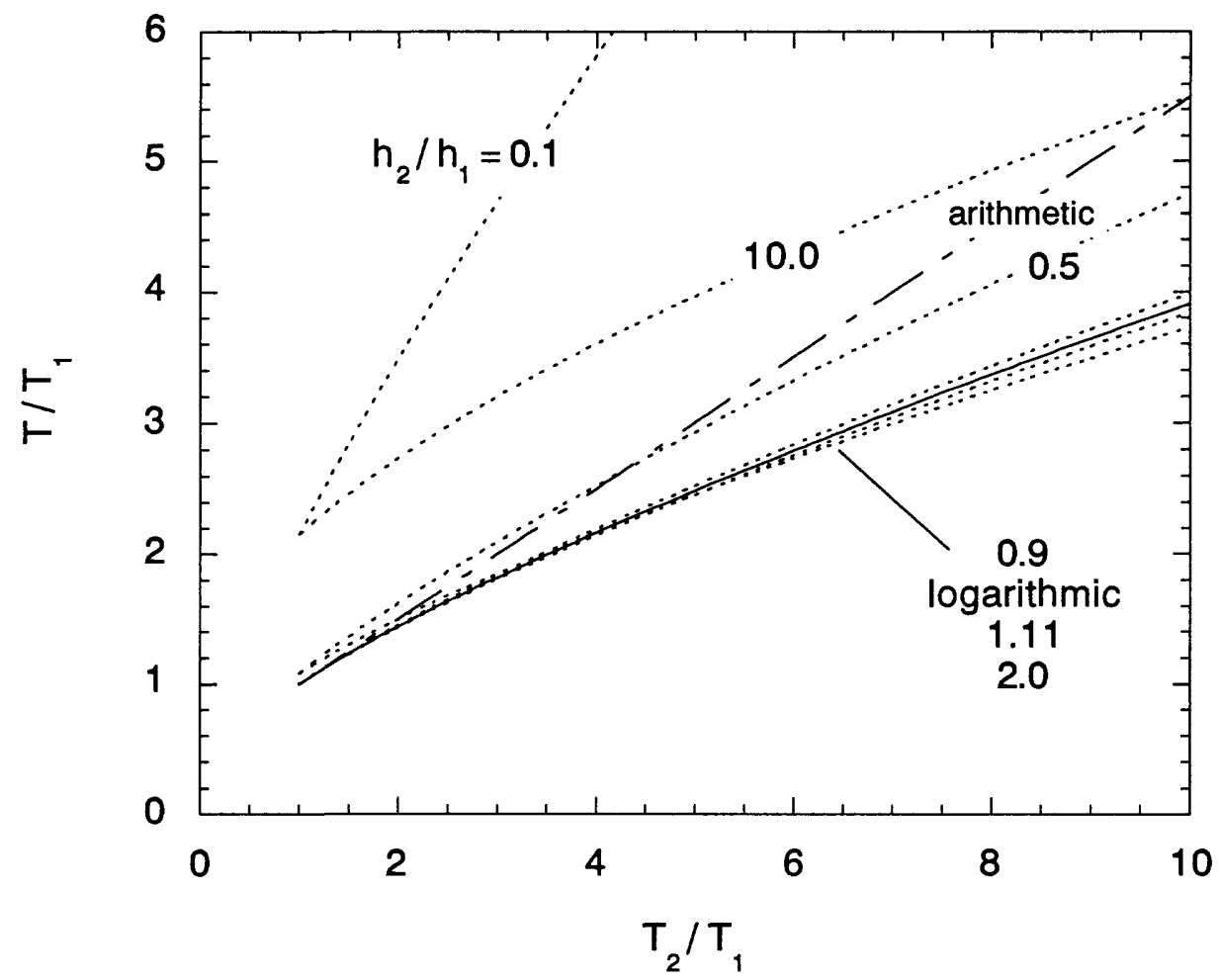

Figure 3.--Graph showing ratio of effective transmissivity as arithmetic mean saturated thickness times logarithmic mean hydraulic conductivity to the transmissivity at point 1 $\left(T / T_{1}\right)$ as a function of the ratio of transmissivity at point 2 to that at point $1\left(T_{2} / T_{1}\right)$. Arithmetic and logarithmic effective transmissivities shown for comparison. 


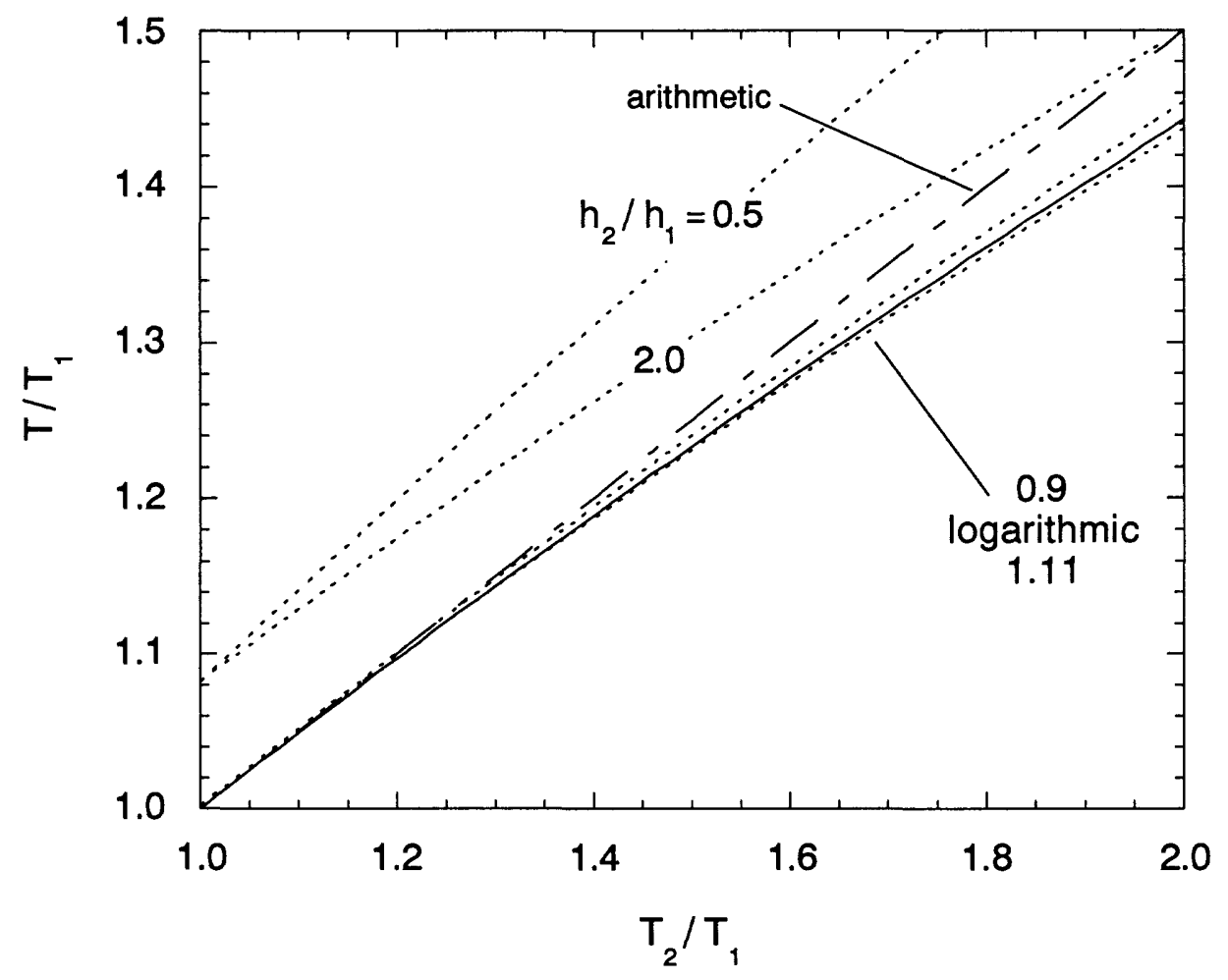

Figure 4.--Graph showing enlarged portion of Figure 3 for small values of the ratio of transmissivity at point 2 to that at point 1 . 


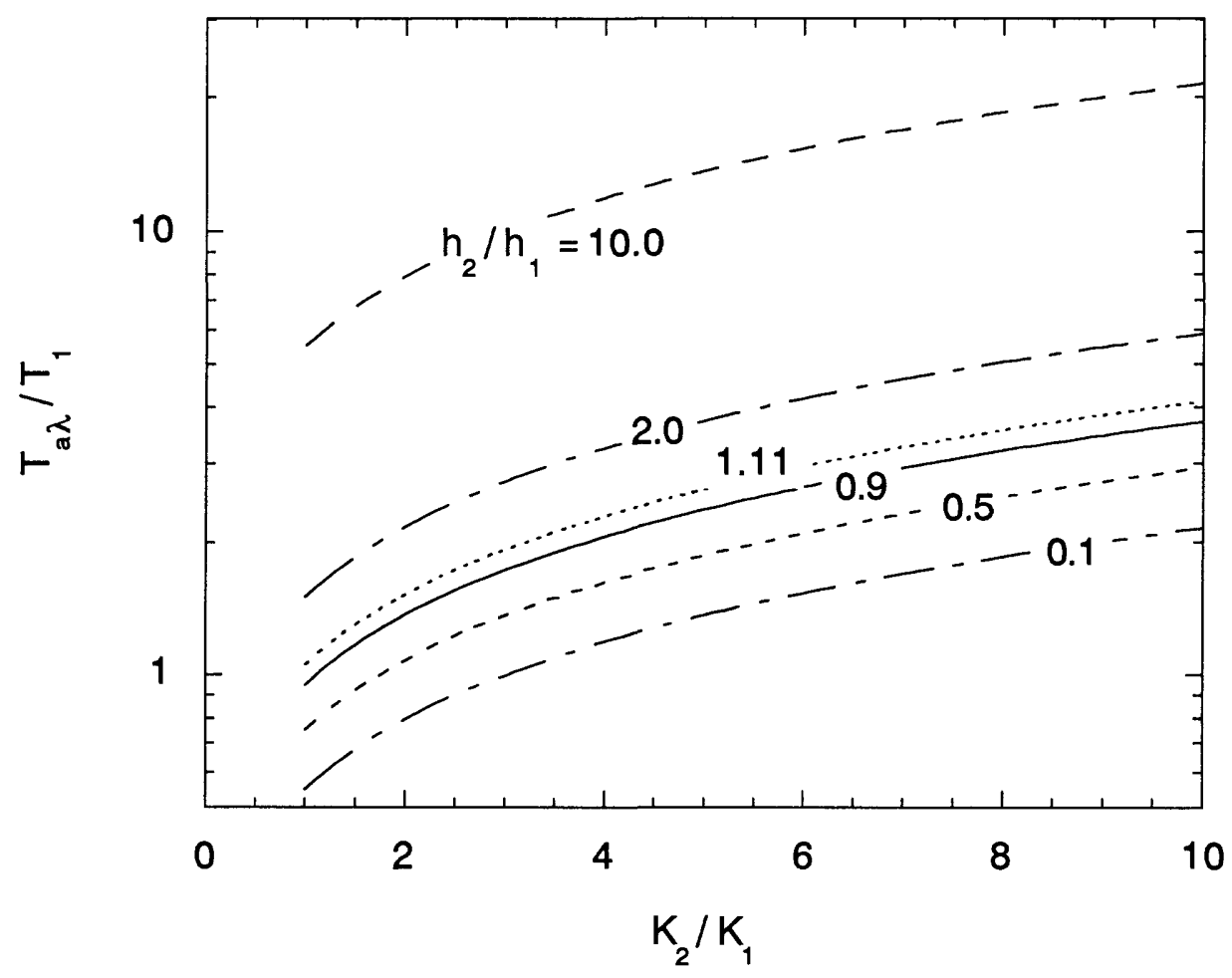

Figure 5.--Graph showing the ratio of effective transmissivity as arithmetic mean saturated thickness times logarithmic mean hydraulic conductivity to the transmissivity at point 1 $\left(\mathrm{T} / \mathrm{T}_{1}\right)$ as a function of the ratio of hydraulic conductivity at point 2 to that at point 1 $\left(\mathrm{K}_{2} / \mathrm{K}_{1}\right)$ for several values of the ratio of head at point 2 to that at point $1\left(\mathrm{~h}_{2} / \mathrm{h}_{1}\right)$. 


\section{NUMERICAL METHODS}

\section{Finite-Difference Representation of Flow Equation}

The steady-state two-dimensional ground-water flow equation can be solved using a block-centered finite-difference representation. The aquifer is discretized into rectangular blocks with a node at the center of each block (fig. 6). A discrete approximation of the governing equation is obtained by solving for the heads at the nodes [after Pinder and Bredehoeft, 1968; Trescott et al., 1976; Konikow and Bredehoeft, 1978]:

$$
\begin{aligned}
& \frac{1}{\Delta x_{i}}\left\{\left[T_{x x(i+1 / 2, j)} \frac{\left(h_{i+1, j}-h_{i, j}\right)}{\Delta x_{i+1 / 2}}\right]-\left[T_{x x(i-1 / 2, j)} \frac{\left(h_{i, j}-h_{i-1, j}\right)}{\Delta x_{i-1 / 2}}\right]\right\} \\
& +\frac{1}{\Delta y_{j}}\left\{\left[T_{y y(i, j+1 / 2)} \frac{\left(h_{i, j+1}-h_{i, j}\right)}{\Delta y_{j+1 / 2}}\right]-\left[T_{y y(i, j-1 / 2)} \frac{\left(h_{i, j}-h_{i, j-1}\right)}{\Delta y_{j-1 / 2}}\right]\right\} \\
& +W_{i, j}=0
\end{aligned}
$$

where subscript $i$ is the index for the discretization in the $x$ direction and subscript $j$ is the index for the discretization in the $\mathrm{y}$ direction. The term $\Delta \mathrm{x}_{\mathrm{i}}$ is the $\mathrm{x}$ dimension of all blocks at the $\mathrm{x}$ location corresponding to $\mathrm{i}$. The term $\Delta \mathrm{x}_{\mathrm{i}+1 / 2}$ is the distance between node $i, j$ and node $\mathrm{i}+1, \mathrm{j}$, for all $\mathrm{i}: \Delta \mathrm{x}_{\mathrm{i}+1 / 2}=\left(\Delta \mathrm{x}_{\mathrm{i}}+\Delta \mathrm{x}_{\mathrm{i}+1}\right) / 2$. The $\Delta \mathrm{y}$ terms in (28) are analogous.

The block-centered finite-difference saturated flow model of McDonald and Harbaugh (1988) (MODFLOW) solves a three-dimensional equation analogous to (28), where $\mathrm{W}$ includes vertical flow between layers and depends on the difference between $\mathrm{h}_{\mathrm{i}, \mathrm{j}}$ and the corresponding heads in adjacent layers. The algorithms developed in the following sections have been coded in new MODFLOW subroutines for computing horizontal conductance (see Appendix B). 


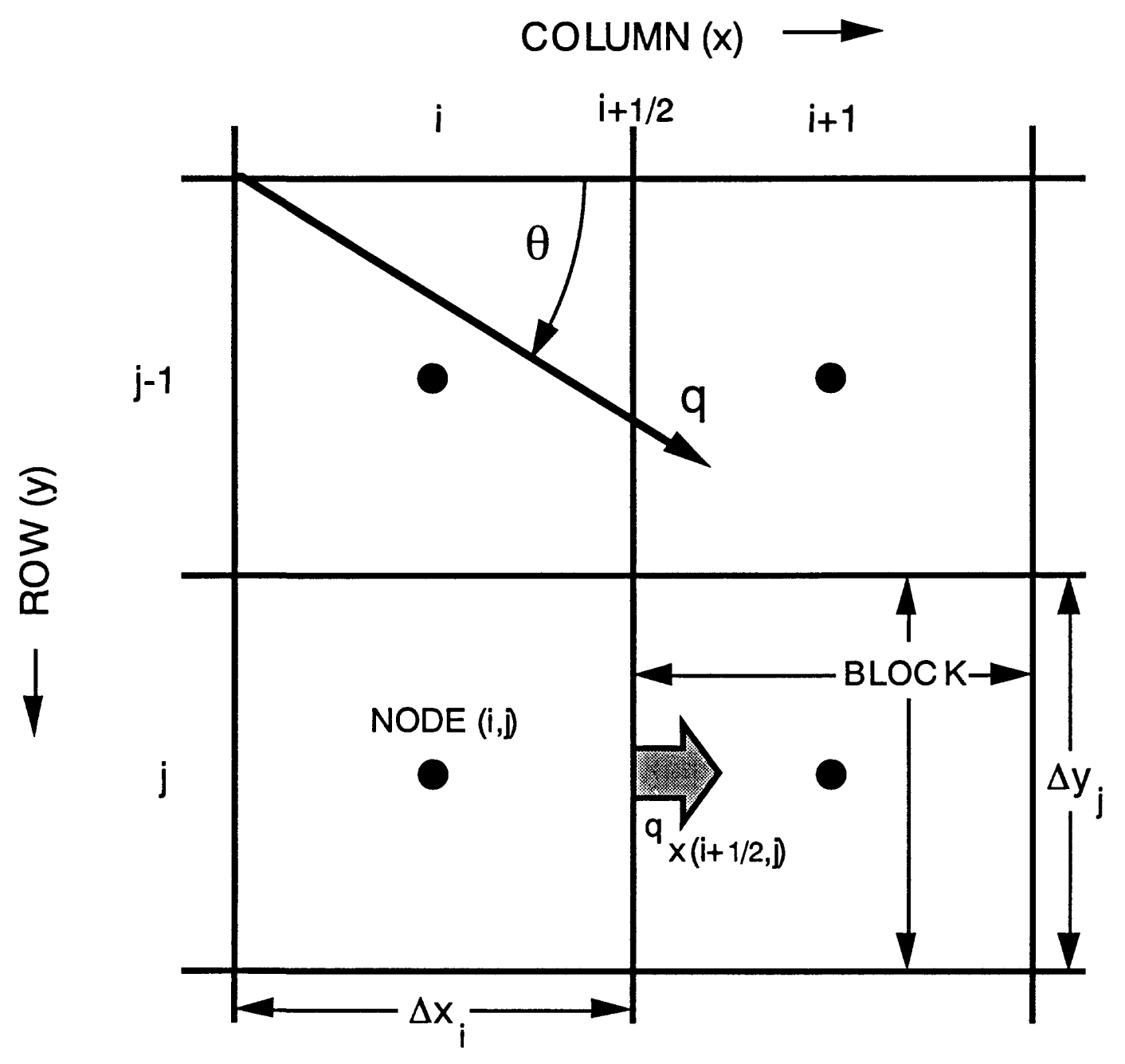

Figure 6.--Schematic of two-dimensional finite-difference discretization scheme showing flux in the $x$ direction at $(i+1 / 2, j)$ and a flux vector $q$ oriented at angle $\theta$ to the $x$ axis. 


\section{Interblock Transmissivity}

The transmissivity terms in (28) are interblock or block interface values and are usually computed as some average of the values of $T$ in the adjacent blocks. Two commonly used functions are the weighted arithmetic mean (Pinder and Bredehoeft, 1968)

$$
\mathrm{T}_{\mathrm{xx}(\mathrm{i}+1 / 2, \mathrm{j})}=\frac{\Delta \mathrm{x}_{\mathrm{i}+1} \mathrm{~T}_{\mathrm{xx}(\mathrm{i}, \mathrm{j})}+\Delta \mathrm{x}_{\mathrm{i}} \mathrm{T}_{\mathrm{xx}(\mathrm{i}+1, \mathrm{j})}}{\Delta \mathrm{x}_{\mathrm{i}}+\Delta \mathrm{x}_{\mathrm{i}+1}}, \quad \mathrm{~T}_{\mathrm{xx}(\mathrm{i}, \mathrm{j})}, \mathrm{T}_{\mathrm{xx}(\mathrm{i}+1, \mathrm{j})} \neq 0,
$$

and the weighted harmonic mean (Pinder, 1970; Routt and Crawford, 1973):

$$
\mathrm{T}_{\mathrm{xx}(\mathrm{i}+1 / 2, \mathrm{j})}=\frac{\mathrm{T}_{\mathrm{xx}(\mathrm{i}, \mathrm{j})} \mathrm{T}_{\mathrm{xx}(\mathrm{i}+1, \mathrm{j})}\left(\Delta \mathrm{x}_{\mathrm{i}}+\Delta \mathrm{x}_{\mathrm{i}+1}\right)}{\Delta \mathrm{x}_{\mathrm{i}+1} \mathrm{~T}_{\mathrm{xx}(\mathrm{i}, \mathrm{j})}+\Delta \mathrm{x}_{\mathrm{i}} \mathrm{T}_{\mathrm{xx}(\mathrm{i}+1, j)}} ; \quad \mathrm{T}_{\mathrm{xx}(\mathrm{i}, \mathrm{j})}+\mathrm{T}_{\mathrm{xx}(\mathrm{i}+1, \mathrm{j})} \neq 0 .
$$

The y components are computed analogously. As shown in the Theory section, the harmonic mean yields exact fluxes and nodal heads for one-dimensional steady-state flow with no recharge when transmissivity is uniform within each finite-difference block.

The expression for the weighted arithmetic mean (29) is the value of transmissivity at the location of the block interface obtained by linear interpolation between the nodal values. This interpolation is implied by the Taylor series expansion of Pinder and Bredehoeft (1968). In the papers of Appel (1976) and Anderson and others (1984), equation (29) is presented but with the indices on the $\Delta x$ terms in the numerator switched. Their expression, which is not due to Pinder and Bredehoeft (1968), is equivalent to determining the average value of transmissivity along the line between the two nodes when the transmissivity is uniform on each block. The expression presented by Appel (1976, eq. 2) and Anderson and others (1984) has, to our knowledge, no rigorous derivation for the ground-water flow equation. Fortunately, the incorrect expression yields the same value of transmissivity when the blocks are uniform, i.e. when no spatial weighting occurs.

Other methods for determining the interblock transmissivity include using the geometric mean and using the "upstream" value only. The geometric mean, although an ad hoc method for ground-water flow, has been shown to perform satisfactorily in onedimensional unsaturated flow simulations where hydraulic conductivity is nonlinearly dependent on head (Haverkamp et al., 1978). As shown above, the geometric mean is 
similar to the logarithmic mean. Using the "upstream" value, or the value from the block with the higher head, is common in the petroleum simulation literature for the analogous finite-difference simulation of transient immiscible displacment (Crichlow, 1977), but this method has no rigorous derivation for application to steady-state ground-water flow.

The desired interblock transmissivity is that which computes the correct flux when the heads at the nodes are known, or, conversely, which yields the correct heads at the nodes when the flux is specified. Thus, the exact effective interblock transmissivity is the ratio of the exact flux divided by the finite-difference representation of the head gradient using the exact heads (for example, in the $\mathrm{x}$ direction):

$$
T_{x x(i+1 / 2, j)}=\frac{-q_{x(i+1 / 2, j)} \Delta x_{i+1 / 2, j}}{h_{i+1, j}-h_{i, j}},
$$

where the terms on the right hand side are known. This relation can be used, in steadystate and with no recharge, to derive the exact interblock transmissivity for cases in which the flux and heads are known analytically. The similarity between equation (31) and equation (7) above indicates that the effective transmissivity functions derived in the Theory section are suitable for interblock transmissivities in block-centered finite-difference flow models. In this use, points 1 and 2 correspond to nodes in the finite-difference grid.

\section{Transmissivity uniform over each block}

The weighted harmonic mean, equation (30), yields the exact solution for onedimensional flow with no recharge if the transmissivity is assumed to be uniform over each finite-difference block. In addition, this mean automatically accounts for cases of uniform transmissivity and zero transmissivity, except if both transmissivities are zero. Of the alternative interblock transmissivity functions considered here (see table 1), the harmonic mean most heavily weights the lower transmissivity value. The appropriate spatial weighting depends on the grid method, the result here (equation 30) being appropriate for block-centered grids. 


\section{Transmissivity varies linearly between nodes}

Appel (1976) presented a function (herein called the logarithmic mean) for computing the interblock $\mathrm{T}$ that is exact for steady-state one-dimensional flow with no recharge where $T$ is a linear function of distance:

$$
T_{x x(i+1 / 2, j)}=\frac{T_{x x(i+1, j)}-T_{x x(i, j)}}{\ln \left[\frac{T_{x x(i+1, j)}}{T_{x x(i, j)}}\right]} ; \quad \begin{aligned}
T_{x x(i, j)}, T_{x x(i+1, j)} \neq 0 \\
T_{x x(i, j)} \neq T_{x x(i+1, j)} .
\end{aligned}
$$

Here, we prove that this interblock transmissivity also yields exact finite-difference solutions when the direction of flow is not aligned with the grid. That is, using the logarithmic mean for the interblock $\mathrm{T}$ in a two-dimensional model (or interblock $\mathrm{K}$ in a three-dimensional model) results in an exact solution to the flow problem if flow is uniform and aligned in the direction of changing $\mathrm{T}$, regardless of the grid orientation.

Consider that the direction of flow $\mathrm{s}$ is at an angle $\theta$ to the finite-difference grid (fig. 6). The transformation from $\mathrm{x}$ and $\mathrm{y}$ to the $\mathrm{s}$ coordinate is given by:

$$
s=x \cos \theta+y \sin \theta
$$

where it is assumed that $\mathrm{s}=0$ at $\mathrm{x}=\mathrm{y}=0$.

The transmissivity is assumed to change in only the s direction, and to be uniform orthogonal to $\mathrm{s}$. Defining the rate of change of $\mathrm{T}$ as a function of distance in the $\mathrm{s}$ direction as $\alpha \equiv \mathrm{dT} / \mathrm{ds}$, the transmissivity at any point is given by:

$$
\mathrm{T}(\mathrm{s})=\mathrm{T}_{1}+\alpha \mathrm{s} \quad ; \quad \mathrm{T}(\mathrm{x}, \mathrm{y})=\mathrm{T}_{1}+\alpha(\mathrm{x} \cos \theta+\mathrm{y} \sin \theta),
$$

where $T_{1}$ is the transmissivity at $\mathrm{s}=0$. For this case, transmissivity is isotropic.

Assume the reference node $(i, j)$ is located at $x=y=0$. The adjacent node in the $x$ direction $(i+1, j)$, is located at $x=\Delta x_{i+1 / 2}, y=0$. Using (34), the transmissivity at this node is

$$
\mathrm{T}_{\mathrm{xx}(\mathrm{i}+1, \mathrm{j})}=\mathrm{T}_{1}+\alpha \Delta \mathrm{x}_{\mathrm{i}+1 / 2} \cos \theta
$$


The logarithmic mean $T_{x x}$ at (i+1/2,j) is, substituting (35) for $T_{2}$ into (32):

$$
\mathrm{T}_{\mathrm{xx}(\mathrm{i}+1 / 2, \mathrm{j})}=\frac{\alpha \Delta \mathrm{x}_{\mathrm{i}+1 / 2} \cos \theta}{\ln \left(1+\frac{\alpha \Delta \mathrm{x}_{i+1 / 2} \cos \theta}{\mathrm{T}_{1}}\right)}
$$

The model flux in the $\mathrm{x}$ direction is the negative of this interblock $\mathrm{T}$ multiplied by the head gradient between the nodes. The exact head at node $(i+1, j)$ is evaluated by substituting (33) for this node into (13), yielding:

$$
h_{i+1, j}=h_{1}-\frac{q}{\alpha} \ln \left(1+\frac{\alpha \Delta x_{i+1 / 2} \cos \theta}{T_{1}}\right) .
$$

The finite difference expression for the discharge per unit width at $(i+1 / 2, j)$ is then

$$
\begin{aligned}
& -T_{x x(i+1 / 2, j)} \frac{\left(h_{i+1, j}-h_{i, j}\right)}{\Delta x_{i+1 / 2}}= \\
& =\left[\frac{-\alpha \Delta x_{i+1 / 2} \cos \theta}{\ln \left(1+\frac{\alpha \Delta x_{i+1 / 2} \cos \theta}{T_{1}}\right)}\right]\left[\frac{-\frac{q}{\alpha} \ln \left(1+\frac{\alpha \Delta x_{i+1 / 2} \cos \theta}{T_{1}}\right)}{\Delta x_{i+1 / 2}}\right] \\
& =q \cos \theta,
\end{aligned}
$$

which is the expected result. The results in the y direction are analogous. In addition, this proof can easily be extended to three dimensions, where $\mathrm{T}$ is replaced by $\mathrm{K}$, the hydraulic conductivity, and q, volumetric flux per unit width, is replaced by a volumetric flux per unit area or specific discharge.

Thus, using the analytically calculated heads at the nodes and the logarithmic mean $\mathrm{T}$, the flux is computed exactly. Conversely, if the flux is specified, through boundary conditions, then the heads at the nodes will be exact if logarithmic mean is used for the interblock transmissivity. This proof is also applicable to the "grid point distributed" variation (Settari and Aziz, 1972) of the finite-difference formulation for the case of uniform parallel flow because the transmissivity is assumed to vary linearly between nodes, regardless of the location of the block boundary. 


\section{Unconfined aquifer with uniform hydraulic conductivity}

The analysis of the Theory Section indicates that for uniform flow under unconfined conditions, with a horizontal aquifer bottom and flow oriented in a grid direction, and with a constant hydraulic conductivity, the exact interblock transmissivity is computed as the (unweighted) artihmetic mean:

$$
T_{x x(i+1 / 2, j)}=\frac{T_{x x(i, j)}+T_{x x(i+1, j)}}{2} ; \quad T_{x x(i, j)}, T_{x x(i+1, j)} \neq 0
$$

It is recognized that the Dupuit approximation assumes that the change in head relative to the aquifer thickness is small. When the change in saturated thickness is small between nodes, then the differences between alternative interblock $T$ functions is also small. However, examination of documented model applications indicate that the numerical model is likely to be applied to unconfined situations where the change in saturated thickness may be significant.

Following the proof of the previous section, we can show that use of the arithmetic mean transmissivity yields an exact solution for unidirectional unconfined flow in any direction in a two-dimensional grid, if the aquifer bottom is flat and the hydraulic conductivity is uniform. As above, head changes only in the direction of flow, $\mathrm{s}$, and is given by equation (20). Thus, for flow at an angle $\theta$ to the grid, the head at node $(i+1, j)$ is:

$$
h_{i+1, j}=\left(h_{1}^{2}-\frac{2 q \Delta x_{i+1 / 2} \cos \theta}{K}\right)^{1 / 2},
$$

where the head at node $(i, j)$ is $h_{i, j}=h_{1}$. The transmissivity at node $(i, j)$ is $K h_{1}$, the transmissivity at node $(i+1, j)$ is given by $(40)$ times $K$, and the arithmetic mean transmissivity $T_{\mathbf{x x}(i+1 / 2, \mathrm{j})}$ is

$$
\mathrm{T}_{\mathrm{xx}(\mathrm{i}+1 / 2, \mathrm{j})}=0.5 \mathrm{~K}\left[\mathrm{~h}_{1}+\left(\mathrm{h}_{1}^{2}-\frac{2 \mathrm{q} \Delta \mathrm{x}_{\mathrm{i}+1 / 2} \cos \theta}{\mathrm{K}}\right)^{1 / 2}\right],
$$

assuming that the aquifer bottom has elevation zero. Substituting (40) and (41) into the finite-difference expression for the flux at the block interface (equation (31)) yields: 


$$
\begin{aligned}
& -T_{\mathbf{x x}(i+1 / 2, j)} \frac{\left(h_{i+1, j}-h_{i, j}\right)}{\Delta x_{i+1 / 2}}= \\
& \quad=\frac{-K}{2 \Delta x_{i+1 / 2}}\left[\left(h_{1}^{2}-\frac{2 q \Delta x_{i+1 / 2} \cos \theta}{K}\right)^{1 / 2}+h_{1}\right]\left[\left(h_{1}^{2}-\frac{2 q \Delta x_{i+1 / 2} \cos \theta}{K}\right)^{1 / 2}-h_{1}\right] \\
& =q \cos \theta
\end{aligned}
$$

which is the desired result. Thus, under the special conditions of unconfined flow, flat aquifer bottom, no recharge, and unidirectional uniform flow, use of the arithmetic mean interblock transmissivity yields the exact flow equation solution regardless of the orientation of the finite-difference grid. Furthermore, if uniform recharge is occurring, this approach will also yield the exact flux at the location halfway between the nodes. That is, if the finite-difference blocks are uniform, the method is also exact for unidirectional flow with recharge.

\section{Unconfined aquifer with hydraulic conductivity varying linearly between nodes}

The Theory Section shows that for uniform unconfined flow in a grid direction, with a horizontal aquifer bottom at elevation zero and no recharge, the exact effective transmissivity is the arithmetic mean potentiometric head times the logarithmic mean hydraulic conductivity. For a general model with variable aquifer bottom elevation, but ignoring the slope of the aquifer bottom, the finite-difference interblock transmissivity is:

$$
T_{\mathbf{x x}(i+1 / 2, j)}=\frac{\left(h_{i, j}-b_{i, j}\right)+\left(h_{i+1, j}-b_{i+1, j}\right)}{2} K_{x x(i+1 / 2, j)}
$$

where

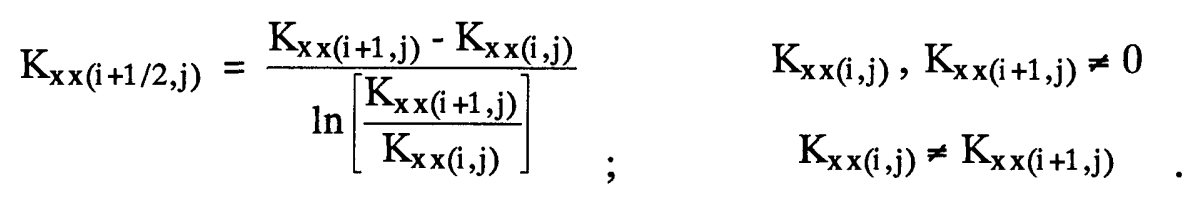

and where $b[\mathrm{~L}]$ is the elevation of the aquifer bottom. This form is more general than equation (39) above and reduces to equation (39) when the hydraulic conductivity is 
uniform. In addition, this form reduces to equation (32) for a confined system with uniform saturated thickness when the potentiometric head in (43) is replaced by the aquifer top elevation. For these reasons, equation (43) may be preferred for situations where one of the nodes is unconfined but the other is confined, although further investigation of this case may be warranted.

The computational effort for this interblock transmissivity is more than the previously considered methods. In effect, the effort for this case is comparable to the sum of the efforts for the arithmetic and logarithmic means, because both means are computed here. However, for most cases this increase is probably insignificant compared to the computational effort associated with solving the system of finite-difference equations. The additional computational effort associated with this interblock transmissivity could be minimized for transient problems by storing the logarithmic mean interblock hydraulic conductivity.

Following the proof of the previous section, we can show that use of the arithmetic mean transmissivity yields an exact solution for unidirectional unconfined flow in any direction in a two-dimensional grid, if the aquifer bottom is horizontal and has elevation zero, and the hydraulic conductivity varies linearly in the direction of flow. As above, the direction of the head gradient is parallel to the direction of flow, $\mathrm{s}$, and head is given by equation (27). Thus, for flow at an angle $\theta$ to the grid, the head at node $(i+1, j)$ is:

$$
\mathrm{h}_{\mathrm{i}+1, \mathrm{j}}=\left[\mathrm{h}_{1}^{2}-\frac{2 \mathrm{q}}{\alpha_{\mathrm{k}}} \ln \left(1+\frac{\alpha_{\mathrm{k}} \Delta \mathrm{x}_{\mathrm{i}+1 / 2} \cos \theta}{\mathrm{K}_{1}}\right)\right]^{1 / 2},
$$

and the hydraulic conductivity at node $(\mathrm{i}, \mathrm{j}+1)$ is:

$$
\mathrm{K}_{\mathrm{xx}(\mathrm{i}+1, \mathrm{j})}=\mathrm{K}_{1}+\alpha_{\mathrm{k}} \Delta \mathrm{x}_{\mathrm{i}+1 / 2} \cos \theta .
$$

The logarithmic mean hydraulic conductivity at $(\mathrm{i}+1 / 2, \mathrm{j})$ is, substituting $(46)$ and $\mathrm{K}_{1}=$ $\mathrm{K}_{\mathrm{xx}(\mathrm{i}, \mathrm{j})}$ into (44):

$$
\mathrm{K}_{\mathrm{xx}(\mathrm{i}+1 / 2, \mathrm{j})}=\frac{\alpha_{\mathrm{k}} \Delta \mathrm{x}_{\mathrm{i}+1 / 2} \cos \theta}{\ln \left(1+\frac{\alpha_{\mathrm{k}} \Delta \mathrm{x}_{\mathrm{i}+1 / 2} \cos \theta}{\mathrm{K}_{1}}\right)} .
$$


The interblock transmissivity is the arithmetic mean saturated thickness times the logarithmic mean hydraulic conductivity,

$$
T_{x x(i+1 / 2, j)}=h_{a(i+1 / 2, j)} K_{x x(i+1 / 2, j)}
$$

where the arithmetic mean saturated thickness is

$$
h_{a(i+1 / 2, j)}=\frac{h_{1}+h_{i+1, j}}{2}=0.5\left\{h_{1}+\left[h_{1}^{2}-\frac{2 q}{\alpha_{k}} \ln \left(1+\frac{\alpha_{k} \Delta x_{i+1 / 2} \cos \theta}{K_{1}}\right)\right]^{1 / 2}\right\} \text {, }
$$

Substituting (45), (48) and (49) into the finite-difference expression for the flux at the block interface (equation (31)) yields,

$$
\begin{aligned}
& -T_{x x(i+1 / 2, j)} \frac{\left(h_{i+1, j}-h_{i, j}\right)}{\Delta x_{i+1 / 2}}= \\
& -0.5\left\{h_{1}+\left[h_{1}^{2}-\frac{2 q}{\alpha_{k}} \ln \left(1+\frac{\alpha_{k} \Delta x_{i+1 / 2} \cos \theta}{K_{1}}\right)\right]^{1 / 2}\right\} \frac{\alpha_{k} \Delta x_{i+1 / 2} \cos \theta}{\ln \left(1+\frac{\alpha_{k} \Delta x_{i+1 / 2} \cos \theta}{K_{1}}\right)} \\
& \quad\left\{\left[h_{1}^{2}-\frac{2 q}{\alpha_{k}} \ln \left(1+\frac{\alpha_{k} \Delta x_{i+1 / 2} \cos \theta}{K_{1}}\right)\right]^{1 / 2}-h_{1}\right\} \Delta x_{i+1 / 2}{ }^{-1} \\
& =q \cos \theta,
\end{aligned}
$$

which is the desired result. Thus, under the special conditions of unidirectional uniform unconfined flow, where flow is parallel to the direction of changing $\mathrm{K}$, and horizontal aquifer bottom, use of the arithmetic mean saturated thickness times the logarithmic mean hydraulic conductivity for interblock transmissivity yields the exact solution regardless of the orientation of the finite-difference grid. 


\section{EVALUATION OF APPROACH}

In this section, the relative accuracies of the alternative interblock transmissivity functions are illustrated for two- and three-dimensional simulations. Results are first shown for several two-dimensional simulations of unidirectional flow with and without recharge. Because the exact solution for these problems is one-dimensional flow, simple analytical solutions can be used to assess model accuracy. Next, results are compared for a three-dimensional system for which the analytical solution is unavailable. In this case, coarse grid solutions are compared with solutions using a very fine grid. For all of these cases, errors are illustrated by tables of potentiometric head at certain nodes, and by tables of a simple error statistic for all computed heads and fluxes. This average error statistic is the sum of the absolute values of the difference between the model result and the exact result, divided by the sum of the absolute values of the exact result. For example, the average head error statistic is:

$$
\varepsilon_{\mathrm{h}}=\frac{\sum\left|\mathrm{h}_{\text {model }}-\mathrm{h}_{\text {exact }}\right|}{\sum\left|\mathrm{h}_{\text {exact }}\right|}
$$

For the cases for which the analytical solution is not available, the fine grid result is used as an estimate of the exact value. Similar statistics are computed for the applicable flux components. Finally, a previously completed three-dimensional large-scale simulation is repeated using the alternative interblock transmissivity functions. This example illustrates the practical effects of using different interblock transmissivity functions. The example simulations are summarized in table 2 .

\section{Two-Dimensional Examples with Analytical Solutions}

Several simple two-dimensional examples are presented where flow is unidirectional and a one-dimensional analytical solution is available. However, the flow is oriented at an angle to the grid to activate two-dimensional aspects of the numerical solution. The numerical grid (fig. 7) is 5 rows (y) by 5 columns (x). Specified flux 


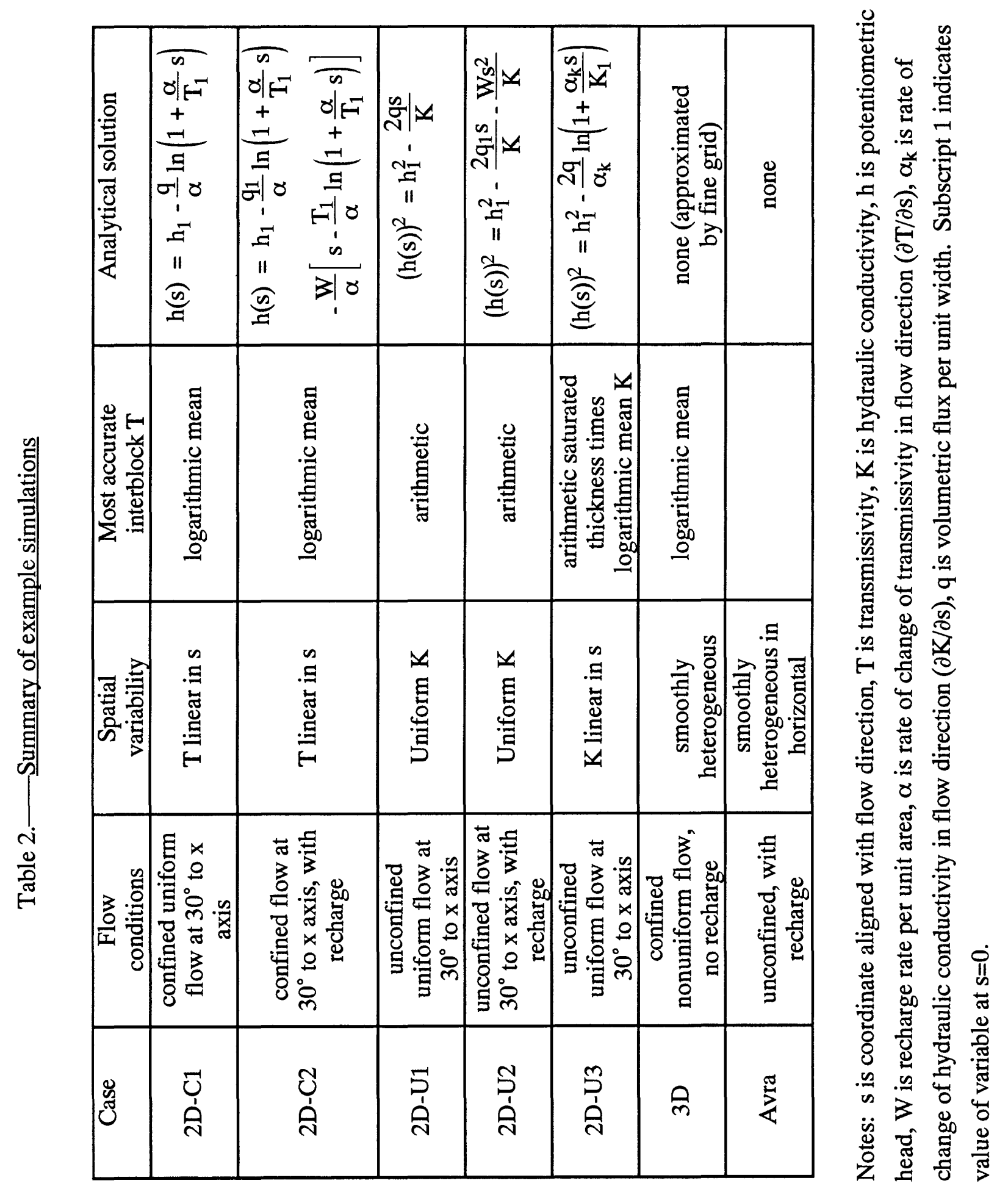




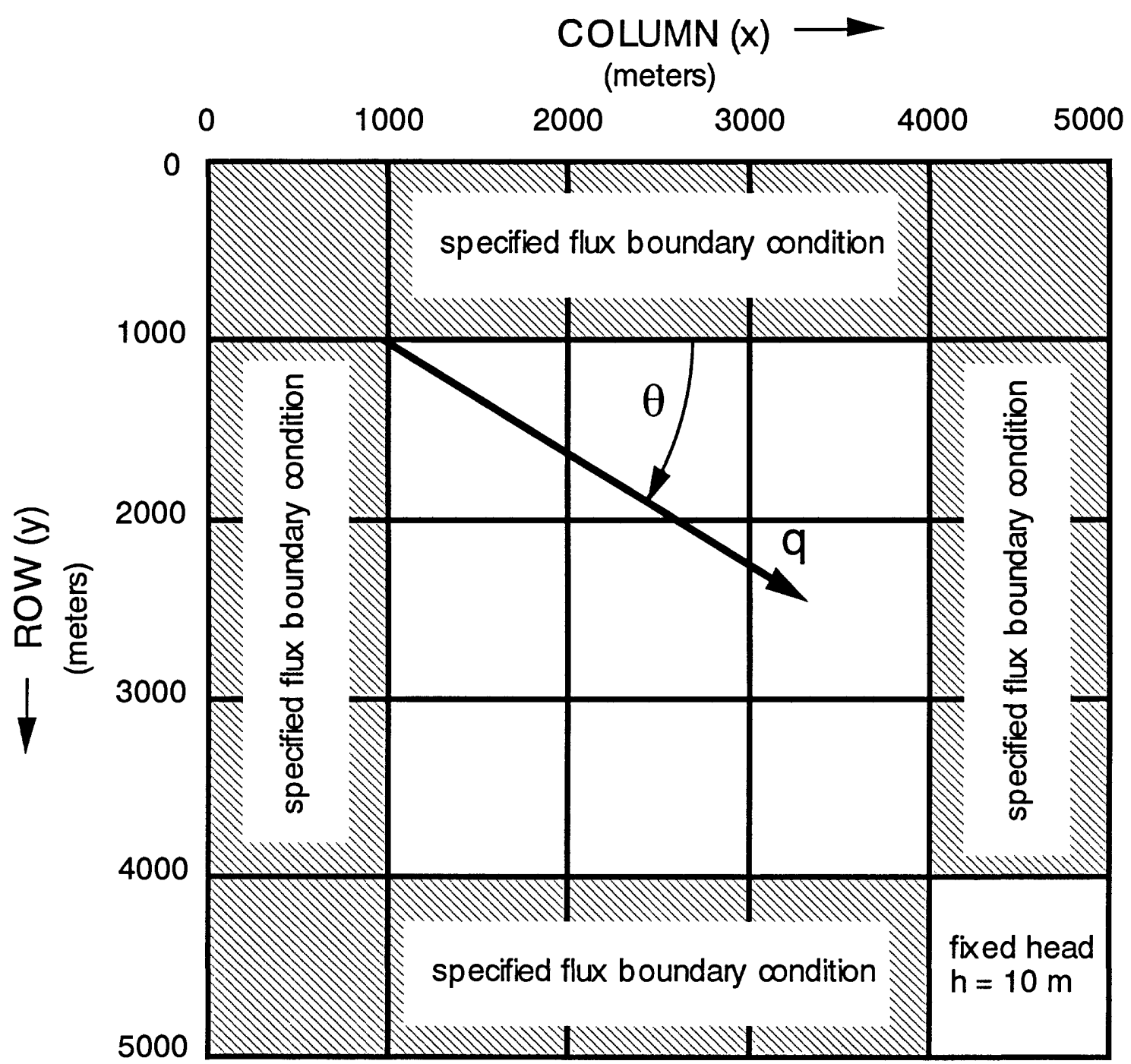

Figure 7.--Schematic of grid for two-dimensional simulations showing boundary conditions and orientation of the parallel flow vector $\mathrm{q}$ at angle $\theta$ to the $\mathrm{x}$ axis. For the simulations presented here, $\theta=30$ degrees.

boundary conditions are used at all boundary nodes except the node at row $=5$ and column 5 , where the head is specified as $h(5,5)=10 \mathrm{~m}$. The grid spacing is $\Delta \mathrm{x}=\Delta \mathrm{y}=1000 \mathrm{~m}$. For these cases, the exact solution is unidirectional flow at an angle of 30 degrees from the $x$ axis, in the direction of increasing row and column indices. 


\section{Transmissivity a linear function of distance in flow direction, no recharge (case $2 \mathrm{D}-\mathrm{C} 1)$}

This case has no recharge and corresponds to the proof above showing that the linear effective mean transmissivity is exact as long as flow is unidirectional. The uniform flow rate is $\mathrm{q}=10^{-3} \mathrm{~m}^{2} / \mathrm{day}$, but the flux boundary conditions are nonuniform because flow is oriented at $30^{\circ}$ to the grid (table 3 ). The transmissivity at node $(1,1)$ is $T(1,1)=10^{-}$ $2 \mathrm{~m}^{2} /$ day and transmissivity increases in the direction of flow (s) at a rate of $\alpha=3 \times 10^{-5} \mathrm{~m}^{2} /$ day $/ \mathrm{m}$ (table 4$)$.

In the Numerical Methods section, we showed that the logarithmic mean transmissivity would yield an exact solution to this problem, where transmissivity is changing in the direction of flow only, and no recharge occurs. Tables 5 and 6 show that this is indeed the case, and indicate the relative errors caused by using other interblock transmissivity functions. The errors caused by using the harmonic mean is about twice the errors caused by using the arithmetic mean. The harmonic mean generally yields heads that are too high, while the arithmetic mean generally yields heads that are too low.

Table 3. - Specified volumetric flux ( $\mathrm{m}^{3} / \mathrm{day}$ ) into boundary cells for cases 2D-C1. 2D-U1 and 2D-U3, flow direction $30^{\circ}$ to grid, no recharge

\begin{tabular}{c|ccccc}
\hline & \multicolumn{5}{|c}{ column } \\
row & 1 & 2 & 3 & 4 & 5 \\
\hline 1 & 1.366 & 0.500 & 0.500 & 0.500 & -0.366 \\
2 & 0.866 & & & & -0.866 \\
3 & 0.866 & &. & & -0.866 \\
4 & 0.866 & & & & -0.866 \\
5 & 0.366 & -0.500 & -0.500 & -0.500 & \\
\hline
\end{tabular}


Table 4. - Transmissivity ( $\mathrm{m}^{2}$ /day) at nodes for cases 2D-C1 and 2D-C2. transmissivity a linear function of distance in flow direction $30^{\circ}$ to grid

\begin{tabular}{c|ccccc}
\hline & \multicolumn{5}{|c}{ column } \\
row & 1 & 2 & 3 & 4 & 5 \\
\hline 1 & 0.010 & 0.036 & 0.062 & 0.088 & 0.114 \\
2 & 0.025 & 0.051 & 0.077 & 0.103 & 0.129 \\
3 & 0.040 & 0.066 & 0.092 & 0.118 & 0.144 \\
4 & 0.055 & 0.081 & 0.107 & 0.133 & 0.159 \\
5 & 0.070 & 0.096 & 0.122 & 0.148 & 0.174 \\
\hline
\end{tabular}

Table 5.- - Head (m) in row 1 for case 2D-C1, transmissivity a linear function of distance in flow direction, no recharge [least accurate mean indicated by italics]

\begin{tabular}{rccccc}
\hline & \multicolumn{5}{c}{ column } \\
Interblock T mean & 1 & 2 & 3 & 4 & 5 \\
\hline & \multicolumn{5}{c}{ head (m) in row 1 } \\
\cline { 2 - 6 } harmonic & 115.5 & 62.80 & 44.33 & 32.61 & 23.95 \\
exact and logarithmic & 105.2 & 62.52 & 44.40 & 32.73 & 24.10 \\
arithmetic & 100.8 & 62.35 & 44.43 & 32.79 & 24.18 \\
\hline
\end{tabular}


Table 6. - Error for case 2D-C1, transmissivity a linear function of distance in flow direction, no recharge [least accurate mean indicated by italics]

\begin{tabular}{cccc}
\hline & \multicolumn{3}{c}{ Model output component } \\
Interblock T mean & head & $\mathrm{q}_{\mathrm{x}}$ & $\mathrm{q}_{\mathrm{y}}$ \\
\hline & average error statistic (dimensionless) \\
\cline { 2 - 4 } harmonic & 0.0207 & 0.0106 & 0.0196 \\
logarithmic & 0 & 0 & 0 \\
arithmetic & 0.0092 & 0.0049 & 0.0089 \\
\hline
\end{tabular}

\section{Transmissivity a linear function of distance in flow direction, with recharge (case 2D-C2)}

This problem is identical to the previous case except that a uniform recharge rate of $\mathrm{W}=2 \times 10^{-7} \mathrm{~m} /$ day is applied over the entire simulated area. The flux at the outside corner of the cell centered at $(1,1)$ is $q=10^{-3} \mathrm{~m}^{2} /$ day. Again, flow is at 30 degrees from the $x$ axis. However, for this case the flux increases linearly with distance in the flow direction due to the uniform recharge. The nonuniform specified flux boundary conditions are given in table 7 . The transmissivity at node $(1,1)$ is $\mathrm{T}(1,1)=10^{-2} \mathrm{~m}^{2} /$ day and transmissivity increases linearly with distance in the flow direction at a rate of $\alpha=3 \times 10^{-5} \mathrm{~m}^{2} / \mathrm{day} / \mathrm{m}$, as in the previous case (table 4).

For this case of uniform recharge, none of the interblock transmissivity functions yields the exact solution, but the logarithmic mean is the most accurate, followed by the arithmetic mean (tables 8 and 9). As with the previous case, the harmonic mean yields the least accurate solution in terms of both computed heads and fluxes. 
Table 7.- Specified volumetric flux ( $\mathrm{m}^{3} / \mathrm{dav}$ ) into boundary cells for cases $2 \mathrm{D}-\mathrm{C} 2$ and 2D-U2, flow direction $30^{\circ}$ to grid, with recharge

\begin{tabular}{c|ccccc}
\hline & \multicolumn{5}{|c}{ column } \\
row & 1 & 2 & 3 & 4 & 5 \\
\hline 1 & 1.4526 & 0.6299 & 0.7165 & 0.8031 & -0.7696 \\
2 & 0.9959 & & & & -1.7459 \\
3 & 1.0825 & & & & -1.8325 \\
4 & 1.1691 & & & & -1.9191 \\
5 & 0.4624 & -0.8799 & -0.9665 & -1.0531 & \\
\hline
\end{tabular}

Table 8. - - Head (m) in row 1 for case 2D-C2, transmissivity a linear function of distance in flow direction, with recharge [least accurate mean indicated by italics]

\begin{tabular}{rrrrrr}
\hline & \multicolumn{5}{c}{ column } \\
Interblock T mean & 1 & 2 & 3 & 4 & 5 \\
\hline & \multicolumn{5}{c}{ head (m) in row 1 } \\
\cline { 2 - 6 } exact & 148.3 & 96.85 & 71.69 & 53.43 & 38.42 \\
harmonic & 161.8 & 97.58 & 71.76 & 53.33 & 38.22 \\
logarithmic & 149.1 & 96.99 & 71.74 & 53.44 & 38.41 \\
arithmetic & 143.6 & 96.66 & 71.71 & 53.49 & 38.50 \\
\hline
\end{tabular}


Table 9. - Error for case 2D-C2, transmissivity a linear function of distance in flow direction, with recharge [least accurate mean indicated by italics]

\begin{tabular}{cccc}
\hline & \multicolumn{3}{c}{ Model output component } \\
Interblock T mean & head & $\mathrm{q}_{\mathrm{x}}$ & $\mathrm{q}$ \\
\hline harmonic & 0.0198 & 0.0086 & 0.0157 \\
\cline { 2 - 4 } logarithmic & 0.0034 & 0.0005 & 0.0010 \\
arithmetic & 0.0064 & 0.0030 & 0.0057 \\
\hline
\end{tabular}

\section{Homogeneous unconfined aquifer, no recharge (case 2D-U1)}

For this unconfined case, transmissivity is modeled as a linear function of head, and the hydraulic conductivity is assumed to be spatially uniform and equal to $K=10^{-3}$ $\mathrm{m} / \mathrm{day}$. The uniform flow rate is $\mathrm{q}=10^{-3} \mathrm{~m}^{2} / \mathrm{day}$, and the aquifer bottom elevation is zero. The nonuniform flux boundary conditions are the same as case 2D-C1 (table 3).

Table 10. - Head (m) in row 1 for case 2D-U1, homogeneous unconfined aquifer, no recharge [least accurate mean indicated by italics]

\begin{tabular}{rrrrrr}
\hline & \multicolumn{5}{c}{ column } \\
Interblock T mean & 1 & 2 & 3 & 4 & 5 \\
\hline & \multicolumn{5}{c}{ head (m) in row 1 } \\
\cline { 2 - 6 } harmonic & 110.5 & 102.4 & 93.45 & 83.57 & 72.33 \\
logarithmic & 106.2 & 97.69 & 88.36 & 77.90 & 65.80 \\
exact and arithmetic & 105.0 & 96.42 & 86.97 & 76.37 & 64.03 \\
\hline
\end{tabular}


The arithmetic mean transmissivity yields the exact solution, as expected (tables 10 and 11). The harmonic mean, because it heavily weights the low transmissivity, yields the least accurate solution and generally results in heads that are too high.

Table 11. Error for case 2D-U1, homogeneous unconfined aquifer, no recharge [least accurate mean indicated by italics]

\begin{tabular}{cccc}
\hline & \multicolumn{3}{c}{ Model output component } \\
Interblock T mean & head & $\mathrm{q}_{\mathrm{x}}$ & $\mathrm{q}_{\mathrm{y}}$ \\
\hline harmonic & 0.1057 & 0.0161 & 0.0286 \\
logarithmic & 0.0234 & 0.0044 & 0.0080 \\
arithmetic & 0 & 0 & 0 \\
\hline
\end{tabular}

Homogeneous unconfined aquifer, with recharge (case 2D-U2)

This case is identical to the previous unconfined case except that uniform recharge occurs throughout the modeled domain. The hydraulic conductivity is spatially uniform and equal to $\mathrm{K}=10^{-3} \mathrm{~m} / \mathrm{day}$ and the aquifer bottom elevation is zero. The flux at the outside corner of the cell centered at $(1,1)$ is $q=10^{-3} \mathrm{~m}^{2} /$ day, and the uniform recharge rate is $\mathrm{W}=2 \times 10^{-7} \mathrm{~m} /$ day. The nonuniform flux boundary conditions are the same as case 2D-C2 (table 7).

As shown in the Numerical Methods section, the use of the arithmetic mean for interblock transmissivity yields the exact solution for this problem because the grid blocks are uniform (tables 12 and 13). As with the previous example, use of the harmonic mean yields the least accurate solution and generally yields heads that are too high. 
Table 12. - - Head $(\mathrm{m})$ in row 1 for case 2D-U2, homogeneous unconfined aquifer, with recharge [least accurate mean indicated by italics]

\begin{tabular}{rccccc}
\hline & \multicolumn{5}{c}{ column } \\
Interblock T mean & 1 & 2 & 3 & 4 & 5 \\
\hline & \multicolumn{5}{c}{ head (m) in row 1 } \\
\cline { 2 - 6 } harmonic & 154.7 & 147.6 & 139.1 & 128.8 & 116.4 \\
logarithmic & 139.0 & 131.1 & 121.5 & 109.7 & 94.86 \\
exact and arithmetic & 136.0 & 128.0 & 118.1 & 106.0 & 90.65 \\
\hline
\end{tabular}

Table 13. Error for case 2D-U2, homogeneous uncofined aquifer, with recharge [least accurate mean indicated by italics]

\begin{tabular}{rccc}
\hline & \multicolumn{3}{c}{ Model output component } \\
Interblock T mean & head & $\mathrm{q}_{\mathrm{x}}$ & $\mathrm{q}$ \\
\hline & average error statistic (dimensionless) \\
\cline { 2 - 4 } harmonic & 0.2424 & 0.0275 & 0.0481 \\
logarithmic & 0.0406 & 0.0077 & 0.0138 \\
arithmetic & 0 & 0 & 0 \\
\hline
\end{tabular}




\section{Unconfined aquifer with hydraulic conductivity a linear function of distance in flow direction, no recharge (case 2D-U3)}

This example is similar to case 2D-U1, an unconfined aquifer with no recharge, except that here the hydraulic conductivity is assumed to be a linear function of the flow direction coordinate. The uniform flux is $\mathrm{q}=10^{-3} \mathrm{~m}^{2} /$ day and the aquifer bottom elevation is taken as zero. The hydraulic conductivity at node $(1,1)$ is $\mathrm{K}(1,1)=10^{-4} \mathrm{~m} /$ day and the hydraulic conductivity increases in the direction of flow at a rate $\alpha_{\mathrm{k}}=3 \times 10^{-6} \mathrm{~m} / \mathrm{day} / \mathrm{m}$ (table 14).

Table 14. - Hydraulic conductivity ( $\mathrm{m} /$ day) at nodes for case 2D-U3, hydraulic conductivity a linear function of distance in flow direction $30^{\circ}$ to grid

\begin{tabular}{c|ccccc}
\hline & \multicolumn{5}{|c}{ column } \\
row & 1 & 2 & 3 & 4 & 5 \\
\hline 1 & 0.0001 & 0.0027 & 0.0053 & 0.0079 & 0.0105 \\
2 & 0.0016 & 0.0042 & 0.0068 & 0.0094 & 0.0120 \\
3 & 0.0031 & 0.0057 & 0.0083 & 0.0109 & 0.0135 \\
4 & 0.0046 & 0.0072 & 0.0098 & 0.0124 & 0.0150 \\
5 & 0.0061 & 0.0087 & 0.0113 & 0.0139 & 0.0165 \\
\hline
\end{tabular}

As shown in the Numerical Methods section, use of the arithmetic mean saturated thickness times the logarithmic mean hydraulic conductivity for the interblock transmissivity yields the exact solution (tables 15 and 16). The harmonic mean yields the least accurate results and generally yields heads that are too high. The logarithmic mean interblock transmissivity yields a more accurate solution than the arithmetic mean, indicating that, for this particular problem, incorporating the spatial variability of hydraulic conductivity is more important than accounting for the dependence of transmissivity on head. 
Table 15. - Head (m) in row 1 for case 2D-U3, unconfined aquifer with hydraulic conductivity a linear function of distance in flow direction, no recharge [least accurate mean indicated by italics]

\begin{tabular}{cccccc}
\hline & \multicolumn{5}{c}{ column } \\
Interblock T & 1 & 2 & 3 & 4 & 5 \\
\hline & \multicolumn{5}{c}{ head (m) in row 1 } \\
\cline { 2 - 6 } harmonic mean T & 83.96 & 35.87 & 29.10 & 24.19 & 19.91 \\
logarithmic mean T & 61.72 & 36.19 & 29.31 & 24.34 & 20.04 \\
arithmetic mean T & 53.75 & 36.36 & 29.42 & 24.41 & 20.10 \\
exact and arithmetic mean h & 59.19 & 36.15 & 29.28 & 24.31 & 20.04 \\
times logarithmic mean K & & & & & \\
\hline
\end{tabular}

Table 16. Error for case 2D-U3, unconfined aquifer with hydraulic conductivity a linear function of distance in flow direction, no recharge

[least accurate mean indicated by italics]

\begin{tabular}{rccc}
\hline & \multicolumn{3}{c}{ Model output component } \\
Interblock T & head & $\mathrm{q}_{\mathrm{x}}$ & $\mathrm{q}_{\mathrm{y}}$ \\
\hline & average error statistic (dimensionless) \\
\cline { 2 - 4 } harmonic mean $\mathrm{T}$ & 0.0479 & 0.0266 & 0.0473 \\
logarithmic mean $\mathrm{T}$ & 0.0073 & 0.0046 & 0.0083 \\
arithmetic mean $\mathrm{T}$ & 0.0114 & 0.0069 & 0.0119 \\
arithmetic mean h times & 0 & 0 & 0 \\
logarithmic mean $\mathrm{K}$ & & & \\
\hline
\end{tabular}




\section{Heterogeneous Three-Dimensional Confined Aquifer (case 3D)}

This case also uses a 5 row $(\Delta y=1000 \mathrm{~m})$ by 5 column $(\Delta x=1000 \mathrm{~m})$ grid, but additionally has 4 layers $(\Delta z=10 \mathrm{~m})$ to illustrate performance of the alternative interblock transmissivity functions in three-dimensional flow. The steady-state boundary conditions include specified uniform flux inward (specific discharge $=10^{-4} \mathrm{~m} /$ day) in column 1 over all layers and rows, specified uniform head $(10 \mathrm{~m})$ in column 5 of layer 1 , and no flow across all other model boundaries (fig. 8). These boundary conditions result in flow generally from the left (column 1) to the right with increasing upward flow towards the right. The bottom two layers have a uniform hydraulic conductivity of $K_{1}=10^{-3} \mathrm{~m} /$ day. In the top two layers (fig. 8), the first three rows, and the first two columns of rows 4 and 5 , have $\mathrm{K}=\mathrm{K}_{1}$. The remaining nodes -- columns 3, 4, and 5 of rows 4 and 5 -- have $\mathrm{K}=$ $10 \times \mathrm{K}_{1}=10^{-2} \mathrm{~m} /$ day. The ratio of vertical hydraulic conductivity to horizontal hydraulic conductivity (anisotropy ratio) is $10^{-3}$. Conceptually, the hydraulic conductivity is assumed to vary linearly between the nodes. The interblock vertical hydraulic conductivity, which is input explicitly, is computed with the same mean as the horizontal transmissivity.

Because an analytical solution is not available for this problem, the exact solution is estimated by a very fine grid. In this fine grid, which is designated $9 \mathrm{x}$, each of the blocks of the coarse grid is replaced by 9 rows by 9 columns by 9 layers. Thus, the entire simulation area of the $9 \mathrm{x}$ grid is 45 rows by 45 columns by 36 layers. At this fine scale, the assumed linear variation of hydraulic conductivity between the coarse grid nodes is input explicitly.

The heads computed at selected nodes with the coarse grids are compared with the $9 \mathrm{x}$ results at the appropriate nodes in tables 17 and 18. Because the change in hydraulic conductivity between nodes is small for the $9 \mathrm{x}$ grid, the alternative interblock functions yield very similar results. The exact results for these comparisons is estimated by the average results from the three $9 \mathrm{x}$ simulations with the alternative interblock functions. For comparison of fluxes, the fine grid results are integrated over the area of the coarse grid block faces. At the scale of the coarse grid the alternative interblock transmissivities yields significantly different results. The average errors (table 19) are larger for this case than the two-dimensional simulations. The harmonic mean yields the least accurate solution. 


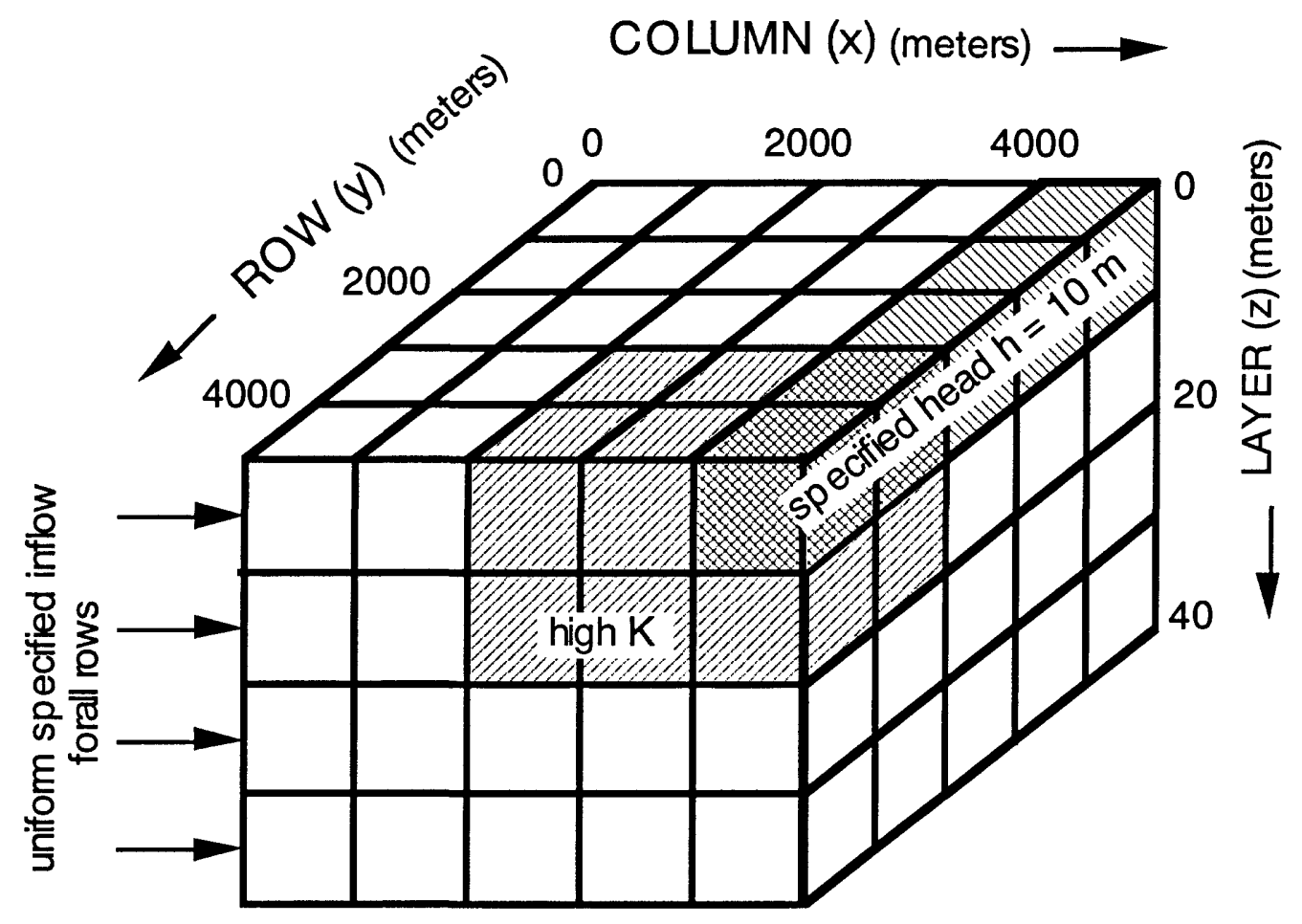

all other boundaries are no flow

Figure 8.--Schematic of grid for three-dimensional simulation showing boundary conditions and shaded cells where node value of hydraulic conductivity is 10 times the value at other nodes.

This case shows that both the choice of interblock hydraulic conductivity and the level of spatial discretization (grid spacing) control model accuracy. When a fine grid is used, the change in hydraulic conductivity from block to block is small, hence the interblock hydraulic conductivities calculated using any method are essentially the same. Furthermore, and perhaps more importantly, solving for the potentiometric head at many additional nodes give a more accurate approximation to the curving head contours and streamlines where hydraulic conductivity is spatially variable. It is clearly desirable to have sufficiently fine spatial discretization such that the choice of interblock hydraulic conductivity is immaterial. However, when moderate or even coarse discretization are used, some improved accuracy can be obtained by choosing appropriate functions for interblock hydraulic conductivity, such as the ones presented in this report. 
Table 17. - - Head (m) in row 3, layer 2 for case 3D, heterogeneous confined aquifer, no recharge

\begin{tabular}{rrrrrr}
\hline & \multicolumn{5}{c}{ column } \\
Interblock T mean & 1 & 2 & 3 & 4 & 5 \\
\hline harmonic & 302.2 & 205.0 & 118.0 & 64.42 & 20.56 \\
\cline { 2 - 6 } logarithmic & 279.6 & 183.5 & 102.5 & 56.67 & 18.73 \\
arithmetic & 272.2 & 176.4 & 97.64 & 54.37 & 18.08 \\
harmonic 9x & 275.3 & 175.3 & 101.6 & 58.69 & 22.77 \\
logarithmic 9x & 274.9 & 175.0 & 101.3 & 58.52 & 22.70 \\
arithmetic 9x & 274.7 & 174.8 & 101.1 & 58.44 & 22.66 \\
\hline
\end{tabular}

Table 18. - - Head $(\mathrm{m})$ in column 3 , layer 3 for case 3D, heterogeneous confined aquifer, no recharge

\begin{tabular}{rccccc}
\hline & \multicolumn{5}{c}{ row } \\
Interblock T mean & 1 & 2 & 3 & 4 & 5 \\
\hline & \multicolumn{5}{c}{ head (m) in column 3, layer 3 } \\
\cline { 2 - 6 } harmonic & 158.3 & 147.2 & 121.5 & 82.38 & 75.33 \\
logarithmic & 146.9 & 134.8 & 107.9 & 79.99 & 73.63 \\
arithmetic & 143.3 & 130.9 & 103.7 & 80.02 & 73.67 \\
harmonic 9x & 148.3 & 135.2 & 106.1 & 83.44 & 76.73 \\
logarithmic 9x & 148.1 & 135.0 & 106.0 & 83.42 & 76.72 \\
arithmetic 9x & 148.0 & 134.9 & 105.9 & 83.42 & 76.72 \\
\hline
\end{tabular}


Table 19. - Error for case 3D, heterogeneous confined aquifer, no recharge [least accurate mean indicated by italics]

\begin{tabular}{rcccc}
\hline & \multicolumn{4}{c}{ Model output component } \\
Interblock T mean & head & $\mathrm{q}_{\mathrm{x}}$ & $\mathrm{q}$ & $\mathrm{q}_{\mathrm{z}}$ \\
\hline & \multicolumn{4}{c}{ average error statistic (dimensionless) } \\
\cline { 2 - 5 } harmonic & 0.1062 & 0.1159 & 0.1868 & 0.3053 \\
logarithmic & 0.0237 & 0.0964 & 0.1287 & 0.1490 \\
arithmetic & 0.0351 & 0.1040 & 0.1384 & 0.1449 \\
\hline
\end{tabular}

\section{Simulation from Study of Avra Valley Aquifer, Arizona (case Avra)}

Alternative interblock transmissivities are used to resimulate predevelopment steady-state flow in the Avra Valley aquifer to illustrate the practical significance of these methods. Hanson and others (1990) describe the hydrogeologic setting and details of the numerical simulations which are only briefly summarized here. Hanson and others (1990, p. 4) report:

the alluvium is subdivided into lower and upper units on the basis of hydrogeologic characteristics. The lower alluvium is thousands of feet thick, consists of gravel and conglomerate along the basin margins and in the southern part of the basin, and grades into gypsiferous and anhydritic clayey silt and mudstone in the north-central part of the basin. The upper alluvium consists mainly of gravel, sand, and clayey silt, and ranges from less than [ 30 to about $300 \mathrm{~m}$ ] in thickness. ... Fan and playa environments are generally characterized by clay and silt concentrations of less than 20 percent and more than 60 percent, respectively. The interfingered-zone subregion generally contains from 20 to 60 percent clay and silt. This subregion was subdivided into two adjacent zones with 20 to 40 and 40 to 60 percent clay and silt... 
The system was modeled using the program of McDonald and Harbaugh (1988). Two model layers were used, layer 1 representing the unconfined upper hydrogeologic layer, and layer 2 representing the confined lower hydrogeologic layer. The finite-difference grid blocks are large, 1 mile on each side. Hanson and others (1990) calibrated the steady-state model by adjusting the transmissivity of layer 2 and the hydraulic conductivity of layer 1 until a reasonable agreement with observed predevelopment (around 1940) heads was achieved. Direct recharge, streamflow infiltration, and pumping were all negligible under predevelopment conditions. All modeled inflow to the system occurs at constant head nodes and represents inflow from adjacent aquifers. Calibration yielded a (Hanson and others, 1990, p. 18)

root-mean-square difference between measured and simulated water levels in 100 wells [of] $16 \mathrm{ft}(5 \mathrm{~m}) . .$. Most errors were negative, indicating that simulated water levels were slightly higher than measured. The largest negative errors occurred mainly in the southwestern part of the model area . .. where estimates of heads and aquifer components are less certain than elsewhere. Differences between hand-drawn contours of measured water levels and simulated head for layer 1 generally ranged from 5 to $10 \mathrm{ft}$ (1.5 to $3 \mathrm{~m}$ ) [in the] north ... to $20 \mathrm{ft}(6 \mathrm{~m})$ [in the] south ... with the largest difference of about $40 \mathrm{ft}(12 \mathrm{~m})$ in the south half of the valley.

For resimulation, the only modification to the predevelopment steady-state simulation of Hanson and others (1990) is the method to compute horizontal interblock transmissivity. The original model of McDonald and Harbaugh (1988) uses the harmonic mean interblock transmissivity. Here, we choose the interblock mean separately for each layer, on the basis of the character of spatial variability for that layer. Layer 1 is unconfined and has hydraulic conductivity that varies spatially due to variability in gravel content associated with stream channels (fig. 9). The hydraulic conductivity of layer 1 ranges from less than $0.2 \mathrm{~m} /$ day to over $30 \mathrm{~m} /$ day. The transmissivity of layer 1 varies spatially due to the spatially variable hydraulic conductivity and the dependence of transmissivity on saturated thickness, and hence on head. On this basis, we choose to compute the interblock transmissivity as the arithmetic mean saturated thickness times the logarithmic mean hydraulic conductivity (LAYAVG=30, input $L A Y C O N=31$ ). Layer 2 is confined and has spatially varying transmissivity due to the gradation of composition and interfingering of basin-margin alluvium with the lower permeability of the clay, silt and mudstone of the center of the basin (fig. 10). The transmissivity of layer 2 ranges from less than $9 \mathrm{~m}^{2} / \mathrm{day}$ to over $400 \mathrm{~m}^{2} /$ day. Because the change in transmissivity between nodes is conceptualized 


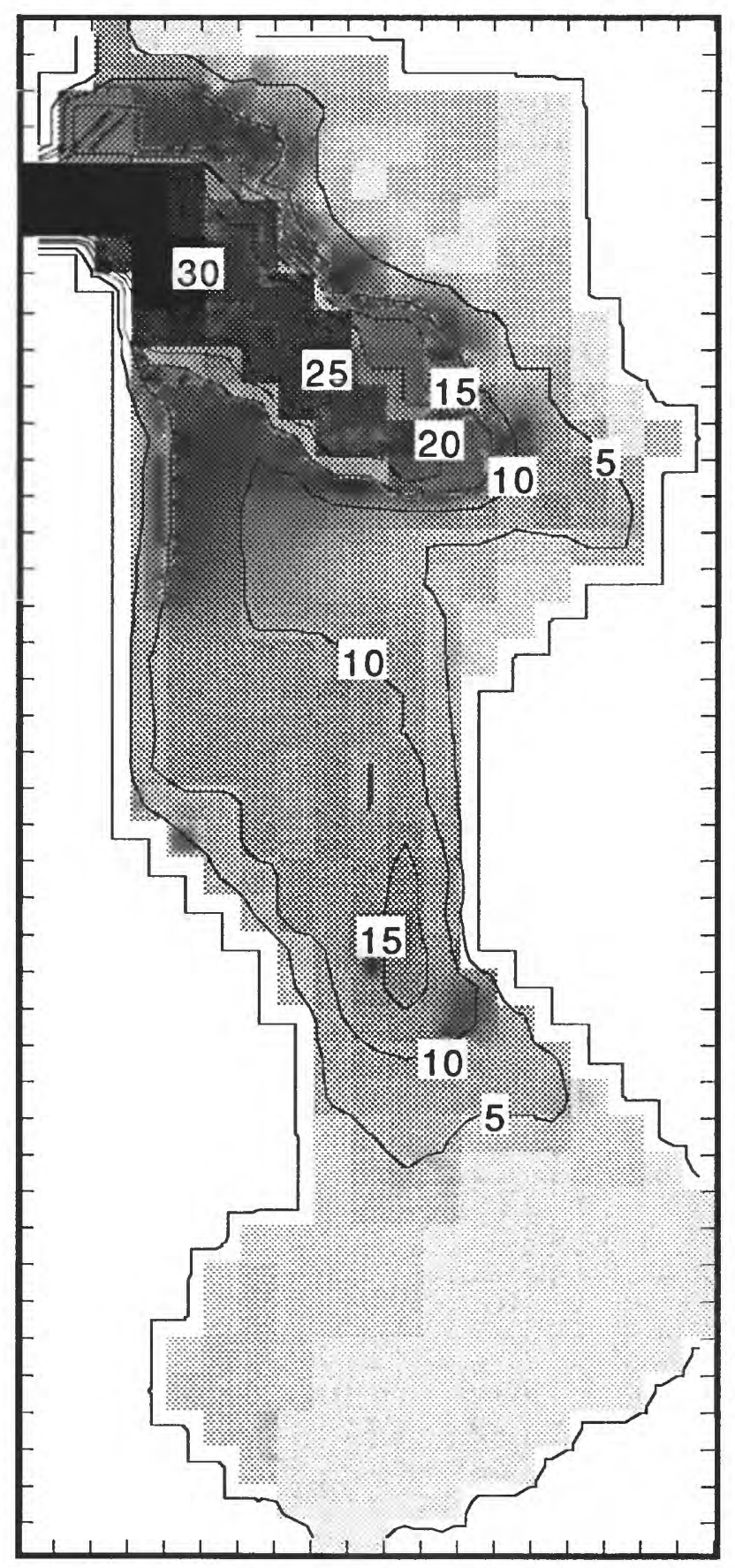

Figure 9. Contour and gray-scale map of hydraulic conductivity (in meters per day) of layer one of Avra Valley aquifer model. Model parameters from Hanson and others (1990). 


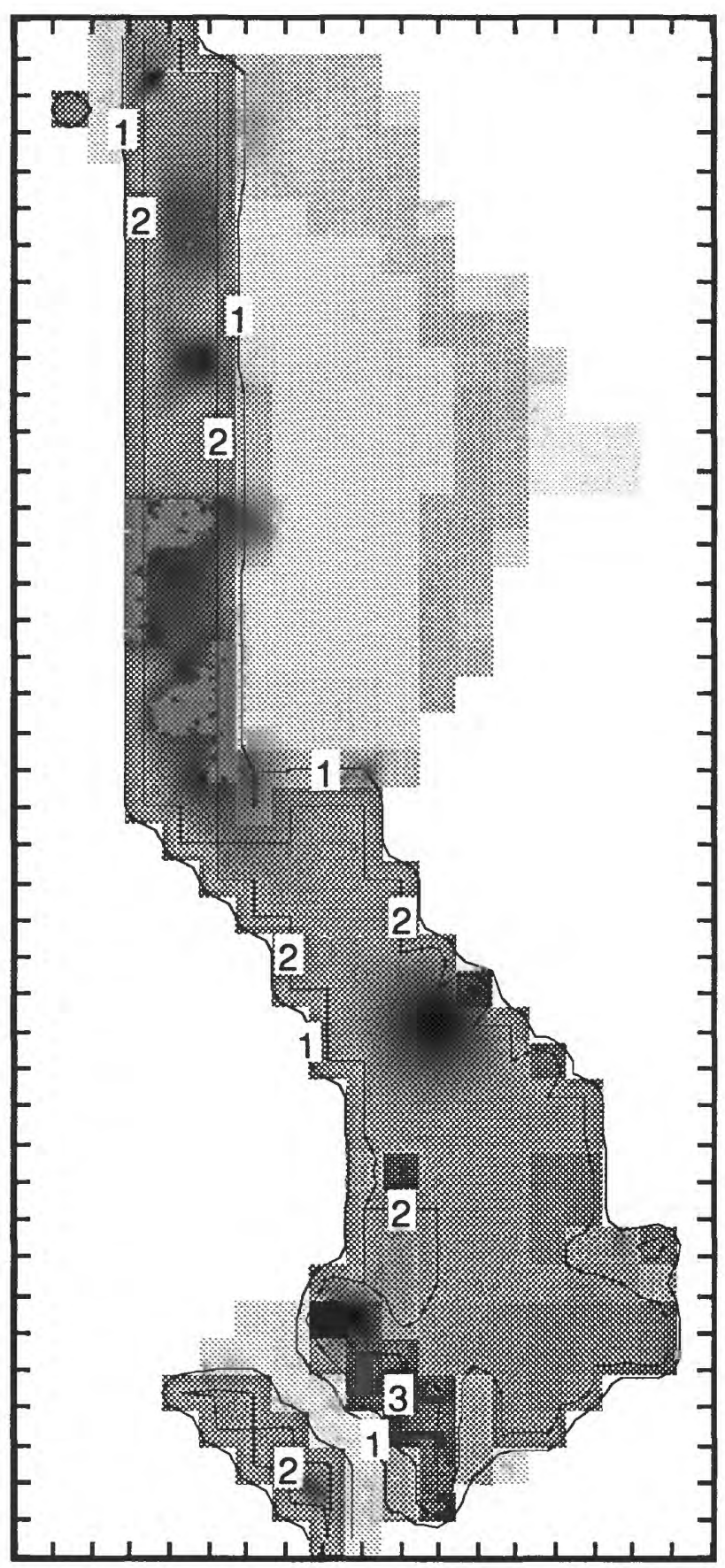

Figure 10. Contour and gray-scale map of transmissivity (in hundreds of meters squared per day) of layer two of Avra Valley aquifer model. Model parameters from Hanson and others (1990). 
nodes is conceptualized as being somewhat smooth, and not abrupt, we use the logarithmic mean interblock transmissivity (LAYAVG=20, input LAYCON=20) for layer 2.

The effects of alternative interblock transmissivity functions on computed heads are relatively minor. Our resimulated heads (fig. 11) are generally higher (fig. 12), with the difference between our results and the results of Hanson and others (1990) ranging from about $-1 \mathrm{~m}$ to about $+4 \mathrm{~m}$, averaging $+1.2 \mathrm{~m}$. Compared with the root-mean-squared calibration error of $5 \mathrm{~m}$ reported by Hanson and others (1990), these changes in head are small.

Because this simulation is controlled largely by specified heads at the inflow as well as outflow boundaries, simulated heads are relatively insensitive to transmissivity. However, fluxes show somewhat more significant changes because of the use of alternative interblock tranmissivity. The change in computed inflow and outflow at constant head nodes is shown in table 20. The differences in fluxes at individual nodes can be quite significant, up to 93 percent for a relatively low-flow node. However, the uncertainty inherent in computed fluxes is qualitatively greater than uncertainty in heads, because of the lack of direct measurements of aquifer discharge. Hence, these changes may still be within the bounds of uncertainty of the calibrated model. The net flow through the aquifer changes from $6.46 \times 10^{4} \mathrm{~m}^{3} /$ day to $6.74 \times 10^{4} \mathrm{~m}^{3} /$ day, an increase of about 4 percent. This result is consistent with the harmonic mean yielding lower interblock transmissivities than those used here. Overall, the interpretation of the model results are unlikely to change due to the use of the alternative interblock transmissivities.

The computational effort is slightly increased for the resimulation with alternative interblock transmissivity due to the additional operations required, particularly for the top layer with $L A Y A V G=30$. However, this increase is relatively insignificant compared with the overall computational burden, representing an increase in total computer time of less than 3 percent for this case. 


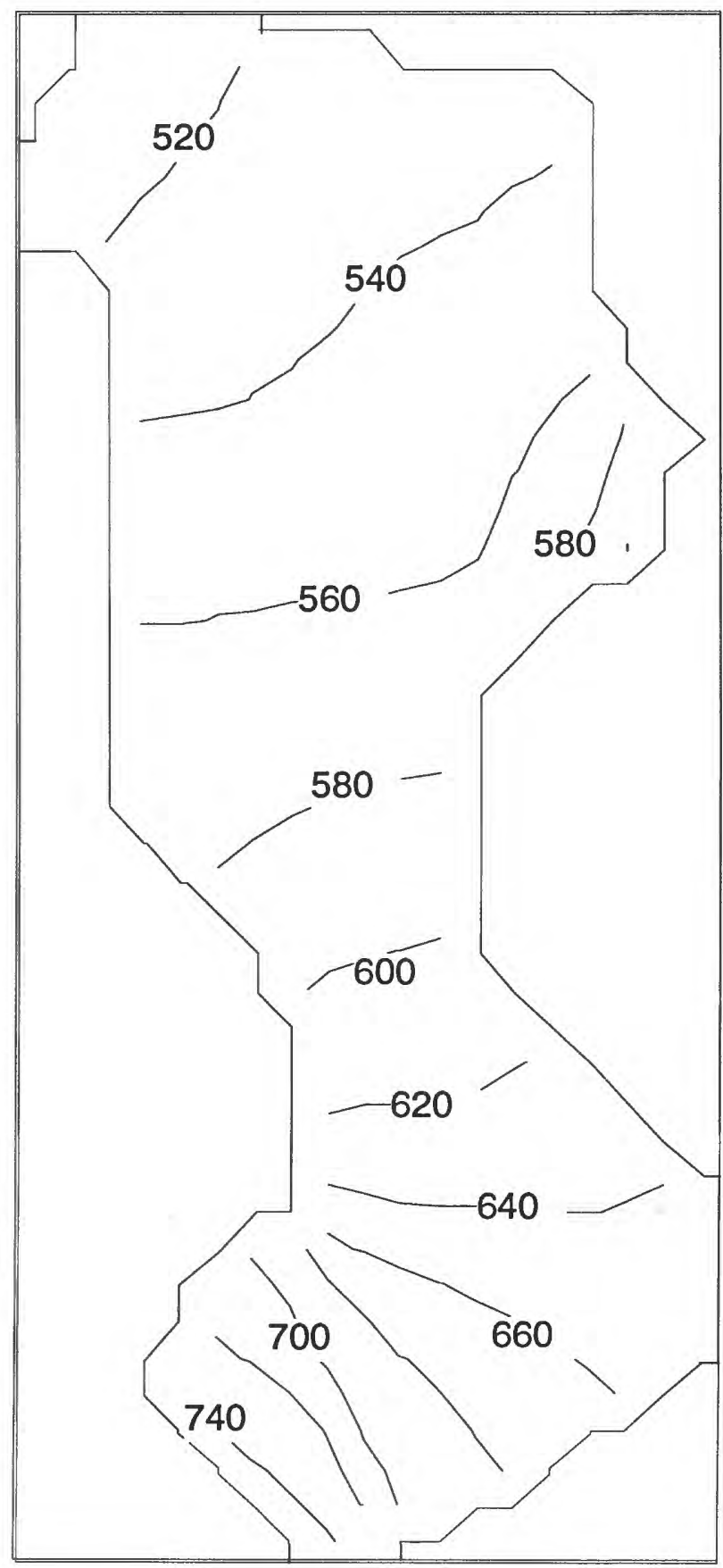

Figure 11. Contour map of new simulated head (in meters) of layer one of Avra Valley aquifer model using alternative interblock transmissivities. Contour interval is 20 meters. 


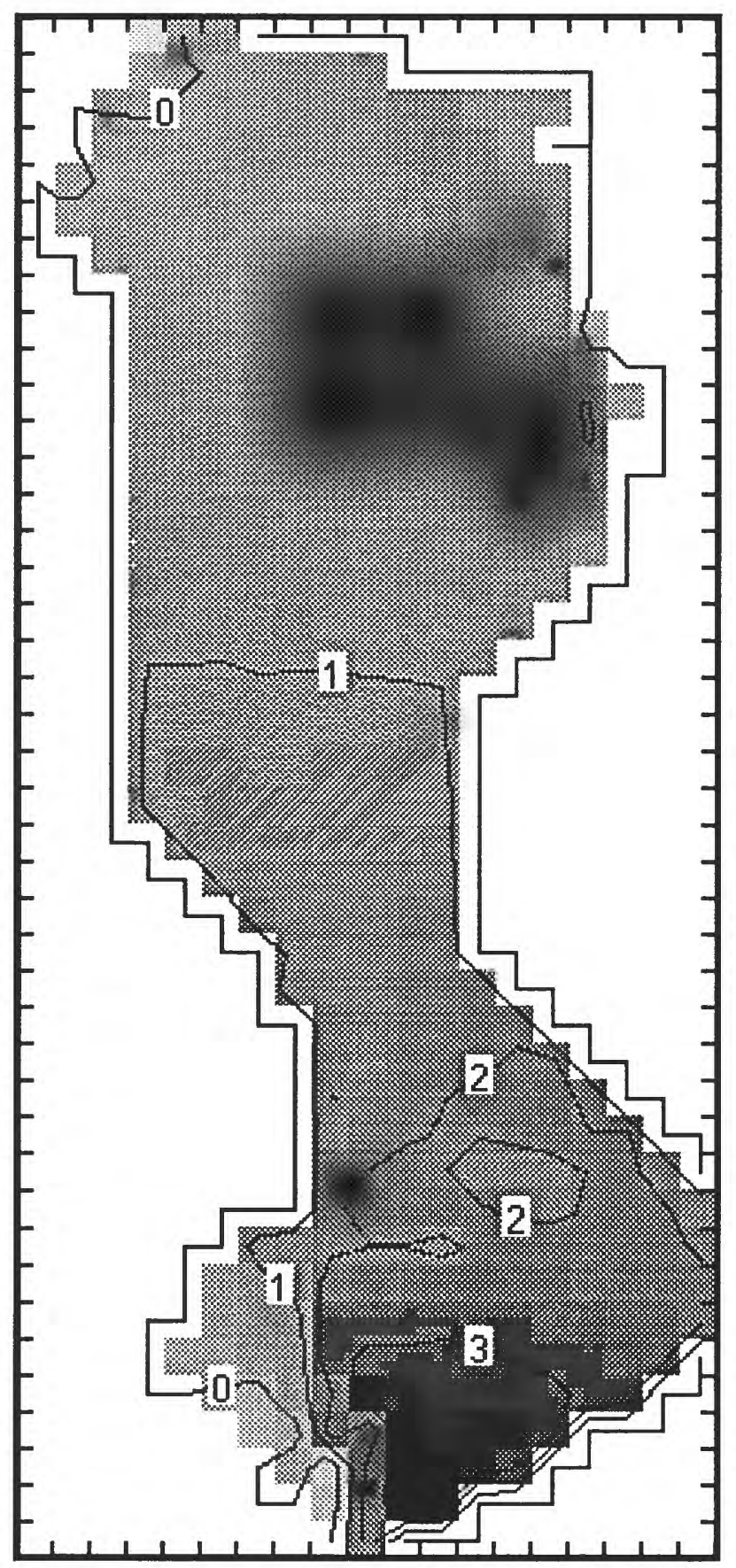

Figure 12. Contour and gray-scale map of simulated new head in layer one minus results of Hanson and others (1990) (in meters) for Avra Valley aquifer model 
Table 20. Computed fluxes at constant head boundary nodes for Avra Valley aquifer example simulation [original data from Hanson et al., 1990]

\begin{tabular}{|c|c|c|c|c|c|c|}
\hline \multicolumn{3}{|c|}{ Node index } & \multicolumn{2}{|c|}{ computed flux $\left(\mathrm{m}^{3} / \mathrm{hr}\right)$} & \multicolumn{2}{|c|}{$\begin{array}{c}\text { Difference in } \\
\text { computed fluxes }\end{array}$} \\
\hline layer & row & $\mathrm{col}$ & original & new & $\mathrm{m}^{3} / \mathrm{hr}$ & percent \\
\hline 1 & 1 & 3 & -57 & -95 & -38 & 67 \\
\hline 1 & 2 & 3 & -480 & -480 & 0 & 0 \\
\hline 1 & 3 & 2 & -388 & -386 & 1 & 0 \\
\hline 1 & 4 & 2 & -813 & -862 & -49 & 6 \\
\hline 1 & 5 & 1 & -642 & -635 & 6 & -1 \\
\hline 1 & 6 & 1 & -249 & -256 & -6 & 3 \\
\hline 1 & 12 & 18 & 152 & 200 & 48 & 31 \\
\hline 1 & 13 & 17 & 424 & 433 & 9 & 2 \\
\hline 1 & 14 & 17 & 424 & 410 & -14 & -3 \\
\hline 1 & 15 & 17 & 288 & 308 & 20 & 7 \\
\hline 1 & 38 & 5 & 201 & 203 & 2 & 1 \\
\hline 1 & 39 & 6 & 404 & 413 & 10 & 2 \\
\hline 1 & 40 & 7 & 253 & 285 & 33 & 13 \\
\hline 1 & 41 & 8 & 37 & 40 & 3 & 7 \\
\hline 1 & 42 & 9 & 41 & 37 & -4 & -10 \\
\hline 2 & 1 & 3 & -12 & -20 & -8 & 65 \\
\hline 2 & 2 & 3 & -16 & -27 & -10 & 65 \\
\hline 2 & 3 & 2 & -9 & -18 & -9 & 93 \\
\hline 2 & 12 & 17 & -27 & -32 & -5 & 17 \\
\hline 2 & 13 & 17 & 4 & 3 & 0 & -6 \\
\hline 2 & 38 & 5 & 23 & 24 & 1 & 3 \\
\hline 2 & 39 & 6 & 119 & 122 & 3 & 2 \\
\hline 2 & 40 & 7 & 111 & 111 & 0 & 0 \\
\hline 2 & 41 & 8 & 117 & 119 & 2 & 2 \\
\hline 2 & 42 & 9 & 93 & 103 & 9 & 10 \\
\hline
\end{tabular}




\section{SUMMARY AND CONCLUSIONS}

Some widely used finite-difference ground-water simulation computer programs use block-centered grids and the weighted harmonic mean of the block transmissivities for the interblock transmissivity. We have shown that the logarithmic mean transmissivity is the appropriate interblock transmissivity for one-dimensional flow in a confined aquifer having a transmissivity that varies linearly; whereas it has been known that the harmonic mean is the appropriate formulation where the transmissivity is spatially uniform in each finite-difference block but changes abruptly at the block interface. For the case of onedimensional flow in an unconfined aquifer where the hydraulic conductivity is uniform, the appropriate interblock transmissivity is the unweighted arithmetic mean of transmissivities at the block centers; and where hydraulic conductivity varies as a linear function of distance in the direction of flow the appropriate interblock transmissivity is the arithmetic mean saturated thickness times the logarithmic mean hydraulic conductivity.

We tested the relative accuracies of different interblock transmissivities for selected hypothetical two-dimensional problems, involving confined and unconfined flow conditions, for which analytical solutions are available for comparison. We also considered a three-dimensional heterogeneous confined aquifer problem for which the results using a very fine grid (the test problem involved 100 blocks whereas the very fine grid involved 72,900 blocks) are taken to "represent" the exact unknown solution. For the two-dimensional hypothetical problems the grid block sizes used are uniform and for the hypothetical three-dimensional problem the grid block sizes in the plan view are uniform and the thickness of the blocks on the z-direction (or depth) is 1 percent of the horizontal block dimensions. We did not experiment with variable block size configurations. For the test problems selected, with uniform and linearly varying transmissivity or hydraulic conductivity, and the interblock transmissivities considered, the weighted harmonic mean formulation resulted in the least accurate computed heads. The "accuracy" criterion used for the comparisons was the sum of the absolute values for all blocks of the differences between the computed heads and "exact" heads, divided by the sum of the absolute values for all blocks of the "exact" heads. Flux component error statistics yielded the same results.

Alternative interblock transmissivities were used to resimulate predevelopment steady-state flow in the Avra Valley aquifer to illustrate the practical significance of these methods. A numerical model had been made previously for the predevelopment flow 
using the harmonic mean interblock transmissivity formulation. For our resimulation the only change to the previous simulation is the method used to compute interblock transmissivity. For the unconfined (top) layer we computed the interblock transmissivity as the arithmetic mean saturated thickness times the logarithmic mean hydraulic conductivity. For the confined layer we used the logarithmic mean transmissivity formulation. The effects of the alternative interblock transmissivity functions on computed heads gave differences from the previous simulation results of from about -1 to +4 meters, averaging +1.2 meters, and an increase of net flow through the aquifer of about 4 percent. These differences in computed heads, compared to the root-mean-squared calibration error of 5 meters reported from the previous model calibration work, are small. At individual blocks the differences in the fluxes computed at constant head boundaries for the simulations varied by as much as 93 percent for a block where the flux was relatively low. We judged that the overall interpretation of the model results would likely not have changed as a result of the use of the alternative interblock transmissivities. The increased computational effort associated with the use of the alternative interblock transmissivity functions for the Avra Valley aquifer resimulation was less then 3 percent of the total computer time.

It is not an objective of this report to attempt to recommend a particular interblock transmissivity formulation for all field situations. There is little evidence to support any such universal approach. However, the results of the several hypothetical test problems that we considered suggest that for field situations where the spatial variation of the transmissivity of hydraulic conductivity is "nearly" linear and the block size dimensions areally are to be uniform, the alternative interblock transmissivity functions may give more accurate results than the weighted harmonic mean. The additional computational effort needed for the alternative transmissivity functions is nominal. One obvious limitation of the selected test problems and our comparative analysis was that the block sizes selected were uniform in the horizontal plane. Appel's (1976) results suggest that relative errors would be similar for variable spacing grids.

The block-by-block transmissivity values input to most ground-water models are estimates made by superimposing the selected model block grid and a map that characterizes the analyst's perception of the dominant large scale spatial structure of the transmissivity. It is accepted that small scale variations occur around this large scale structure. It is beyond the scope of this report to attempt to provide guidelines on how to develop such a large scale representation or to judge when such a representation is justified. 
However, if such a map has been prepared and it represents the large scale variation as a continuous and smoothly varying function, the results of the test problems given here suggest that consideration of the interblock transmissivity functions other than the weighted harmonic mean may be justified.

Finally, the importance of spatial discretization in modeling flow in heterogeneous aquifers cannot be overstated. Different methods for computing interblock transmissivity yield significant differences only when the change in transmissivity from one node to the next is relatively large. In addition to making the choice of interblock transmissivity function immaterial, a fine spatial discretization (small blocks) yields a more accurate approximation to the curving head contours and streamlines where transmissivity is spatially variable. If model heads computed with alternative interblock transmissivities are significantly different, the modeler should reexamine the level of spatial discretization to ensure that a sufficiently accurate head solution is obtained. 


\section{REFERENCES}

Andersen, P. F., Faust, C. R., and Mercer, J. W., 1984, Analysis of conceptual designs for remedial measures at Lipari Landfill, New Jersey: Ground Water, v. 22, no. 2, p. 176-190.

Appel, C. A., 1976, A note on computing finite difference interblock transmissivities: Water Resources Research, v. 12, no. 3, p. 561-563.

Bear, J., 1979, Hydraulics of Groundwater: McGraw-Hill, New York, 567 p.

Bird, R. B., W. E. Stewart, and E. N. Lightfoot, 1960, Transport Phenomena, Wiley, New York, $780 \mathrm{p}$.

Butler, S. S., 1957, Engineering Hydrology: Prentice-Hall, Englewood Cliffs, NJ, 356 p.

Collins, R. E., 1961, Flow of fluids through porous materials; New York, Reinhold Publishing Corp., $270 \mathrm{p}$.

Crichlow, H. B., 1977, Modern reservoir engineering -- A simulation approach: PrenticeHall, Englewood Cliffs, New Jersey, 354 p.

Gelhar, L., 1986, Stochastic subsurface hydrology from theory to applications: Water Resources Research, v. 22, no. 9, p. 135S - 145S.

Goggin, D. J., M. A. Chandler, G. Kocurek, and L. W. Lake, 1992, Permeability transects of eolian sands and their use in generating random permeability fields: SPE Formation Evaluation, v. 7, no. 1, p. 7-16.

Gomez-Hernandez, J. J., and S. M. Gorelick, 1989, Effective groundwater model parameter values: Influence of spatial variability of hydraulic conductivity, leakance, and recharge: Water Resources Research, v. 25, no. 3, p. 405-419.

Goode, D. J., 1990, Particle velocity interpolation in block-centered finite difference groundwater flow models: Water Resources Research, v. 26, no. 5, p. 925-940.

Hanson, R. T., S. R. Anderson, and D. R. Pool, 1990, Simulation of ground-water flow and potential land subsidence, Avra Valley, Arizona: U.S. Geological Survey Water Resources Investigations Report 90-4178, 41 p.

Haverkamp, R., Vauclin, M., Touma, J., Wierenga, P. J., and Vachaud, G., 1977, A comparison of numerical simulation models for one-dimensional infiltration: Soil Science Society of America Journal, v. 41, p. 285-294.

Konikow, L. F., and Bredehoeft, J. D., 1978, Computer model of two-dimensional solute transport and dispersion in ground water: U.S. Geological Survey Techniques of Water-Resources Investigations Book 7, Chapter C2, 90 p. 
McDonald, M. G., and Harbaugh, A. W., 1988, A modular three-dimensional finite-difference ground-water flow model: U.S. Geological Survey Techniques of Water-Resources Investigations Book 6, Chapter A1, 586 p.

McDonald, M. G., Harbaugh, A. W., Orr, B. R., and Ackerman, D. J., 1991, A method of converting no-flow cells to variable-head cells for the U.S. Geological Survey modular finite-difference ground-water flow model: U.S. Geological Survey OpenFile Report 91-536, 99 p.

Pinder, G. F., 1970, An iterative digital model for aquifer evaluation: U.S. Geological Survey Open-File Report, Reston, Virginia, 44 p.

Pinder, G. F., and Bredehoeft, J. B., 1968, Application of the digital computer for aquifer evaluation: Water Resources Research, v. 4, no. 5, p. 1069-1093.

Routt, K. R., and Crawford, P. B., 1973, A new and fast method for solving large number of reservoir simulation equations, Third Numerical Simulation of Reservoir Performance Symposium, Society of Petroleum Engineers, Houston, Texas, January 10-12, 1973.

Schnabel, R. R., and Richie, E. B., 1984, Calculation of internodal conductances for unsaturated flow simulations: A comparison: Soil Science Society of America Journal, v. 48, p. 1006-1010.

Settari, A., and Aziz, K., 1972, Use of irregular grid in reservoir simulation: Society of Petroleum Engineers Journal, v. 12, no. 2, p. 103-114.

Smith, L., 1981, Spatial variability of flow parameters in a stratified sand: Mathematical Geology, v. 13, no. 1, p. 1-21.

Trescott, P. C., Pinder, G. F., and Larson, S. P., 1976, Finite-difference model for aquifer simulation in two dimensions with results of numerical experiments: U.S.

Geological Survey Techniques of Water-Resources Investigations, Book 7, Chapter $\mathrm{C} 1,116 \mathrm{p}$.

Warren, J. E., and H. S. Price, 1961, Flow in heterogeneous porous media: Society of Petroleum Engineering Journal, v. 1, p. 153-169.

Weber, K. J., 1986, How heterogeneity affects oil recovery: p. 487-544 in Lake, L. W., and H. B. Carroll, Jr., (eds) Reservoir characterization, Academic Press. 


\section{APPENDIX A}

\section{PROOF THAT THE LOGARITHMIC MEAN TRANSMISSIVITY IS LARGER THAN THE GEOMETRIC MEAN TRANSMISSIVITY}

We want to prove that the logarithmic mean interblock transmissivity is larger than the geometric mean transmissivity. We will restrict the cases to positive, unequal transmissivities. That is,

Prove $\quad \frac{T_{2}-T_{1}}{\ln \left(T_{2} / T_{1}\right)}>\left(T_{1} T_{2}\right)^{1 / 2} \quad$ for $T_{1}, T_{2}>0 ; T_{1} \neq T_{2}$

It will be convenient to limit our cases to $\mathrm{T}_{2}>\mathrm{T}_{1}$, but the subscripts can be interchanged so that this is always the case for two positive, unequal transmissivities. Consider the ratio of the logarithmic mean to the geometric mean, which can be rearranged to:

$$
\frac{\frac{\mathrm{T}_{2}}{\mathrm{~T}_{1}}-1 / \ln \frac{\mathrm{T}_{2}}{\mathrm{~T}_{1}}}{\left(\frac{\mathrm{T}_{2}}{\mathrm{~T}_{1}}\right)^{1 / 2}}
$$

Defining $x=\left(T_{2} / T_{1}\right)^{1 / 2}$, this ratio can be written:

$$
\frac{x^{2}-1 / \ln x^{2}}{x}=\frac{x^{2}-1}{2 x \ln x}=\frac{x-\frac{1}{x}}{2 \ln x}
$$

where it is understood that $x>1$ if $T_{2}>T_{1}$. Consider the function $F(x)=x-1 / x-2 \ln x$ in the region $1<x$. Note that $F^{\prime}(x)=(1-1 / x)^{2}$. For $x>1, F^{\prime}(x)>0$, because the derivative is positive for all $x>1$ and the function $F(x)$ is continuous in that region, then the function $\mathrm{F}(\mathrm{x})$ is monotonically increasing in that region. Note that at the "boundary" point for the region, namely $x=1$, that $F(x=1)=0$ from which it follows that for all $x>1, F(x)>0$, or $F(x)=x-1 / x-2 \ln x>0$; then $x-1 / x>2 \ln x$, and, because $x>1$, the term $\ln x>0$, so that

$$
\frac{x-\frac{1}{x}}{2 \ln x}>1 \text { and } \frac{x^{2}-1}{2 x \ln x}>1
$$


Recalling that $\mathrm{x}=\left(\mathrm{T}_{2} / \mathrm{T}_{1}\right)^{1 / 2}$, this is equivalent to

$$
\frac{T_{2}-T_{1}}{\ln \left(T_{2} / T_{1}\right)}>\left(T_{1} T_{2}\right)^{1 / 2}
$$

which is what we set out to prove. 


\section{APPENDIX B}

\section{NUMERICAL IMPLEMENTATION IN THE FLOW MODEL OF MCDONALD AND HARBAUGH (1988)}

\section{OVERVIEW}

The alternative interblock transmissivity functions described in the Numerical Methods section are programmed in subroutines to be used with the modular ground-water flow model of McDonald and Harbaugh (1988). This model uses block-centered finite differences and the user inputs the horizontal hydraulic conductivity or transmissivity at each node. However the vertical interblock leakance (vertical hydraulic conductivity divided by vertical distance between nodes) is input directly. Hence, the computation of interblock conductance within the model is only applicable to the horizontal (row and column) conductances. The optional interblock transmissivity functions are implemented as a revision to the Block-Centered-Flow (BCF2) package of the modular model (McDonald and Harbaugh, 1988; McDonald and others, 1991).

Modifications include:

1. Changes to the MAIN program to identify modifications and to pass scratch array BUFF to selected BCF subroutines for possible use when $L A Y A V G=30$. Also, common block / FLWAVG / LAYAVG(80) is added.

2. Changes to subroutine BCF2AL to interpret input $L A Y C O N$ values to determine layer hydraulic characteristics (stored LAYCON) and interblock transmissivity (LAYAVG). Also, common block / FLWAVG / LAYAVG(80) is added and the program stops if any LAYAVG=30 and IAPART is zero.

3. Changes to subroutine BCF2FM to pass scratch array BUFF through for possible use when LAYAVG=30. Also, common block / FLWAVG / LAYAVG(80) is added. 4. Changes to subroutines SBCF2H and SBCF2N to call different subroutines for computing interblock conductance, depending on LAYAVG. Also, common block / FLWAVG / LAYAVG(80) is added to both subroutines.

5. Three new BCF3 subroutines are added to compute horizontal interblock conductance. 
In relating the numerical algorithms in this appendix to the formula developed in the body of the report, the reader must bear in mind that the indexing used in this report is different from that used in the model and documentation of McDonald and Harbaugh (1988). In the body of this report, index $i$ corresponds to the $x$ coordinate and $j$ corresponds to the $y$ coordinate. The figures in this report illustrating two-dimensional grids have the $\mathrm{x}$ coordinate and $\mathrm{i}$ index increasing from left to right, and the $\mathrm{y}$ coordinate and $\mathrm{j}$ index increasing from top to bottom. This discretization convention has been used by numerous previous investigators (for example, Pinder and Bredehoeft, 1968; Konikow and Bredehoeft, 1978; Kipp, 1987).

The model of McDonald and Harbaugh (1988) can be applied to a problem where it is assumed that the $x$ direction corresponds to model columns which are indexed by $\mathrm{j}$. The y direction can be assumed to correspond to model rows which are indexed by i. For this conceptualization, the transmissivity in the $\mathrm{x}$ direction $\left(\mathrm{T}_{\mathrm{xx}}\right)$ corresponds to the transmissivity in the direction of changing column index. However, in the report of McDonald and Harbaugh (1988), this transmissivity is called the "transmissivity along the rows" and is stored in the conductance term $\mathrm{CR}(\mathrm{j}, \mathrm{i}, \mathrm{k})$, where $\mathrm{k}$ is the layer (vertical) index. Likewise, the transmissivity in the y direction $\left(\mathrm{T}_{\mathrm{yy}}\right)$ is called the "transmissivity along the columns" by McDonald and Harbaugh (1988) and stored in conductance array CC(i,j,k). Furthermore, the cell width in the $\mathrm{x}$ direction $(\Delta \mathrm{x})$ (distance from the left side of a cell to the right side) is called the "cell width along rows" and stored in array DELR(j). Likewise, the grid spacing in the y direction $(\Delta y)$ is called the "cell width along columns" and is stored in array DELC(i). These alternative discretization conventions should be kept in mind when relating the equations presented in the body of this report with the numerical algorithms presented here for the model of McDonald and Harbaugh (1988). 


\section{Changes to MaIN Program}

\section{Program header changed from:}

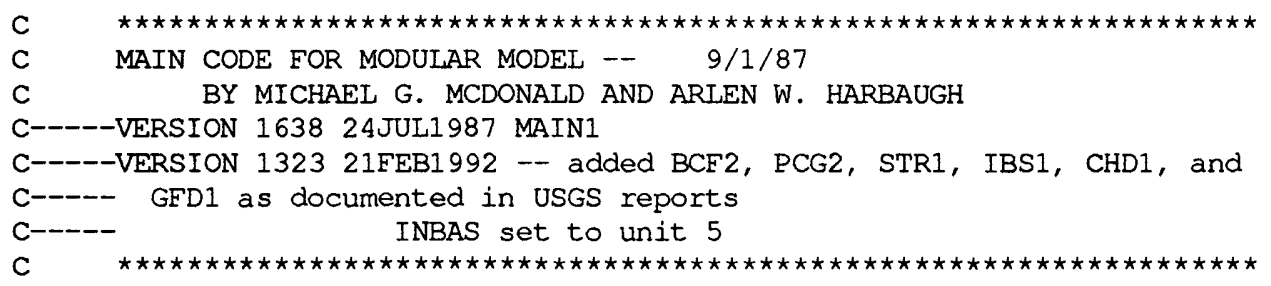

to:

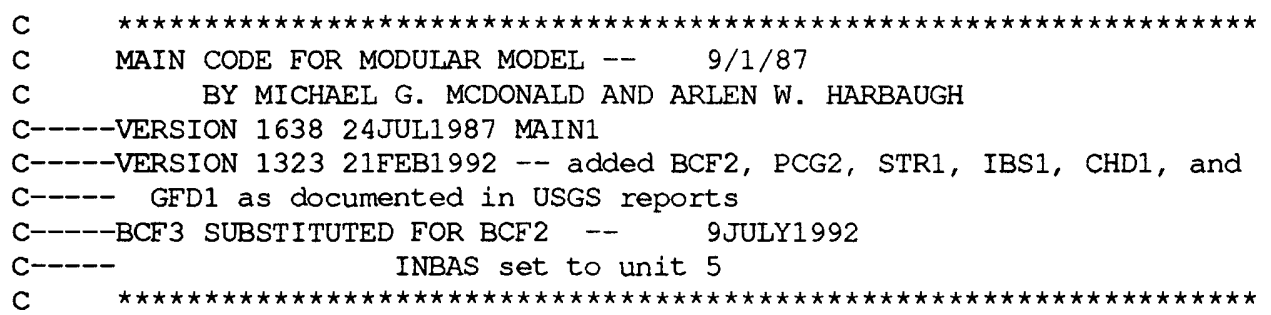

Add common block to store interblock transmissivity flag for each layer, changed from:

C SPECIFICATIONS:
COMMON X(350000)
COMMON /FLWCOM/LAYCON $(80)$
CHARACTER 4 HEADNG, VBNM

to:

SPECIFICATIONS:
COMMON X $(350000)$
COMMON /FLWCOM/LAYCON $(80)$
COMMON /FLWAVG/LAYAVG $(80)$
CHARACTER*4 HEADNG, VBNM

Call to allocate space for BCF part of solution changed from:

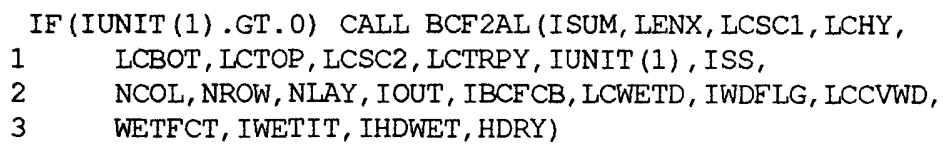




\section{CHANGES TO BCF SUBROUTINES}

Subroutine BCF2AL changed to set LAYAVG values from input LAYCON values. Subroutine header changed from:

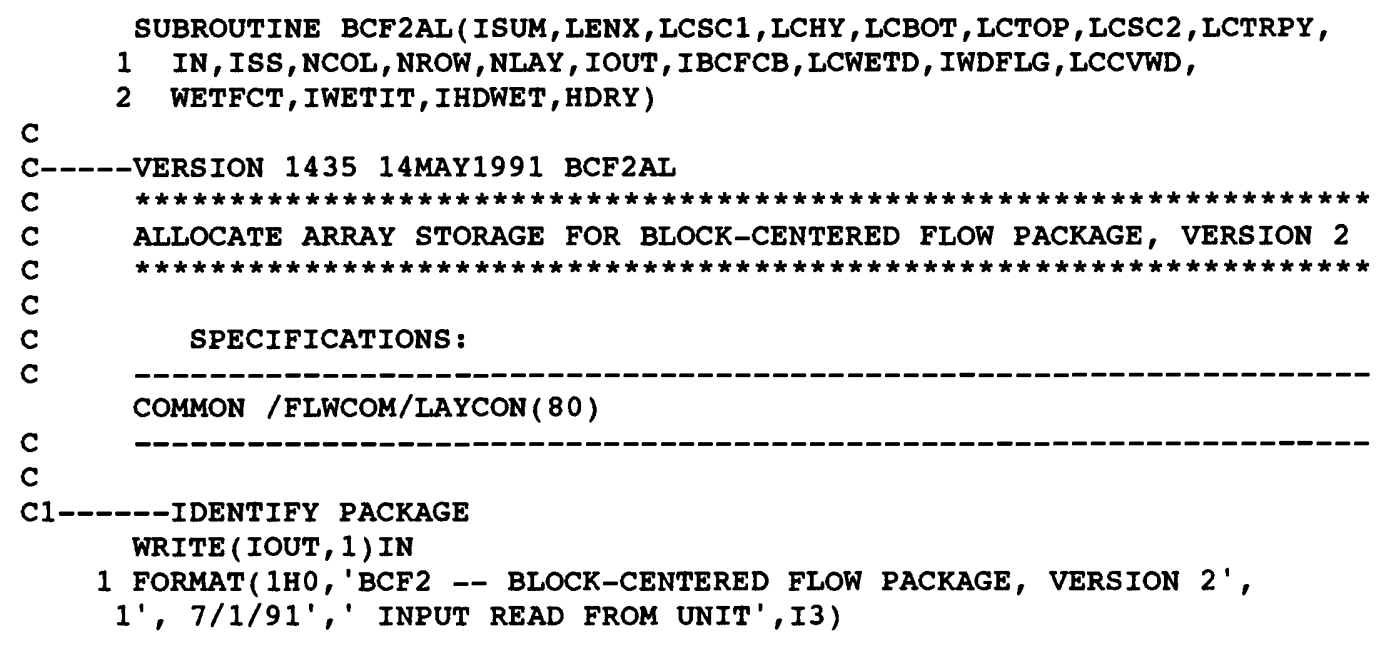

to:

SUBROUTINE BCF 3AL (ISUM, LENX, LCSC1, LCHY, LCBOT, LCTOP, LCSC2, LCTRPY,

1 IN , ISS , NCOL , NROW , NLAY , IOUT , IBCFCB , LCWETD, IWDFLG , LCCVWD,

c

2 WETFCT, IWETIT, IHDWET, HDRY, LCRHS , LCBUFF)

C-----VERSION 1436 9JULY1992 BCF3AL

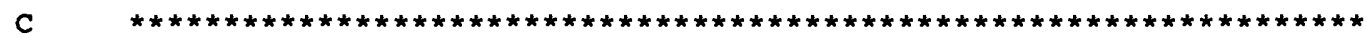

C ALIOCATE ARRAY STORAGE FOR BLOCK-CENTERED FLOW PACKAGE, VERSION 3

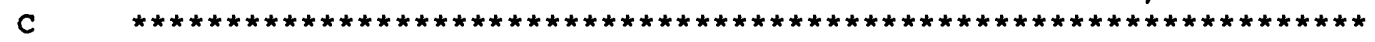

C SPECIFICATIONS:

C -

CHARACTER * 12 AVGNAM (4)

COMMON /FLWCOM/LAYCON $(80)$

COMMON /FLWAVG/LAYAVG ( 80 )

DATA AVGNAM/'harmonic ', 'ARIthmetic ',

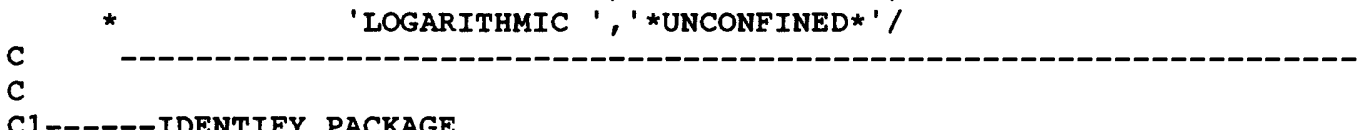

C1------IDENTIFY PACKAGE

WRITE ( IOUT, 1) IN

1 FORMAT (1HO, 'BCF3 - BLOCK-CENTERED FLOW PACKAGE, VERSION 3', $1^{\prime}, 7 / 9 / 92^{\prime}, '$ INPUT READ FROM UNIT', I3) 
Reading and setting of layer codes (LAYCON) changed from:

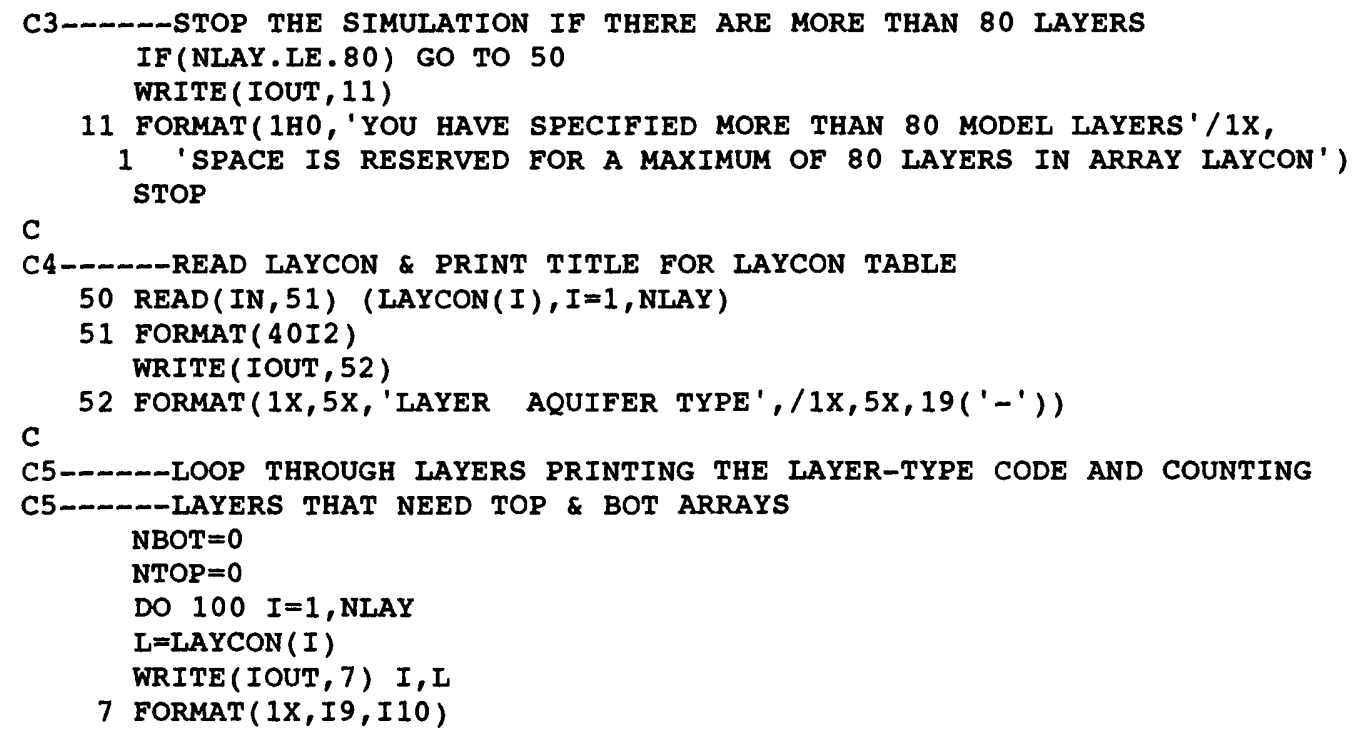

to:

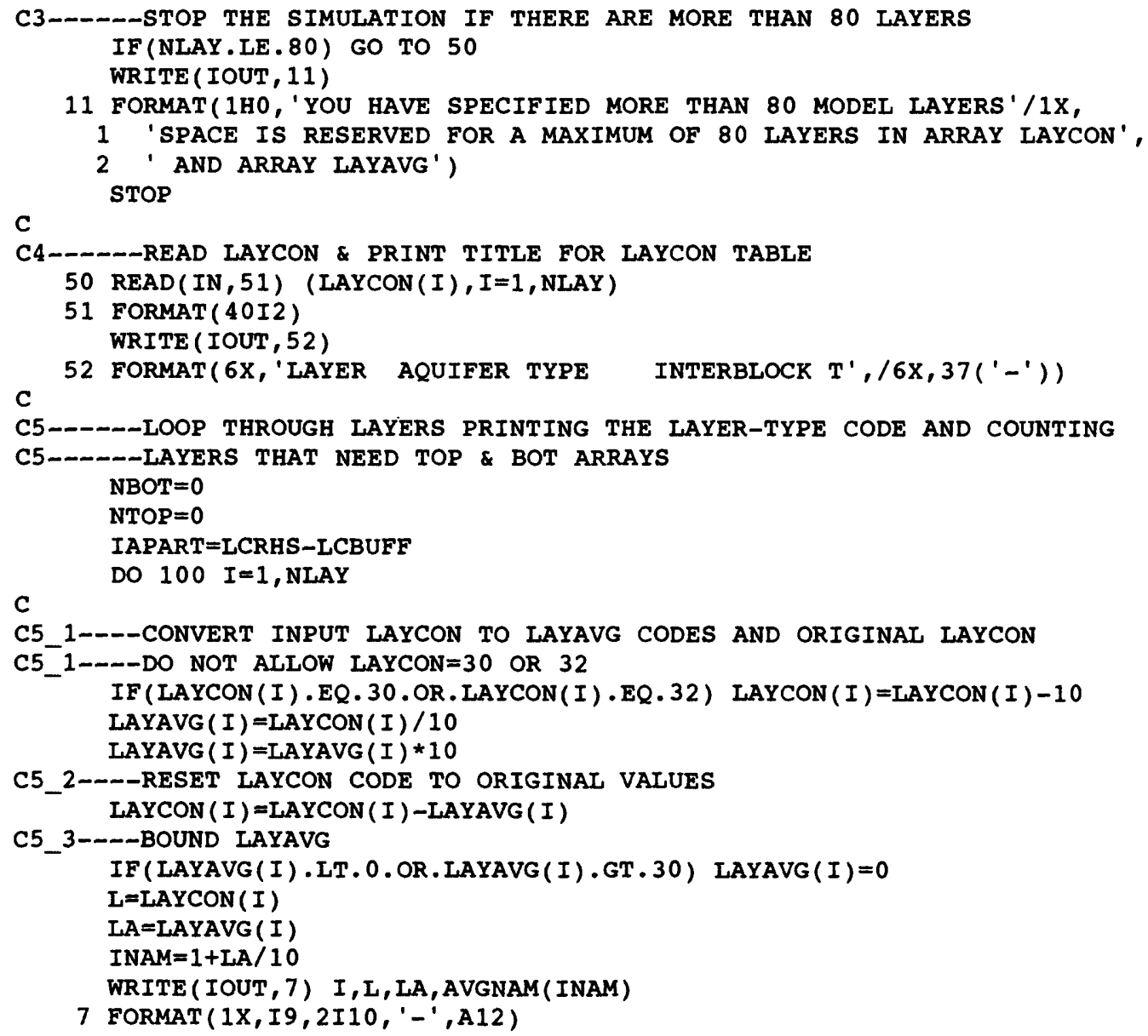




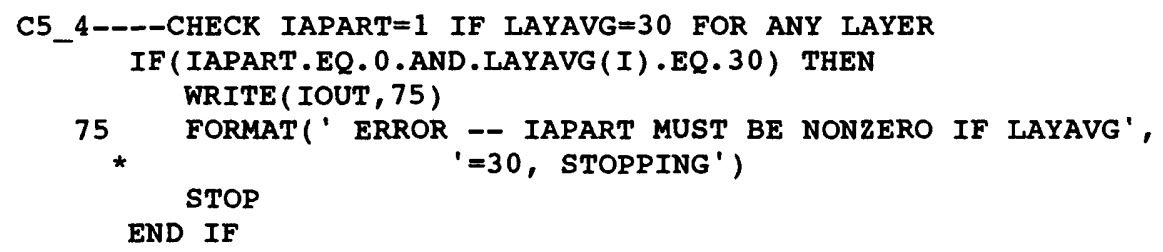

Subroutine BCF2RP changed to call SBCF3N.

Header changed from:

SUBROUTINE BCF2RP ( IBOUND, HNEW, SC1, HY , CR, CC, CV, DELR, DELC, BOT , TOP,

1 SC2, TRPY, IN, ISS, NCOL, NROW, NLAY, NODES, IOUT, WETDRY, IWDFLG , CVWD)

C

C-----VERSION 1275 6JUNE1991 BCF2RP

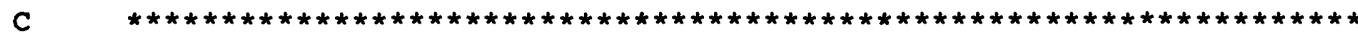

C READ AND INITIALIZE DATA FOR BLOCK-CENTERED FLOW PACKAGE,

C VERSION 2

to:

SUBROUTINE BCF 3RP ( IBOUND, HNEW, SC1, HY , CR, CC , CV, DELR, DELC, BOT, TOP, C 1 SC2, TRPY, IN, ISS , NCOL, NROW, NLAY, NODES, IOUT, WETDRY, IWDFLG , CVWD)

C-----VERSION 1276 9JULY1992 BCF3RP

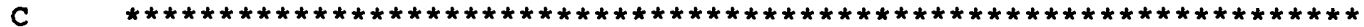

C READ AND INITIALIZE DATA FOR BLOCK-CENTERED FLOW PACKAGE,

C VERSION 3

Call to SBCF2N changed from:

CALL SBCF2N (HNEW, IBOUND, SC1, SC2, CR, CC, CV, HY, TRPY, DELR, DELC, ISS,

to:

CALL SBCF 3N (HNEW, IBOUND, SC1, SC2, CR , CC , CV , HY , TRPY , DELR, DELC, ISS, 
Subroutine BCF2FM changed to use optional interblock transmissivity subroutines and pass BUFF for possible use.

BUFF added to dimension statement, Header changed from:

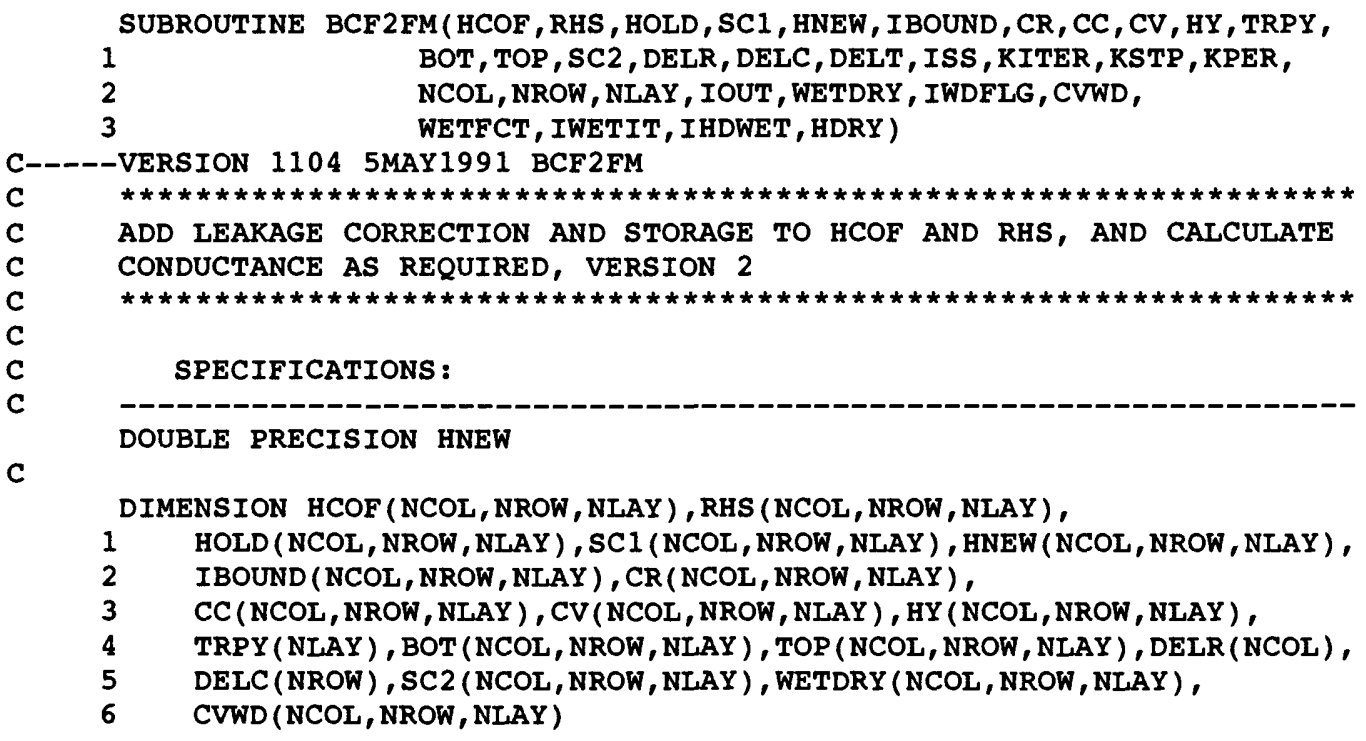

to:

SUBROUTINE BCF 3FM (HCOF , RHS, HOLD, SC1, HNEW, IBOUND , CR , CC , CV , HY, TRPY, BOT , TOP , SC2 , DELR, DELC, DELT, ISS, KITER, KSTP, KPER, NCOL, NROW, NLAY, IOUT, WETDRY, IWDFLG , CVWD, WETFCT, IWETIT, IHDWET, HDRY, BUFF)

C-----VERSION 1105 9JULY1992 BCF 3FM

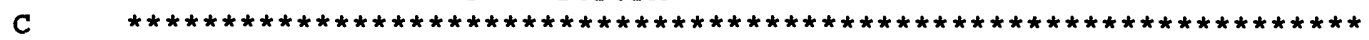

C ADD LEAKAGE CORRECTION AND STORAGE TO HCOF AND RHS, AND CALCULATE

C CONDUCTANCE AS REQUIRED, VERSION 3

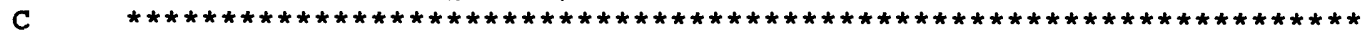

C SPECIFICATIONS :

C

DOUBLE PRECISION HNEW

C

DIMENSION HCOF (NCOL, NROW, NLAY), RHS (NCOL, NROW, NLAY), HOLD ( NCOL, NROW, NLAY) , SC1 (NCOL, NROW, NLAY), HNEW (NCOL, NROW, NLAY), IBOUND (NCOL, NROW, NLAY) , CR (NCOL, NROW, NLAY), CC (NCOL, NROW, NLAY) , CV (NCOL, NROW, NLAY), HY (NCOL, NROW, NLAY), TRPY (NLAY) , BOT (NCOL , NROW, NLAY) , TOP (NCOL, NROW, NLAY) , DELR (NCOL), DELC (NROW) , SC2 (NCOL , NROW, NLAY), WETDRY (NCOL, NROW, NLAY), CVWD (NCOL, NROW, NLAY), BUFF ( NCOL , NROW, NLAY) 
Call to subroutine SBCF2H changed from:

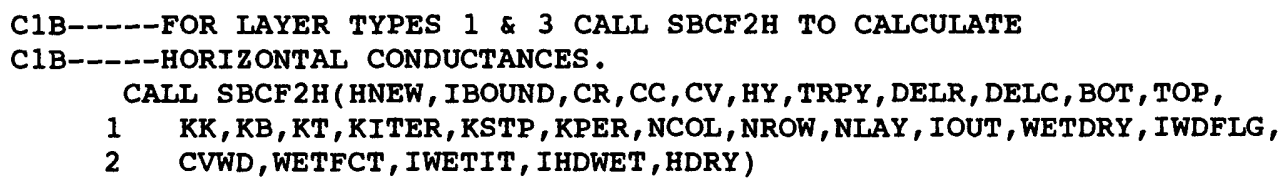

to:

C1B-----FOR LAYER TYPES $1 \& 3$ CALL SBCF3H TO CALCULATE

C1B-----HORIZONTAL CONDUCTANCES .

CAIL SBCF 3H (HNEW, IBOUND, CR , CC, CV , HY, TRPY, DELR, DELC, BOT, TOP,

1 KK, KB, KT , KITER, KSTP , KPER, NCOL , NROW, NLAY, IOUT, WETDRY, IWDFLG,

2 CVWD, WETFCT, IWET IT , IHDWET, HDRY, BUFF )

Subroutine SBCF2H changed to call optional interblock transmissivity subroutines.

Header changed from:

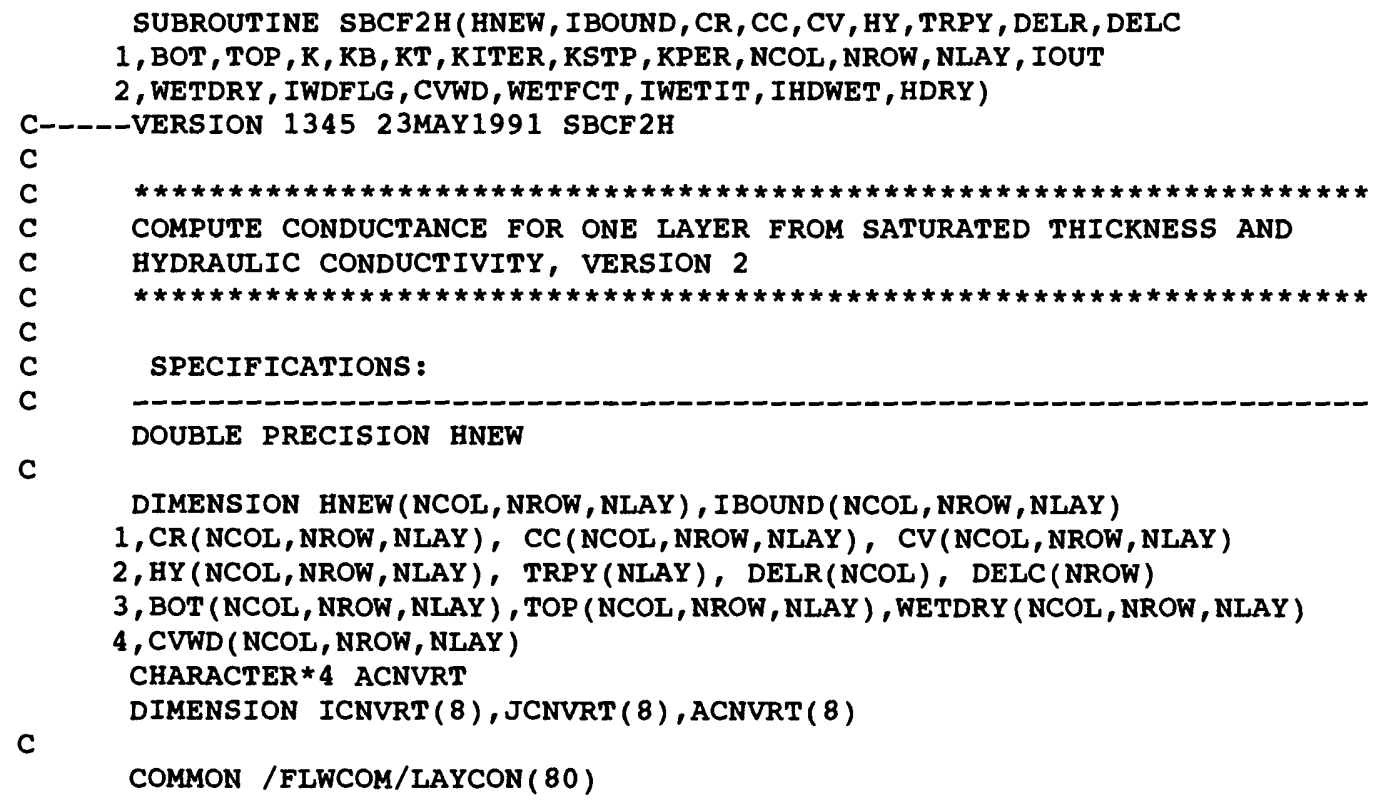




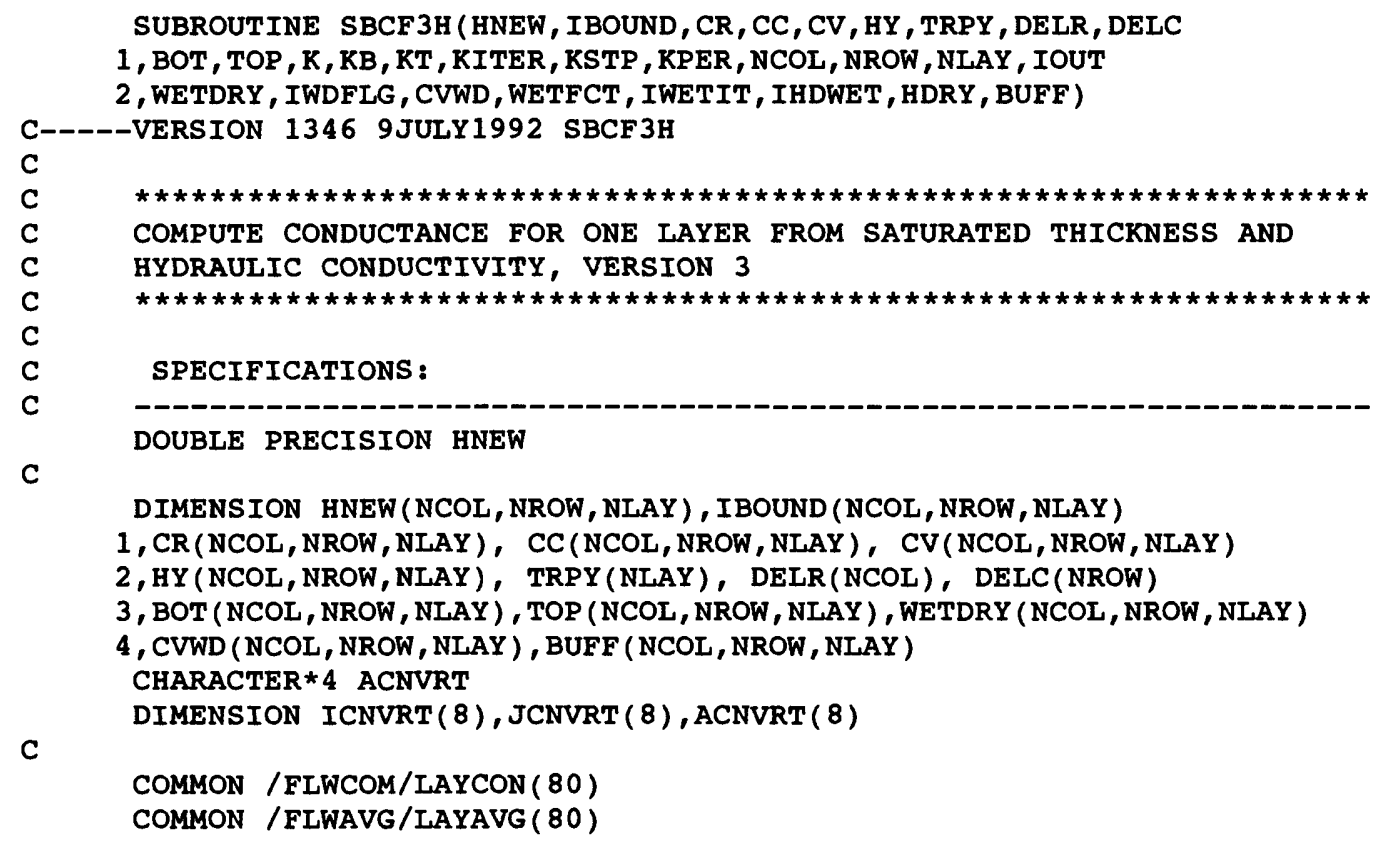

Action for inactive nodes changed from:

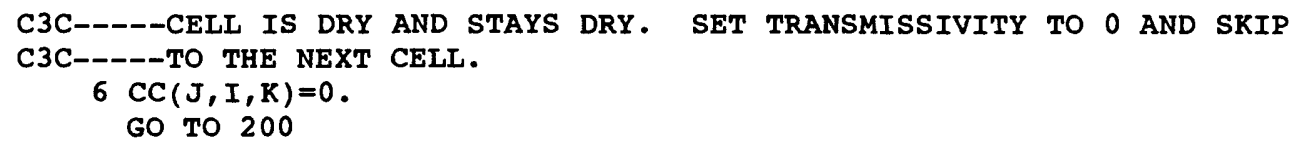

to:

C3C-----CELL IS DRY AND STAYS DRY. SET TRANSMISSIVITY TO 0 AND SKIP C3C----TO THE NEXT CELL.

$6 \operatorname{CC}(J, I, K)=0$.

C3D-----ZERO BUFF (SATURATED THICKNESS) FOR LAYAVG $=30$ IF (LAYAVG (K) E EQ.30) BUFF $(J, I, K)=0$. GO TO 200

Temporary storage of transmissivity changed from:

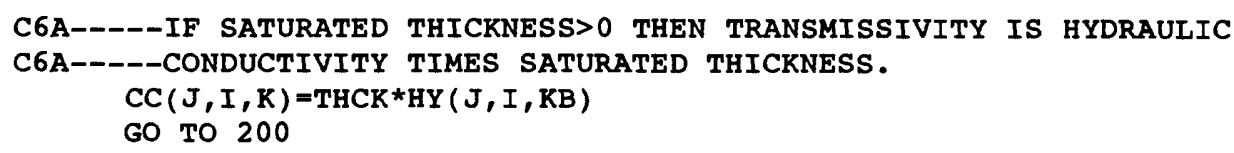

to: 


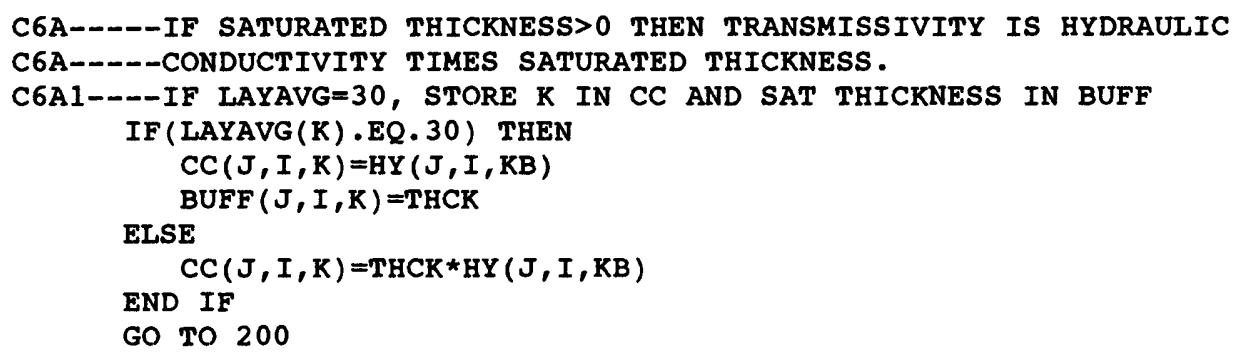

Call to subroutine to compute interblock transmissivity changed from:

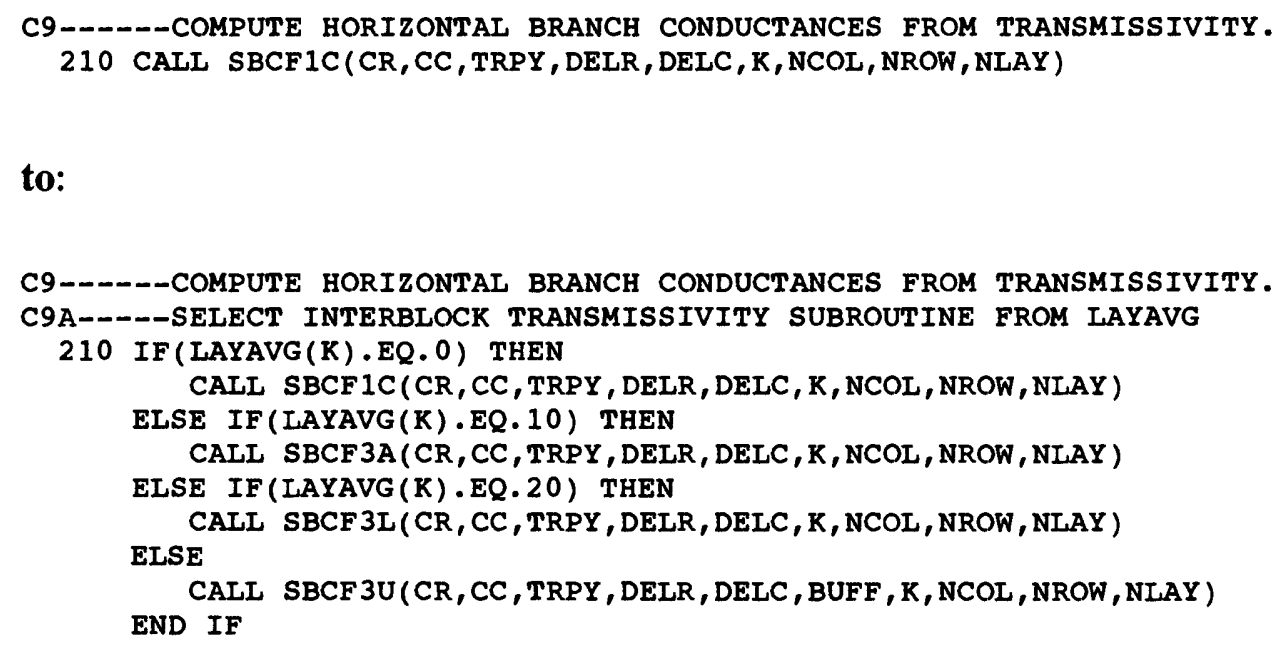

to:

Change SBCF2N to call optional interblock transmissivity subroutines when initializing for simulations with constant transmissivity.

\section{Header changed from:}

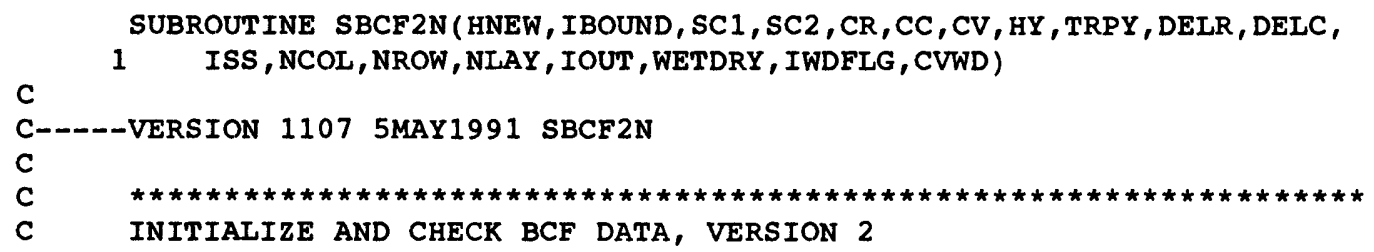




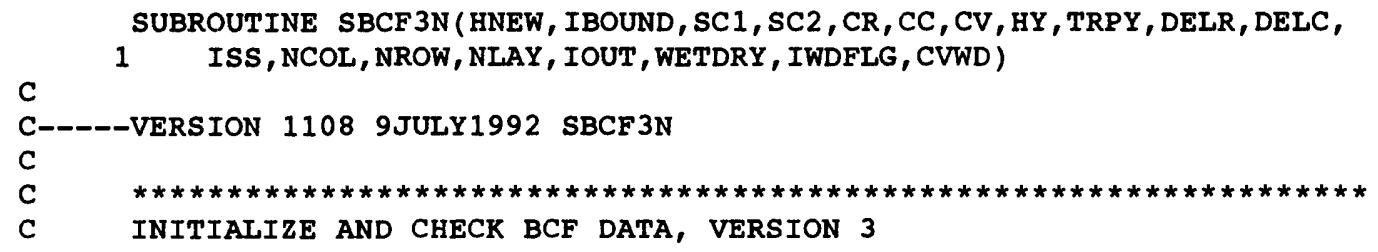

Common block declaration changed from:

COMMON /FLWCOM/LAYCON (80)

to:

COMMON /FLWCOM/LAYCON $(80)$

COMMON /FLWAVG/LAYAVG $(80)$

Call to subroutine to compute interblock transmissivity changed from:

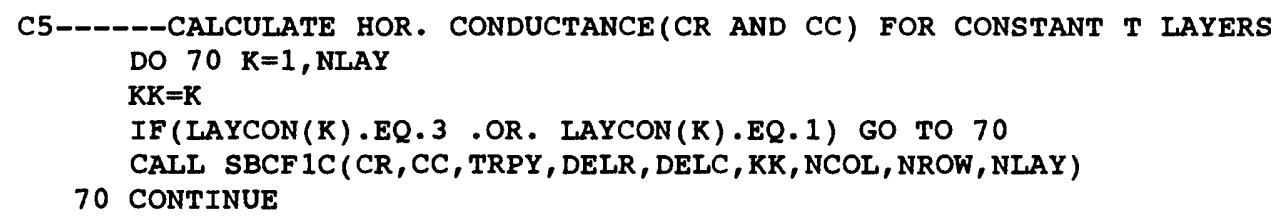

to:

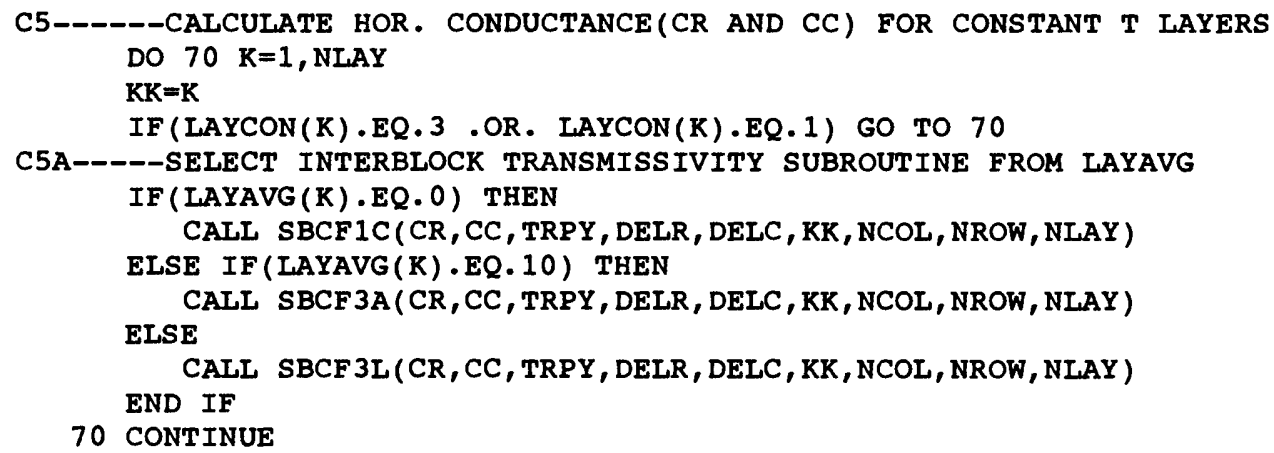




\section{NEW BCF SUBROUTINES FOR OPTIONAL INTERBLOCK TRANSMISSIVITY}

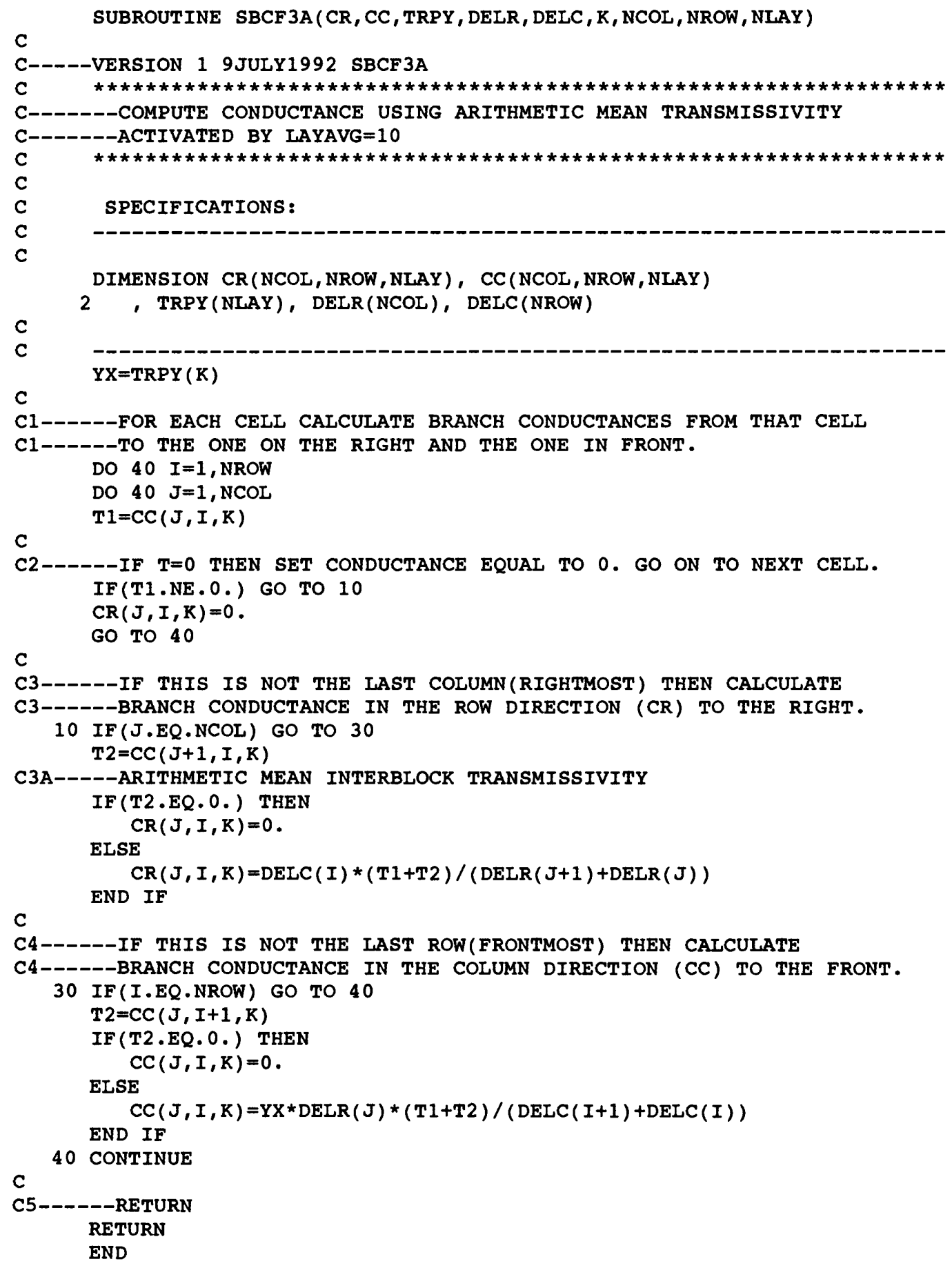




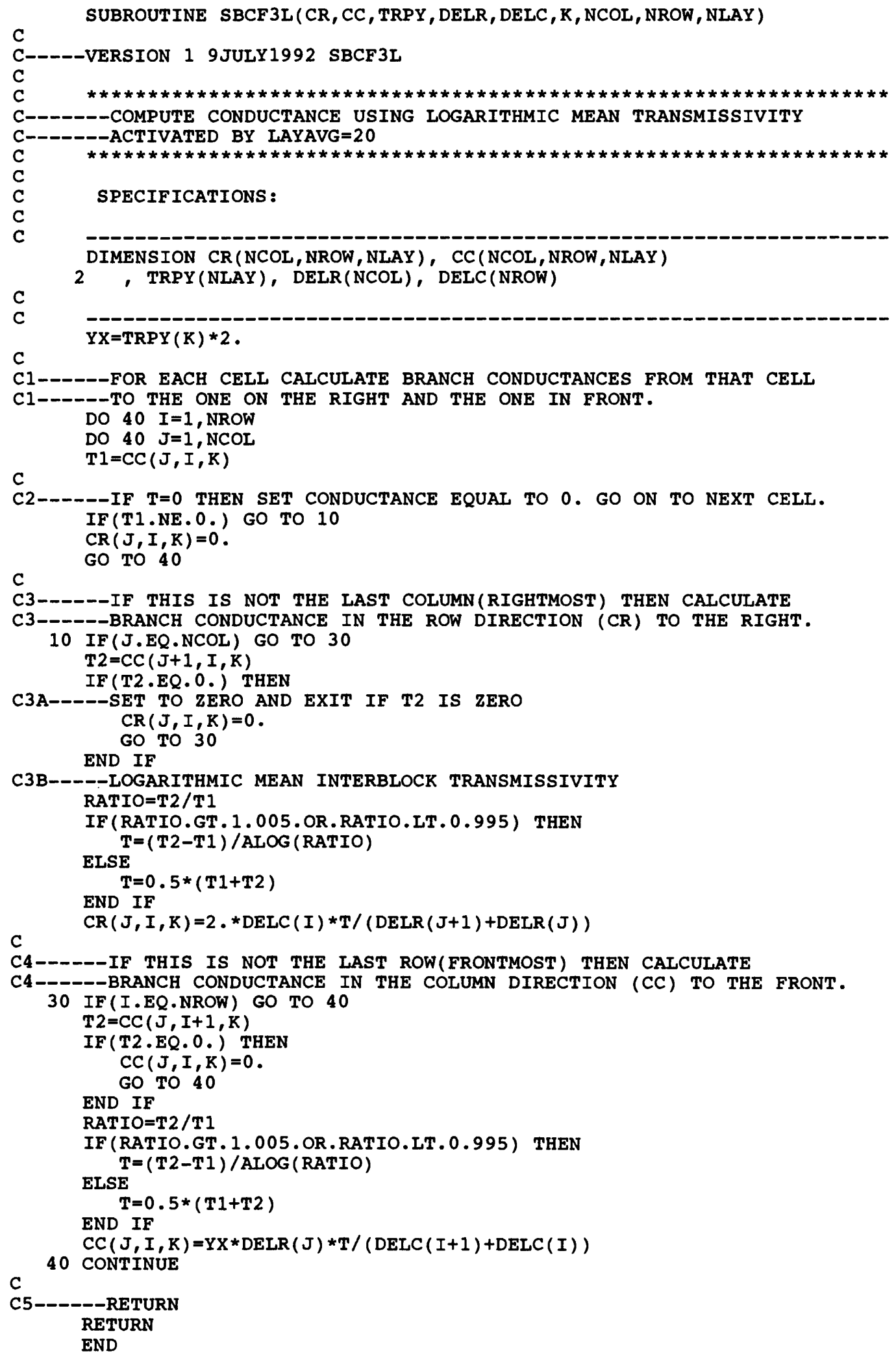




\section{INPUT INSTRUCTIONS}

Alternative interblock transmissivity functions are selected by layer through the value of LAYCON specified in the BCF package input. The meaning of the original LAYCON values are as follows (McDonald and Harbaugh, 1988):

\begin{tabular}{c|c} 
LAYCON & Layer characteristics \\
\hline 0 & confined, $\mathrm{T}$ and $\mathrm{S}$ constant in time \\
1 & unconfined, $\mathrm{S}$ constant in time, $\mathrm{T}$ depends on $\mathrm{h}$ \\
2 & confined/unconfined, $\mathrm{T}$ constant in time, $\mathrm{S}$ depends on $\mathrm{h}$ \\
3 & confined/unconfined, $\mathrm{T}$ and $\mathrm{S}$ depend on $\mathrm{h}$
\end{tabular}

These values are input using I 2 format. To activate alternative interblock transmissivity functions, a two digit number is input using the $\mathrm{I} 2$ format. The first digit (tens) determines the interblock transmissivity function, and the second digit (ones) determines the layer characteristics as in the original model. These values are read from the BCF input file by subroutine BCF3AL. The factor of ten represented by the first digit is stored in a new common block array LAYAVG. For example, if the input LAYCON value is 10,11 , or 12 , the value stored in LAYAVG is 10 . The second digit (ones) is stored in LAYCON. The meaning of the second (ones) digit is identical to the original model of McDonald and Harbaugh (1988), shown above. The meaning of the first (tens) digit is:

\begin{tabular}{c|c} 
LAYAVG & Interblock transmissivity \\
\hline 0 & harmonic mean \\
10 & arithmetic mean \\
20 & logarithmic mean \\
30 & arithmetic mean saturated thickness times \\
& logarithmic mean hydraulic conductivity
\end{tabular}

Thus, the tens part of the input LAYCON value is stored in array LAYAVG, and the ones part of the input LAYCON is stored in LAYCON. The stored values of LAYCON are identical to the original model (McDonald and Harbaugh, 1988), and the stored values of LAYAVG are used only to determine the method to compute interblock transmissivity. 


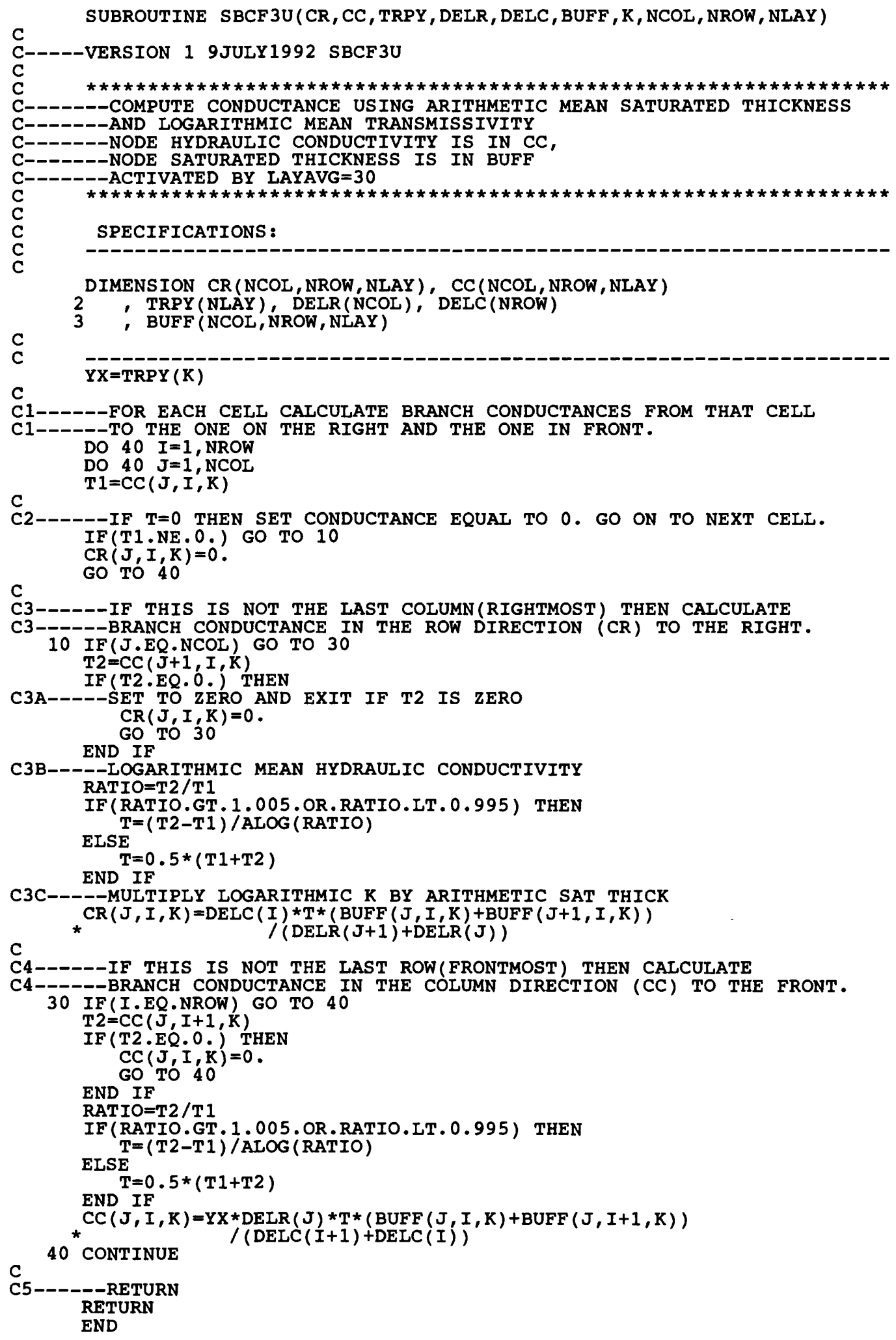


The following table shows the input value of LAYCON used to specify the particular stored values of LAYCON (layer characteristics) and LAYAVG (interblock transmissivity):

Input LAYCON values used to specify indicated layer characteristics (stored LAYCON) and interblock transmissivity (LAYAVG)

\begin{tabular}{c|cccc} 
stored & \multicolumn{4}{|c}{ LAYAVG } \\
LAYCON & 0 & 10 & 20 & 30 \\
\hline 0 & 0 & 10 & 20 & NA \\
1 & 1 & 11 & 21 & 31 \\
2 & 2 & 12 & 22 & NA \\
3 & 3 & 13 & 23 & 33
\end{tabular}

NA: The option LAYAVG $=30$ is not allowed unless the hydraulic conductivity is input (LAYCON=1 or 3). Input LAYCON of 30 or 32 is reset to 20 or 22 , respectively. 